GA-A14651

UC-77

\title{
EFFECT OF STEAM OXIDATION ON STRENGTH, ELASTIC MODULUS, AND STRAIN AT FRACTURE OF GRAPHITE 2020
}

by

C. VELASQUEZ, G. HightOWER, and R. BURNETte

\author{
Prepared under \\ Contract EY-76-C-03-0167 \\ Project Agreement No. 17 \\ for the San Francisco Operations Office \\ Department of Energy
}

GENERAL ATOMIC PROJECT 3224

DATE PUBLISHED: DECEMBER 1977

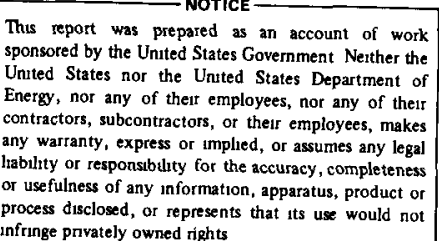

Thus seport was prepared as an account of work Une Enero, nor any of ther employs, Deparment or contractors, subcontractors, of their ory expess or mpled, or as or usefulness of any inform infringe pnvately owned rights

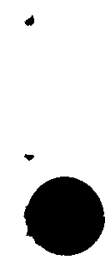

BRTRRAUTION OF THIS DOCUMENT IS UNLUMTED

\section{GENERAL ATOMIC COMPANY}




\section{DISCLAIMER}

This report was prepared as an account of work sponsored by an agency of the United States Government. Neither the United States Government nor any agency Thereof, nor any of their employees, makes any warranty, express or implied, or assumes any legal liability or responsibility for the accuracy, completeness, or usefulness of any information, apparatus, product, or process disclosed, or represents that its use would not infringe privately owned rights. Reference herein to any specific commercial product, process, or service by trade name, trademark, manufacturer, or otherwise does not necessarily constitute or imply its endorsement, recommendation, or favoring by the United States Government or any agency thereof. The views and opinions of authors expressed herein do not necessarily state or reflect those of the United States Government or any agency thereof. 


\section{DISCLAIMER}

Portions of this document may be illegible in electronic image products. Images are produced from the best available original document. 


\section{NOTICE}

This report was prepared as an account of work sponsored by the United States Government. Neither the United States nor the Department of Energy, nor any of their employees, nor any of their contractors, subcontractors, or their employees, makes any warranty, express or implied, or aseumes any legal liability or responsibility for the accuracy, completeness or usefulness of any information, apparatus, product or process disclosed, or represents that its use would not infringe privately owned rights.

Printed in the United States of America

Available from

National Technical Information Service

U.S. Department of Commerce

5285 Port Royal Road

Springfield, Virginia 22161

Price: Printed Copy $\$ 6.00$; Microfiche $\$ 3.00$ 


\begin{abstract}
Stackpole Carbon's graphite grade 2020, a candidate material for support posts in GA HTGRs, was oxidized in steam-helium mixtures to 25 wt \% burnoff. The effects of the oxidation on ultimate strength, elastic modulus, and strain at fracture are reported.

A large number of nonoxidized and oxidized tensile specimens were tested to failure. Average losses of $6.7 \mathrm{wt} \%$ in strength and $7.4 \mathrm{wt} \%$ in elastic modulus at $1 \%$ burnoff were obtained. No significant change in strain at fracture was observed for burnoffs up to $5 \%$. The elastic modulus and ultimate tensile strength of the oxidized samples correlated with bulk density. No significant radial gradients in strength or elastic modulus were observed in the log; however, slight differences in elastic modulus and strain at fracture were observed along the length of the 1og. Radial specimens had significantly higher strength and elastic modulus than axial specimens.
\end{abstract}


$\bullet$ 
CONTENTS

ABSTRACT . . . . . . . . . . . . . . . . . . . iii

1. INTRODUCTION . . . . . . . . . . . . . . . . . . 1

2. MATERIAL ......................... 3

3. EXPERIMENTAL PROCEDURES . . . . . . . . . . . . . . . . . 4

3.1. Sampling and Specimen Preparation ............ 4

3.2. Oxidation . . . . . . . . . . . . . . . . . 5

3.3. Strength, Elastic Modulus, and Strain-At-Fracture

4. EXPERIMENTAL RESULTS . . . . . . . . . . . . . . . 7

4.1. Characterization Data (Nonoxidized Specimens) . . . . . . 7

4.1.1. Bulk Density . . . . . . . . . . . . . 7

4.1.2. Impurity Content ............... 7

4.1.3. Oxidation Rates ................ 7

4.1.4. Tensile Strength, Elastic Modulus, and Strain at Fracture (Control Specimens) . . . . . . . . 10

4.2. Characterization Data (Oxidized Specimens) . . . . . . 10

4.2.1. Effect of Oxidation on Ultimate Tensile Strength . . 10

4.2.2. Effect of Oxidation on Elastic Modulus - Axial and Radial Specimens............ 14

4.2.3. Effect of Oxidation on Strain at Fracture . . . 15

5. CONCLUSIONS . . . . . . . . . . . . . . . . 16

6. ACKNOWLEDGMENTS . . . . . . . . . . . . . . . . 17

7. REFERENCES . . . . . . . . . . . . . . . . . 18 APPENDIX A

\section{FIGURES}

1. HTGR core and support arrangement . . . . . . . . . . . 19

2. Steam-graphite oxidation apparatus . . . . . . . . . . . 20

3. Fe contamination versus location in $10 \mathrm{~g}$. . . . . . . . . . 21 
4. Average and range of reaction rates of each section versus

distance from end of $10 \mathrm{~g}$. . . . . . . . . . . . . 22

5. Gaussian distribution fits to UTS data, 2020 graphite, $\log 6799-00$. . . . . . . . . . . . . . . . . 23

6. UTS versus burnoff, axial, slab 1 . . . . . . . . . . . . 24

7. UTS versus burnoff, axial, slab 3 . . . . . . . . . . . 25

8. UTS versus burnoff, axial, slab 5 . . . . . . . . . . . 26

9. UTS versus burnoff, axial, slab 1 (lot BKR) . . . . . . . . . 27

10. UTS versus burnoff, axial, all slabs . . . . . . . . . . . . 28

11. UTS versus density for oxidized and nonoxidized axial specimens. . 29

12. UTS versus burnoff (to $1 \%$ ), axial samples . . . . . . . . . 30

13. UTS versus burnoff, radial, slab 1, lot BKR .......... 31

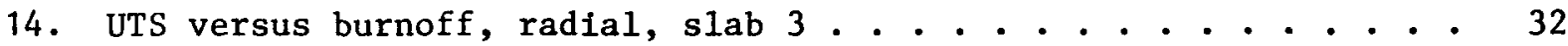

15. UTS versus burnoff, radial, slab 5............... 33

16. UTS versus burnoff, radial, slabs 3 and 5 . . . . . . . . 34

17. UTS versus burnoff (to $1 \%$ ), radial specimens . . . . . . . . . . 35

18. UTS versus density of oxidized and nonoxidized radial specimens . . . . . . . . . . . . . . . . . . . 36

19. Elastic modulus versus burnoff, axial, slab 1 . . . . . . . 37

20. Elastic modulus versus burnoff, axial, slab $3 . . . . . . . .38$

21. Elastic modulus versus burnoff, axial, slab 5 . . . . . . . 39

22. Elastic modulus versus burnoff, radial, slab 3......... . 40

23. Elastic modulus versus burnoff, radial, slab 5......... 41

24. Elastic modulus versus burnoff, all slabs . . . . . . . . . 42

25. Elastic modulus versus bulk density, axial specimens . . . . . . . 43

26. Elastic modulus versus bulk density, radial specimens . . . . . 44

27. Strain at fracture versus burnoff, axial, slab 1 . . . . . . 45

28. Strain at fracture versus burnoff, axial, slab 3 . . . . . . . 46

29. Strain at fracture versus burnoff, axial, slab 5. . . . . . . 47

30. Strain at fracture versus burnoff, radial, slab 3 . . . . . . ${ }_{r} 8$

31. Strain at fracture versus burnoff, radial, slab 5 . . . . . . 49

32. Strain at fracture versus burnoff, all specimens . . . . . . . . 50

33. Gaussian distribution of strain at fracture for oxidized and nonoxidized specimens ................. . 51 


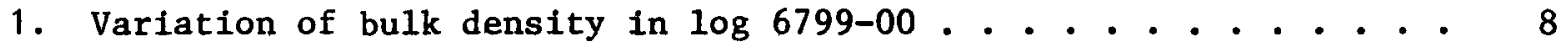

2. Impurities found in Stackpole 2020 graphite $(\log 6799-00)$. . . . 9

3. Summary of tensile strength, elastic modulus, and strain at fracture of nonoxidized control specimens, $\log 6799-00$. . . . . 11

4. Summary of changes in ultimate tnesile strength, elastic modulus, and strain at fracture due to oxidation, $\log 6799-00 .$. . . . . 


\section{INTRODUCTION}

Graphite oxidation in an HTGR could occur as a result of accidental steam ingress of two distinct types: (1) a major steam leak such as from the rupture of a heat exchanger steam tube, and (2) a continuous low level leakage. The degree of oxidation due to the first type of leak is negligible because the reactor would be shut down within seconds of such an event (Ref. 1). The second type of leak is of more concern because such a leak is permitted under the proposed technical specifications for normal full-power operation. This type of leak could result in moisture concentrations in the range 1 to $10 \mathrm{~Pa}$ (10 to 100 Hatm) over the 40-year life of the reactor graphite components. This could lead to small but measurable oxidation of the support structure.

The support posts in an HTGR are arranged in groups of three under each support block and support the weight of each multiple-column fuel assembly, which includes hexagonal reflectors, a core support block, and the gas pressure differential from top to bottom of the core. Similar posts are also utilized to support the permanent side reflector blocks and their floor support block (Fig. 1).* Support post seats are abutted to the support posts at the bottom of the support floor blocks and to bottom support pads which insulate the support posts from the prestressed concrete floor.

In view of the load-bearing requirements of the support posts and their relative inaccessibility, it is necessary to establish the ability of the materials chosen to maintain their structural integrity and strength under oxidizing conditions in reactor service.

The purpose of the oxidation studies presented in this paper is to characterize Stackpole Carbon's grade 2020 graphite by determining the

*Figures appear at the end of the text. 
effect of uniform burnoff on strength, elastic modulus, and strain at fracture. Grade 2020 is a candidate material for support posts in GA HTGRs

(Ref. 2). The oxidation experiments reported here were performed in steamhelium mixtures on small specimens taken uniformly throughout a single log. Control specimens, taken from the same population as the specimens used for the oxidation experiments, were utilized to determine changes in strength, elastic modulus, and strain at fracture. 


\section{MATERIAL}

Stackpole Carbon's grade 2020 is manufactured commerclally by isostatic molding as logs $245 \mathrm{~mm}$ in diameter by $1829 \mathrm{~mm}$ long. A description of grade 2020, along with properties and impurity content, is given in Refs. 1 and 3. AII specimens were taken from grade $2020 \mathrm{GA}$ log number 6799-00. 


\section{EXPERIMENTAL PROCEDURES}

The experimental work consisted of oxidizing large numbers of small test specimens unfformly and isothermally at an elevated temperature in steam-helium mixtures and subsequently measuring the strength, elastic modulus, and strain at fracture of the oxidized specimens. The property values from the oxidized specimens were compared with values from nonoxidized control specimens, taken from the same population as the specimens utilized for oxidation, to determine the changes due to oxidation burnoff.

\subsection{SAMPLING AND SPECIMEN PREPARATION}

Commercial graphite logs of the size required for HTGR support posts have been shown to have, in some cases, a nonuniform distribution of properties within a $\log$ (Refs. 2 through 5). Thus, for the characterization experiment reported here it was necessary to include axial and radial specimens from three slabs along the length of the log: slabs 1, 3, and 5 (see Appendix A, Fig. A-1). A systematic sampling plan was adopted and specimens were machined from the slabs as shown in Appendix A, Fig. A-2.

Specimens were $12.8 \mathrm{~mm}$ (0.505 in.) in diameter by $76.2 \mathrm{~mm}$ ( $3 \mathrm{in.)}$ long prior to oxidation. After oxidation approximately $6 \mathrm{~mm}$ ( $0.25 \mathrm{in.})$ was removed from each end to facilitate testing.

The specimens were divided into three specimen sets: slabs 1, 3, and 5. The specimens from each slab were further divided into axial and radial specimen sets. Specimens from the same slab and the same orientation (same population) were randomly selected to provide control specimens and specimens for oxidation. When property changes due to oxidation were determined, the values for the oxidized specimens were only compared with values for control specimens taken from the same population as the specimens 
used for oxidation. This permitted an unambiguous determination of the property changes.

\subsection{OXIDATION}

A total of 236 specimens were isothermally oxidized in quartz reaction vessels. The specimens, 15 per batch, were supported in the reaction vessels by racks machined from the same graphite as used for the specimens. The reaction vessels were heated to a preselected temperature using clamshe11 resistance furnaces. The apparatus is schematically depicted in Fig. 2. Temperatures were monitored with Chromel-Alumel thermocouples. Temperatures were maintained at $1150 \mathrm{~K}\left(875^{\circ} \mathrm{C}\right)$ by suitable temperature control devices. During oxidation the vessels were purged with a gas mixture composed of $3 \mathrm{kPa}(0.03 \mathrm{~atm})$ water vapor, $5 \mathrm{kPa}(0.05 \mathrm{~atm})$ hydrogen, and the balance helium. The total pressure was approximately $100 \mathrm{kPa}$ (1 atm). The flow rate of 1 liter (STP)/min was maintained at all times. The oxidizing gas mixture was introduced into the vessel through a quartz tube extending the length of the hot zone and positioned below the sample racks. The entry tube contained several small holes to emit the gas mixture and, thus, uniformly expose each specimen simultaneously. During heatup and cooldown, the reaction vessel was purged with helium. The extent of oxidation was determined by intermittently removing and weighing each sample to $\pm 0.1 \mathrm{mg}$. The percent oxidation (burnoff) was calculated from the weight change. Average rates of oxidation were determined by dividing the weight change by the oxidation time.

Relatively uniform burnoff at the selected oxidation temperatures was achieved by adding hydrogen to the gas mixtures to inhibit the reaction rates, thus maintaining a relatively uniform oxidant level within the pores. The conditions chosen to achieve minimal burnoff gradients were based on experimentally determined oxidation profiles measured on $\mathrm{H}-451$ and ATJ graphites (Refs. 6, 7). 


\subsection{STRENGTH, ELASTIC MODULUS, AND STRAIN-AT-FRACTURE MEASUREMENTS}

Tensile stress-strain curves were obtained in ambient air at room temperature using a standard method described in Ref. 4.

The tensile strength of each specimen was calculated by dividing the load at fracture by the original cross-sectional area of the specimen. Strain at fracture is $\Delta \mathrm{L} / \mathrm{L}$, where $\mathrm{L}$ is the length of the sample and $\Delta \mathrm{L}$ is the elongation.

The elastic modulus of each specimen was calculated from its stressstrain curve as the slope of the chord (chord modulus) drawn between points on a second loading portion of the stress-strain curve corresponding to stresses of $0.69 \mathrm{MPa}(100 \mathrm{psi})$ and $6.9 \mathrm{MPa}(1000 \mathrm{psi})$. This chord modulus represents the effective modulus of a graphite component after its first strain excursion (see Ref. 4 for details).

A small number of the specimens from slab 1 were measured as a separate batch early in the program (about 1975). These specimens have been separated from the remainder of the specimens which were measured in 1977. The early batch of specimens was tested to failure without measuring the modulus and omitting the load-unload technique as described in Ref. 4. The early specimens taken from slab 1 are Identified in Appendix $A$ in Tables A-1, A-2, $A-5$, and $A-6$ as lot BKR, whereas the later specimens taken from slabs 1, 2, and 3 are identified in Tables $A-3, A-4$, and A-7 through $A-14$ as 10 to GB. Differences in strength due to oxidation were calculated using control and oxidized specimens from the same population and testing lot, i.e., lot BKR controls with BKR oxidized specimens and lot GDB controls with GDB oxidized specimens. 
4.1. CHARACTERIZATION DATA (NONOXIDIZED SPECIMENS)

\subsubsection{Bulk Density}

The variation of bulk density within $\log 6799-00$ is presented in Table 1. The variation in bulk density along the length of $10 \mathrm{~g} 6799-00$ was about $1 \%$.

\subsubsection{Impurity Content}

Results of spectrochemical analyses on specimens taken along the length of $\log 6799-00$ are shown in Table 2. The iron content varied along the length, ranging from $40 \mathrm{ppm}$ at one end to $<1 \mathrm{ppm}$ at the other (Fig. 3). Similar gradients in iron and ash content were observed in $\log 6487-110$ (Ref. 3).

\subsubsection{Oxidation Rates}

Details of the oxidation rates observed in this study are given in Ref. 8, where it was found that the measured oxidation rates of the tensile specimens varied by up to a factor of 60 within the same oxidation furnace load. The variation in oxidation rate correlated with the position of the specimen within the $10 \mathrm{~g}$, with the highest rates observed in edge samples taken from slab 1 (Fig. 4). It is also significant that iron, a known catalyst for graphite oxidation, exhibited a similar gradient (Fig. 3). It is concluded that the variation in iron content is responsible for the variation in oxidation rates. This conclusion is supported by the data in Ref. 8 . 
TABLE 1

VARIATION OF BULK DENSITY IN LOG 6799-00

\begin{tabular}{c|c|c}
\hline \multirow{2}{*}{} & \multicolumn{2}{|c}{ Density $\left(\mathrm{Mg} / \mathrm{m}^{3}\right)$} \\
\cline { 2 - 3 } & Mean & $\sigma$ \\
\hline Slab 1 & 1.780 & 0.004 \\
Slab 3 & 1.785 & 0.003 \\
Slab 5 & 1.802 & 0.005 \\
\hline
\end{tabular}


TABLE 2

IMPURITIES FOUND IN STACKPOLE 2020 GRAPHITE (LOG 6799-00)

\begin{tabular}{|c|c|c|c|c|c|c|c|c|c|c|c|c|c|c|}
\hline \multirow{2}{*}{$\begin{array}{l}\text { Specimen } \\
\text { Number }\end{array}$} & \multicolumn{12}{|c|}{ Impurity Concentration (ppm) } & \multirow{2}{*}{$\begin{array}{l}\text { Distance from } \\
\text { Top of Log } \\
(\mathrm{mm})\end{array}$} & \multirow[b]{2}{*}{ S1ab } \\
\hline & $\mathrm{Al}$ & $\mathrm{Ba}$ & B & $\mathrm{Ca}$ & $\mathrm{Cu}$ & $\mathrm{Fe}$ & $\mathrm{Pb}$ & $\mathrm{Mg}$ & $\mathrm{Nb}$ & Si & $\mathrm{T} \mathbf{i}$ & $\mathrm{V}$ & & \\
\hline $6799-52-11$ & 60 & 20 & 2 & 200 & $<1$ & 40 & 6 & $<0.5$ & $<6$ & 20 & 20 & 20 & 10 & \\
\hline $6799-52-34$ & 20 & 20 & 2 & 100 & $<1$ & 10 & 60 & $<0.5$ & $<6$ & 80 & 2 & $<0.5$ & 20 & \\
\hline $6799-53-43$ & 20 & 20 & 2 & 100 & 8 & 10 & $<6$ & 1 & 20 & 40 & 40 & 20 & 85 & \\
\hline $6799-53-58$ & 60 & 20 & 2 & 100 & $<1$ & 4 & $<6$ & $<1$ & $<6$ & 60 & 40 & 20 & 95 & \\
\hline $6799-54-71$ & $<1$ & 10 & 2 & 100 & $<0.5$ & $<1$ & $<6$ & 1 & $<6$ & 60 & 20 & 10 & 155 & \\
\hline $6799-54-98$ & 100 & 20 & 2 & 200 & $<1$ & $<1$ & $<6$ & 1 & $<6$ & 60 & 10 & 8 & 175 & \\
\hline Mean & 43 & 18 & 2 & 133 & 2 & 14 & 15 & 0.8 & 8 & 63 & 22 & 13 & & \\
\hline
\end{tabular}




\subsubsection{Tensile Strength, Elast1c Modulus, and Strain at Fracture (Contro1 Specimens)}

Complete data sets for ultimate tensile strength, elastic modulus, and strain at fracture are tabulated in Appendix A, Tables A-1 through A-14.

The mean ultimate tensile strength (UTS), elastic modulus, and strainat-fracture values for $\log 6799-00$ are shown in Table 3. Based on analysis by statistical t-tests, the UTSs of the three slabs were judged to be from a single population since no significant differences from center to edge were found at the $95 \%$ confidence level. The mean UTS of axial specimens was $15.3 \pm 1.5 \mathrm{MPa}$ and the mean of the radial specimens was $18.1 \pm 2.0 \mathrm{MPa}$.

The UTS data followed a Gaussian distribution, as shown in Fig. 5. Strength measurements on $\mathrm{H}-451$, the reference fuel element graphite for HTGRs, were also found to follow a Gaussian distribution (Ref. 5). A chi-square, goodness-of-fit analysis showed that the radial and axial UTS data reasonably fit a Gaussian distribution. Statistical analyses, discussed in more detail in later sections, are based on Gaussian distributions.

There was no correlation between the UTS and bulk density for the nonoxidized control specimens over the density range 1.78 to $1.81 \mathrm{Mg} / \mathrm{m}^{3}$.

\subsection{CHARACTERIZATION DATA (OXIDIZED SPECIMENS)}

Complete data sets for UTS, elastic modulus, and strain at fracture for the oxidized samples and controls are tabulated in Appendix A, Tables A-1 through A-14. A summary of the changes in these properties due to oxidation is given in Table 4. Two lots are reported, as discussed in Section 3.3.

\subsubsection{Effect of Oxidation on Ultimate Tensile Strength}

The UTS of the control specimens and the effect of oxidation on the reduction of tensile strength were found to be different for axial and 
TABLE 3

SUMMARY OF TENSILE STRENGTH, ELASTIC MODULUS, AND STRAIN AT FRACTURE OF NONOXIDIZED CONTROL SPECIMENS, LOG 6799-00

\begin{tabular}{|c|c|c|c|c|c|c|}
\hline & \multicolumn{2}{|c|}{$\begin{array}{c}\text { Ultimate Tensile } \\
\text { Strength } \\
\text { (MPa) }\end{array}$} & \multicolumn{2}{|c|}{$\begin{array}{c}\text { Elastic Modulus } \\
(\mathrm{GPa})\end{array}$} & \multicolumn{2}{|c|}{$\begin{array}{c}\text { Fracture Strain } \\
(\%)\end{array}$} \\
\hline & Mean & $\sigma$ & Mean & $\sigma$ & Mean & $\sigma$ \\
\hline \multicolumn{7}{|c|}{ Axial } \\
\hline 1 & 15.7 & 1.8 & 8.3 & 0.3 & 0.240 & 0.030 \\
\hline 3 & 15.4 & 1.1 & 8.7 & 0.8 & 0.224 & 0.028 \\
\hline 5 & 14.9 & 1.5 & 9.0 & 0.3 & 0.203 & 0.022 \\
\hline \multicolumn{7}{|c|}{ Radial } \\
\hline 1 & 17.8 & 3.4 & 8.7 & 0.4 & 0.248 & 0.053 \\
\hline 3 & 18.0 & 1.4 & 9.8 & 0.3 & 0.235 & 0.020 \\
\hline 5 & 18.5 & 1.1 & 10.4 & 0.4 & 0.236 & 0.020 \\
\hline
\end{tabular}


TABLE 4

SUMMARY OF CHANGES IN ULTIMATE TENSILE STRENGTH, ELASTIC MODULUS, AND STRAIN AT FRACTURE DUE TO OXIDATION, $(\mathbf{a}, \mathbf{b})$ LOG 6799-00

\begin{tabular}{|c|c|c|c|c|c|c|c|c|c|}
\hline \multirow{3}{*}{$\begin{array}{l}\text { Sample } \\
\text { Location, } \\
\text { Slab No. } \\
\text { and } \\
\text { Orientation }\end{array}$} & \multicolumn{9}{|c|}{ (Percent Reduction in Property)/(Percent Burnoff) } \\
\hline & \multicolumn{3}{|c|}{ Ultimate Tensile Strength } & \multicolumn{3}{|c|}{ Elastic Modulus } & \multicolumn{3}{|c|}{ Strain at Fracture } \\
\hline & \begin{tabular}{c|} 
Maximum \\
$(2.3 \%$ \\
Probability)
\end{tabular} & $\begin{array}{c}\text { Mean } \\
\text { (Most } \\
\text { Probable) }\end{array}$ & $\begin{array}{c}\text { Mintmum } \\
(2.3 \% \\
\text { Probabil1ty })\end{array}$ & $\begin{array}{c}\text { Maximum } \\
(2.3 \% \\
\text { Probability })\end{array}$ & $\begin{array}{c}\text { Mean } \\
\text { (Most } \\
\text { Probable) }\end{array}$ & $\begin{array}{c}\text { Minimum } \\
(2.3 \% \\
\text { Probability) }\end{array}$ & $\begin{array}{c}\text { Maximum } \\
(2.3 \% \\
\text { Probability })\end{array}$ & $\begin{array}{c}\text { Mean } \\
\text { (Most } \\
\text { Probable) }\end{array}$ & $\begin{array}{c}\text { Minimum } \\
(2.3 \% \\
\text { Probability) }\end{array}$ \\
\hline $1 \operatorname{axia1}(c)$ & 4.0 & 3.5 & 3.0 & & & & & & \\
\hline 1 axial & 10.0 & 5.9 & 1.3 & 8.3 & 6.7 & 4.8 & 3.8 & 0 & 0 \\
\hline 3 axial & 11.3 & 9.6 & 6.9 & 11.2 & 8.6 & 8.3 & 4.3 & 0.5 & 0 \\
\hline 5 axial & 5.1 & 2.6 & 0 & 6.8 & 4.0 & 0 & 1.8 & 0 & 0 \\
\hline Mean axial & 7.6 & 5.4 & 2.8 & 8.8 & 6.4 & 4.4 & 3.3 & 0.2 & 0 \\
\hline $1 \operatorname{radlal}^{(d)}$ & 7.4 & 6.0 & 4.4 & & & & & & \\
\hline 3 radial & 11.5 & 9.1 & 5.3 & 10.2 & 8.9 & 7.0 & 3.2 & 0.4 & 0 \\
\hline 5 radial & 11.0 & 8.9 & 6.1 & 11.0 & 8.8 & 5.0 & 8.9 & 2.8 & 0 \\
\hline Mean radial & 10.0 & 8.0 & 5.3 & 10.6 & 8.9 & 6.0 & 6.0 & 1.6 & 0 \\
\hline $\begin{array}{l}\text { Mean axial } \\
\text { and radial }\end{array}$ & $\cdot 8.8$ & 6.7 & 4.0 & 9.5 & 7.4 & 5.0 & 4.7 & 0.9 & 0 \\
\hline
\end{tabular}

(a) Oxidation conditions: $1148 \mathrm{~K}, 3 \mathrm{kPa} \mathrm{H} \mathrm{H}_{2}, 5 \mathrm{kPa} \mathrm{H}$, balance He.

(b) Analysis based on CONFID computer code which assumes linear fit to data.

(c) Burnoffs to $25 \%$, lot BKR.

(d) Burnoffs to $15 \%$, lot BKR. 
radial specimens; thus, the axial and radial data are treated separately in the following sections.

\subsubsection{Axial Samples}

The effect of oxidation on the UTS of axial samples for each slab is shown in Figs. 6 through 8. The data from lot BKR slab 1 are shown in Fig. 9. The average rate of strength loss and the maximum and minimum values based on $95 \%$ confidence were calculated using CONFID, a GA computer code which calculates confidence limits for a linear slope. Based on the results of statistical calculations at the $95 \%$ confidence level, the ultimate tensile strengths of all axial control specimens were combined to form a single control population. The reduction in axial UTS using all specimens (excluding lot $\mathrm{BKR}$ ) was calculated. The results are shown in Fig. 10. The upper and lower lines in Fig. 10 are 95\% confidence limits based on calculations using CONFID. Edge and center samples are identified and show no significant difference.

Figure 11 is a plot of axial UTS versus density. The two characteristics of interest are: (1) the continued data dispersion around the calculated mean at all densities and (2) the developed relationship between UTS and bulk density. The data were analyzed by POLFIT, a GA computer code which fits a linear slope by the method of least-squares, and the standard deviation of the dependent variable. In Fig. 11 the dashed lines represent one standard deviation.

A variability of UTS is particularly apparent in the oxidized specimens from slab 5 (Fig. 8).

At $21 \%$ burnoff strength values were not significantly different from the strengths of the controls (Fig. 12). A similar result was obtained for axial and radial specimens of oxidized $\mathrm{H}-451$ graphite (Ref. 6). The data from lot BKR (Fig. 9) show a linear dependence of strength for burnoffs to $25 \%$. 


\subsubsection{Radial Samples}

Figures 13 ( $\log B K R), 14$, and 15 show UTS versus burnoff for oxidized radial specimens.

The results of $t$-test analysis showed that all nonoxidized radial specimens could be treated as a single control population. The ultimate tensile strengths of all oxidized and nonoxidized specimens are plotted in Fig. 16. The data were analyzed using CONFID to establish limits on the effect of burnoff (dashed lines in Fig. 16 show limits at $95 \%$ confidence). In contrast to the results for axial specimens, relatively large UTS losses were found at low burnoff levels (Fig. 17).

Figure 18 is a plot of UTS versus bulk density for radial oxidized and nonoxidized specimens. The dashed lines represent boundaries of one standard deviation established by POLFIT. The solid line represents the slope of UTS versus density as a result of a least-squares regression fit. A relationship between UTS and bulk density is apparent.

\subsubsection{Effect of Oxidation on Elastic Modulus - Axial and Radial Specimens}

The effect of oxidation on elastic modulus is shown in Figs. 19 through 24. The figures include $95 \%$ confidence limits on the linear slope calculated using CONFID. A summary of the modulus data of oxidized specimens is given in Table 3 . The mean control modulus in slab 1 was judged significantly different on a statistical basis from the mean control modulus in slab 5 (see Table 3 and Figs. 19 through 23). In Fig. 24 modulus is plotted versus burnoff for all slabs. The large scatter in the data is attributed to slab 5 .

In Figs. 25 and 26 modulus is plotted versus specimen bulk density for axial and radial specimens, respectively. The data show a monotonic relationahip between density and modulus. 


\subsubsection{Effect of Oxidation on Strain at Fracture}

The effect of oxidation on strain at fracture for each slab and axial and radial specimens is given in Figs. 27 through 31 . The data from all slabs are shown in Fig. 32. Only a slight effect of oxidation is noted. Statistical t-testing of the control group indicated that the axial specimens from slab 5 were statistically significantly different from slabs 1 and 3 . The strain-at-fracture data for the control groups fit a Gaussian distribution (see Fig. 33). 


\section{CONCLUSIONS}

Conclusions are summarized as follows:

1. No differences were detected in UTS, elastic modulus, and strain at fracture between edge and center specimens.

2. The reduction in UTS and elastic modulus of axial specimens having a mean strength of $15.3 \mathrm{MPa}$ prior to oxidation are $5.4 \%$ and $6.4 \%$, respectively, at $1 \%$ burnoff.

3. The reduction in UTS and elastic modulus of radial specimens having a mean strength of $18.1 \mathrm{MPa}$ prior to oxidation are $8 \%$ and $8.9 \%$, respectively, at $1 \%$ burnoff.

4. Changes in strain at fracture at burnoffs up to $5 \%$ were negligible.

5. The UTS of nonoxidized control specimens followed a Gaussian distribution. The strain at fracture of nonoxidized and oxidized specimens also followed a Gaussian distribution. No statistical difference in the mean UTS could be detected in control specimens taken from slabs 1, 3, or 5; however, elastic modulus and strain at fracture in slab 5 were judged statistically different from slabs 1 and 3 .

6. The relationship found between UTS and elastic modulus and bulk density for nonoxidized and oxidized specimens may represent a parameter for evaluating in situ strength of reactor support posts and warrants further consideration. 


\section{ACKNOWLEDGMENTS}

The authors are indebted to Kar1 Koyama of the Research and Services Division, GA, who initiated this study in 1975 and was responsible for the sampling plan and the early results. The work of C. Richards and J. Whaley who performed the mechanical testing is gratefully acknowledged. Also Glen Engle is acknowledged for helpful comments and editing of the final report. 


\section{REFERENCES}

1. Barsel1, A. W., and M. B. Peroomian, "Consequences of Water Ingress into the HTGR Primary Coolant," General Atomic Report GA-A13171, April 15, 1975.

2. Engle, G. B., and L. A. Beavan, "Properties of Unirradiated Reference Grade Graphites for Support and Permanent Side Reflector HTGR Components: PGX, HLM, and 2020," DOE Report GA-A14646, General Atomic Company, to be published.

3. Engle, G. B., "Properties of Unirradiated HTGR Core Support and Permanent Site Reflector Graphites: PGX, HLM, and H-440N," ERDA Report GA-A14328, General Atomic Company, May 1977.

4. Johnson, W. R., and Engle, G. B., "Properties of Unirradiated Fuel Element Graphites H-451 and TS-1240," ERDA Report GA-A13752, General Atomic Company, January 31, 1976.

5. Price, R. J., "Statistical Study of Strength of Near-Isotropic Graphite," ERDA Report GA-A13955, General Atomic Company, May 24, 1976.

6. Velasquez, C., et al., "Effect of Steam Oxidation on the Tensile Strength and Elastic Modulus of H-451," DOE Report GA-A14657, General Atomic Company, to be published.

7. Burnette, R. D., et al., "Studies of the Rate of Oxidation of ATJ Graphite by Steam," paper presented at the 13th Biennial Carbon Conference, Irvine, California, July 18-22, 1977.

8. "HTGR Fuels and Core Development Program Quarterly Progress Report for the Period Ending February 28, 1977," ERDA Report GA-A14298, General Atomic Company, March 1977. 


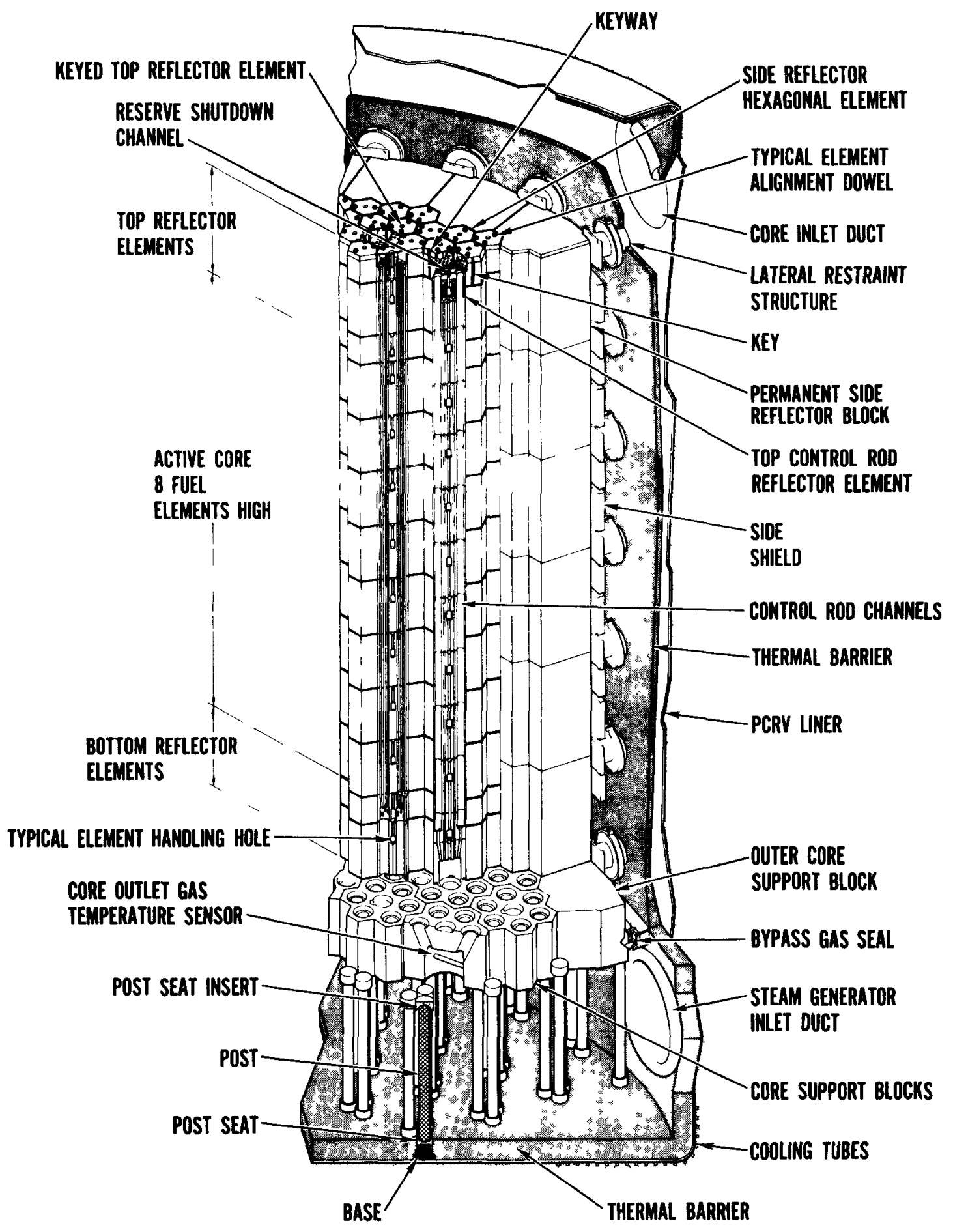

Fig. 1. HTGR core and support arrangement 
THERMOCOUPLE LOCATIONS

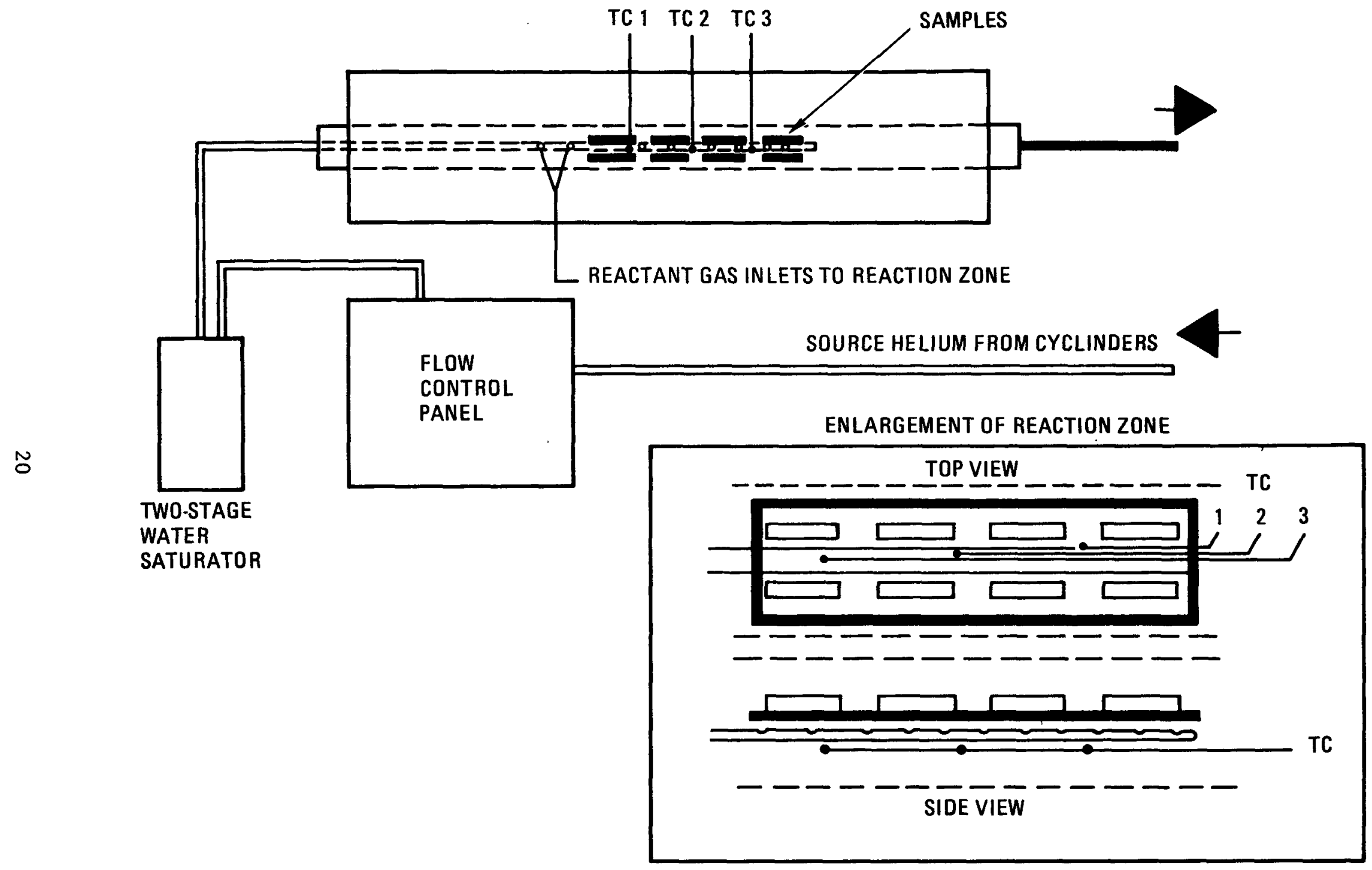

Fig. 2. Steam-graphite oxidation apparatus 


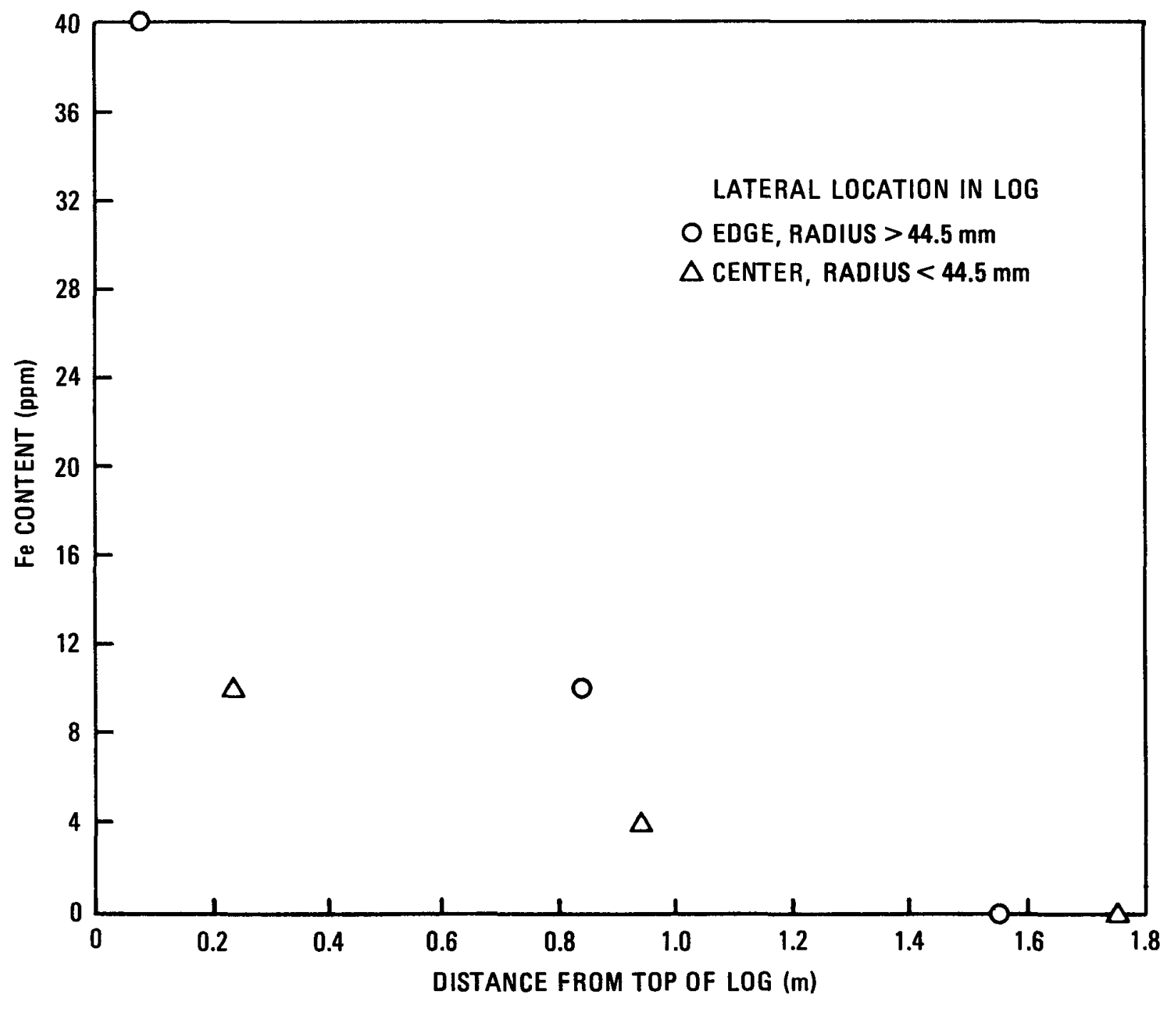

Fig. 3. Fe contamination versus location in $\log$ 


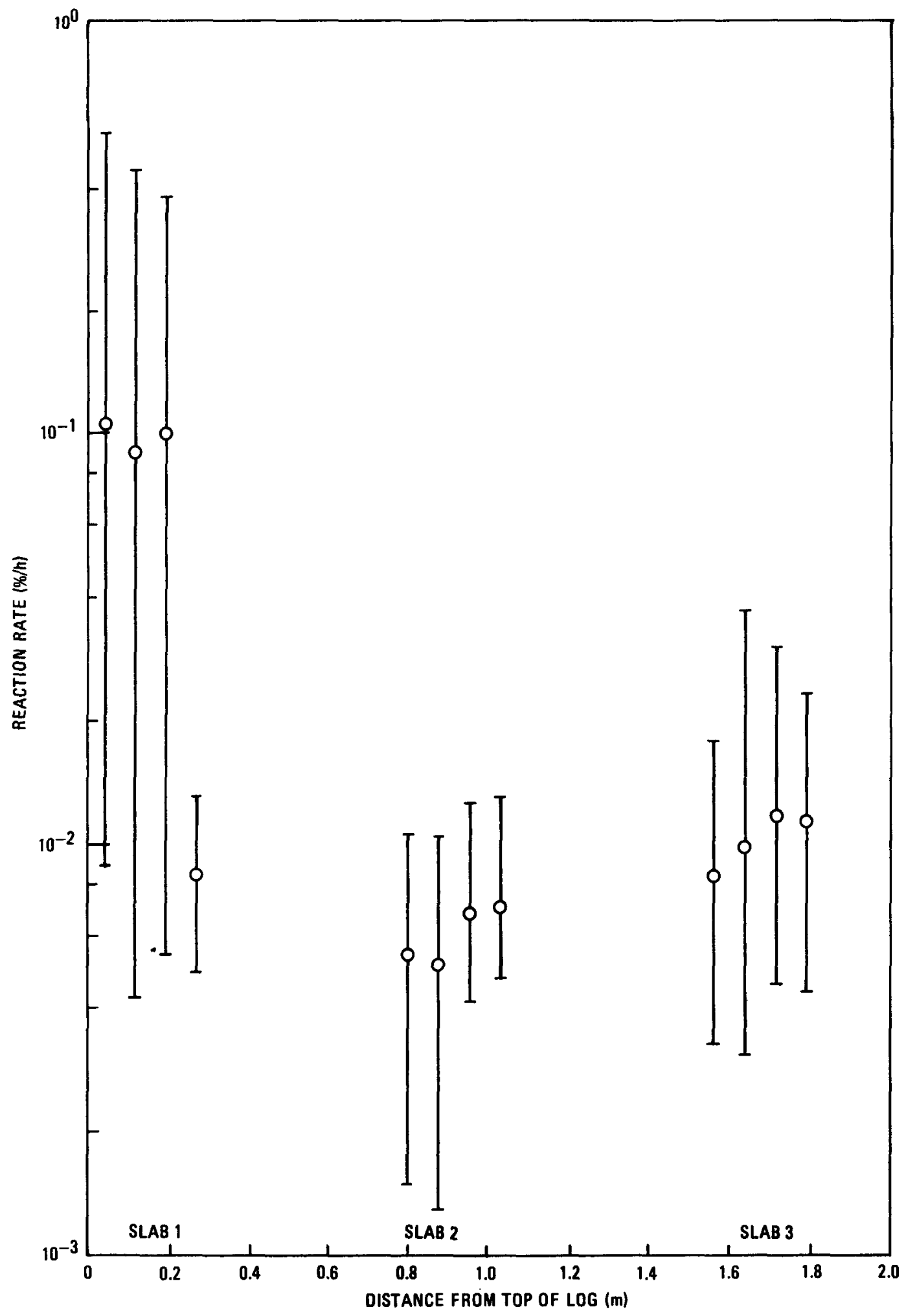

Fig. 4. Average and range of reaction rates of each section versus distance from end of $10 \mathrm{~g}$ 


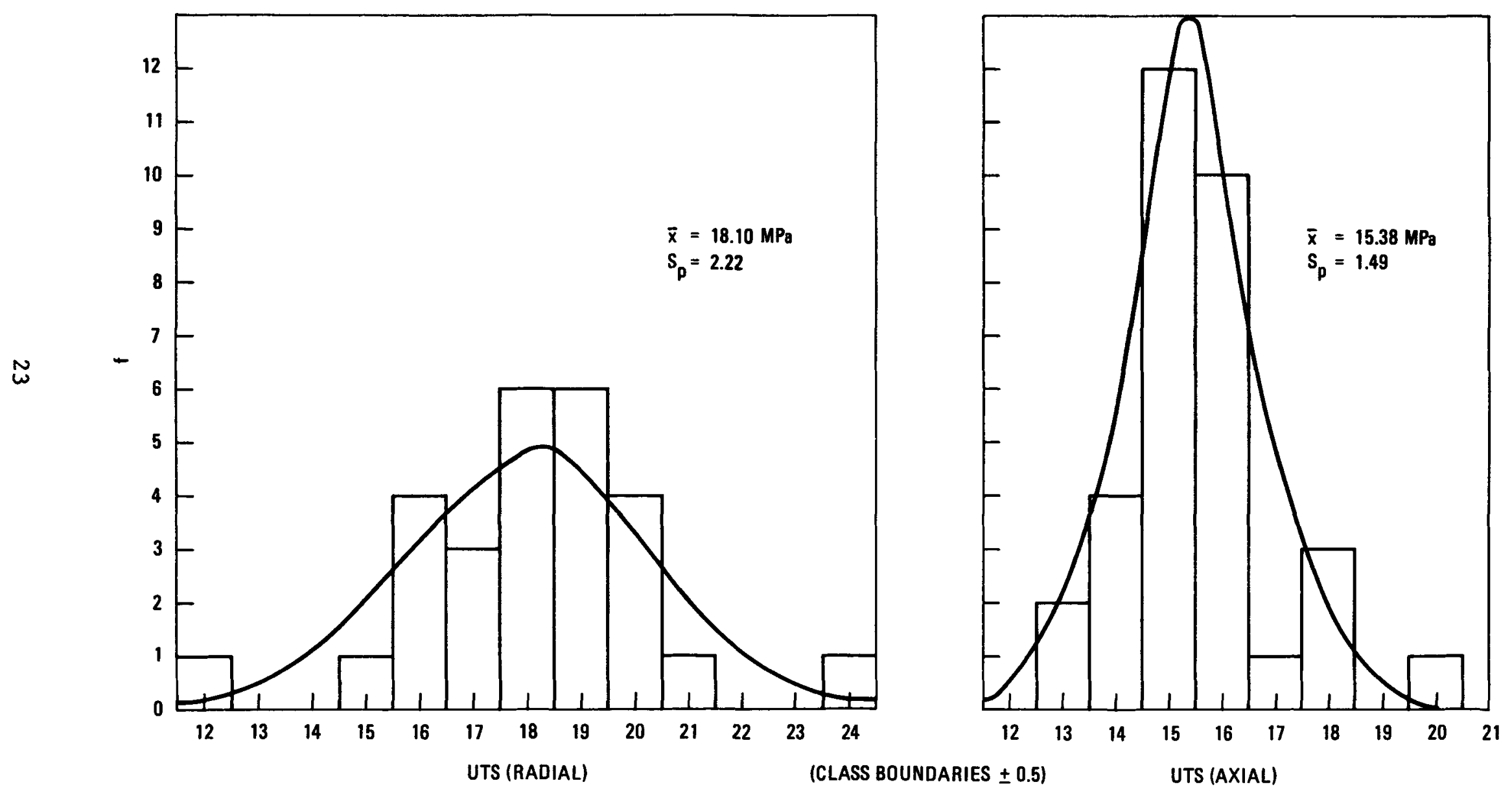

Fig. 5. Gaussian distribution fjts to UTS data, 2020 graphite, $\log 6799-00$ 


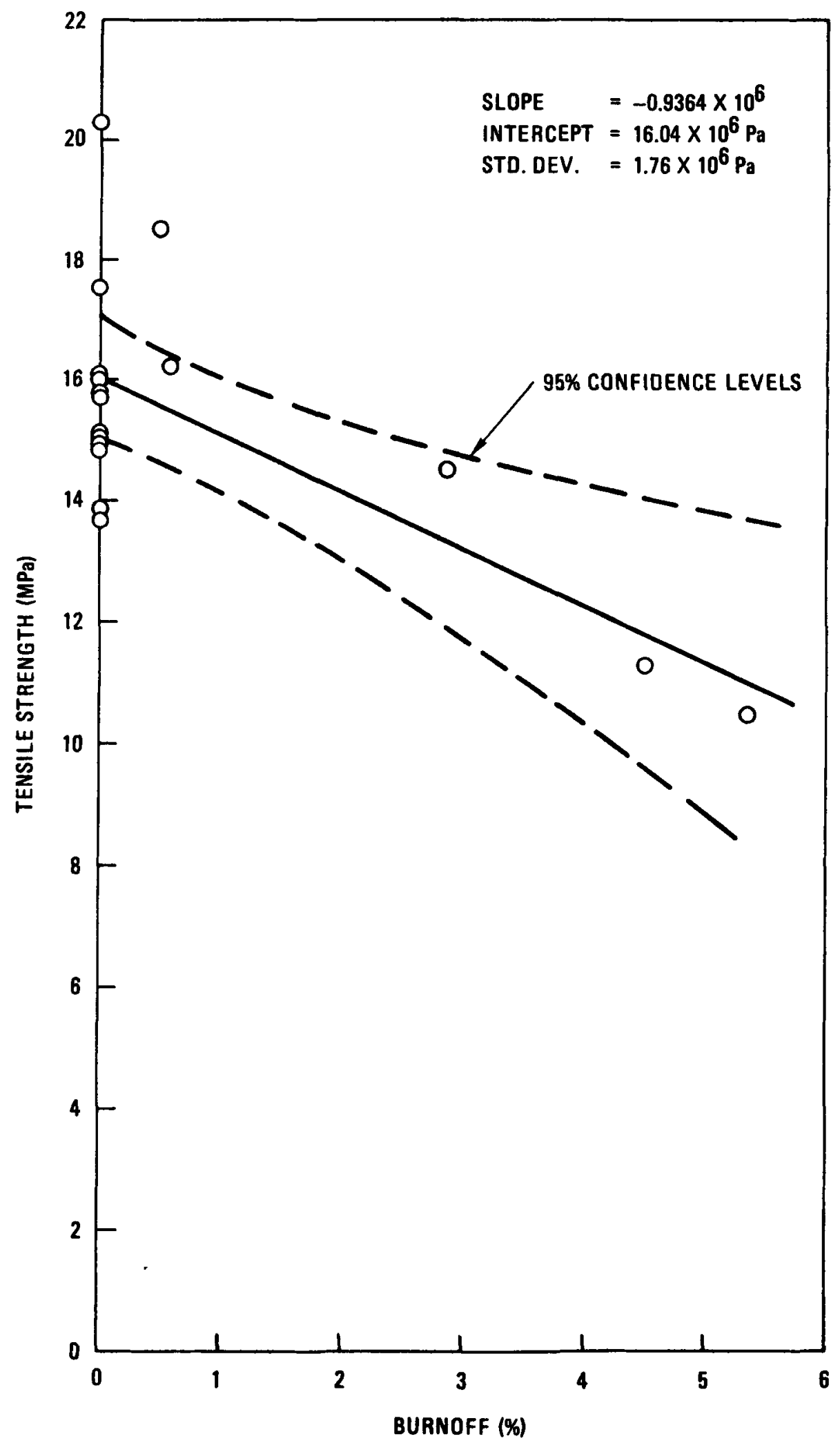

Fig. 6. UTS versus burnoff, axial, slab 1 


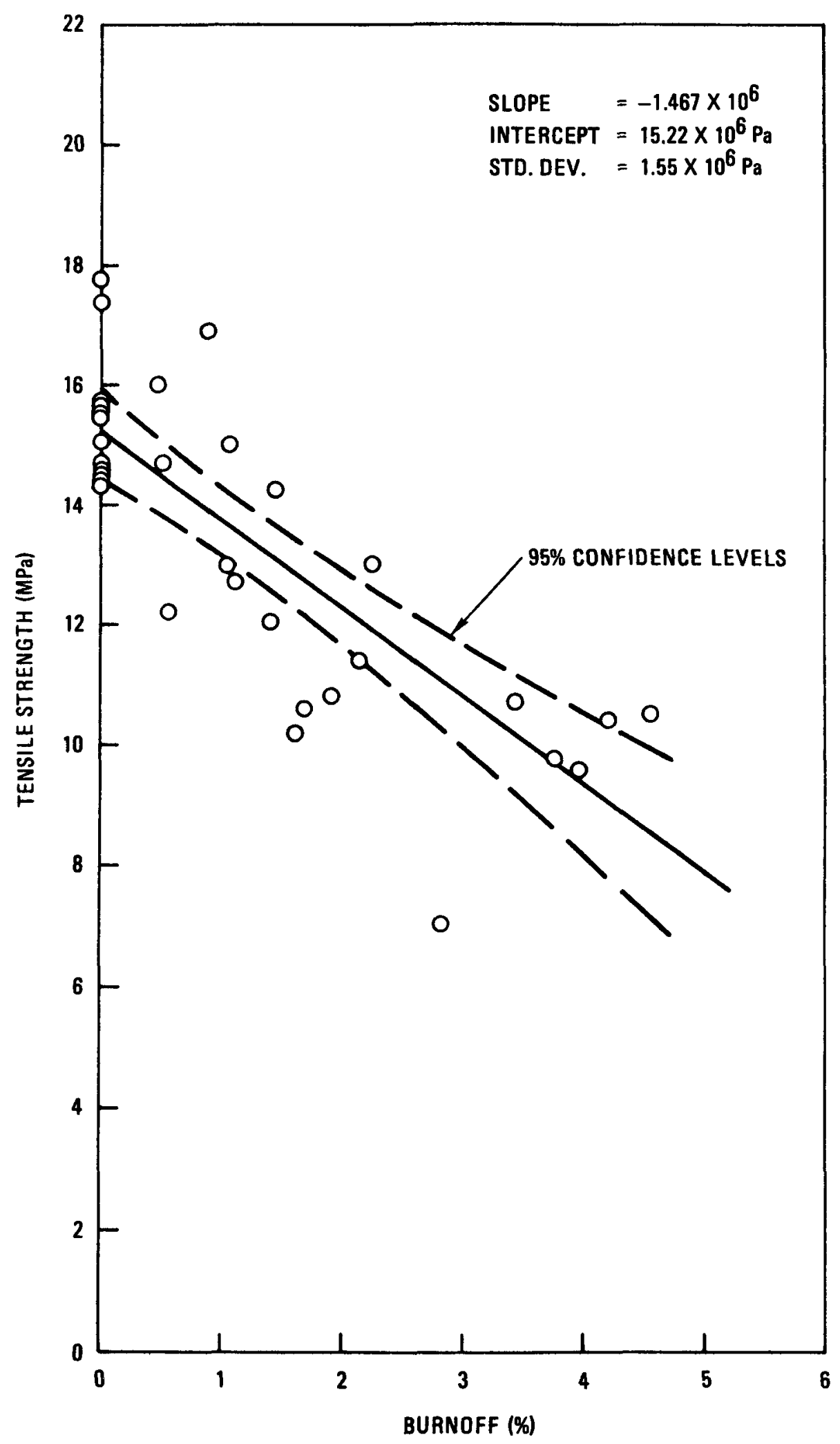

Fig. 7. UTS versus burnoff, axial, slab 3 


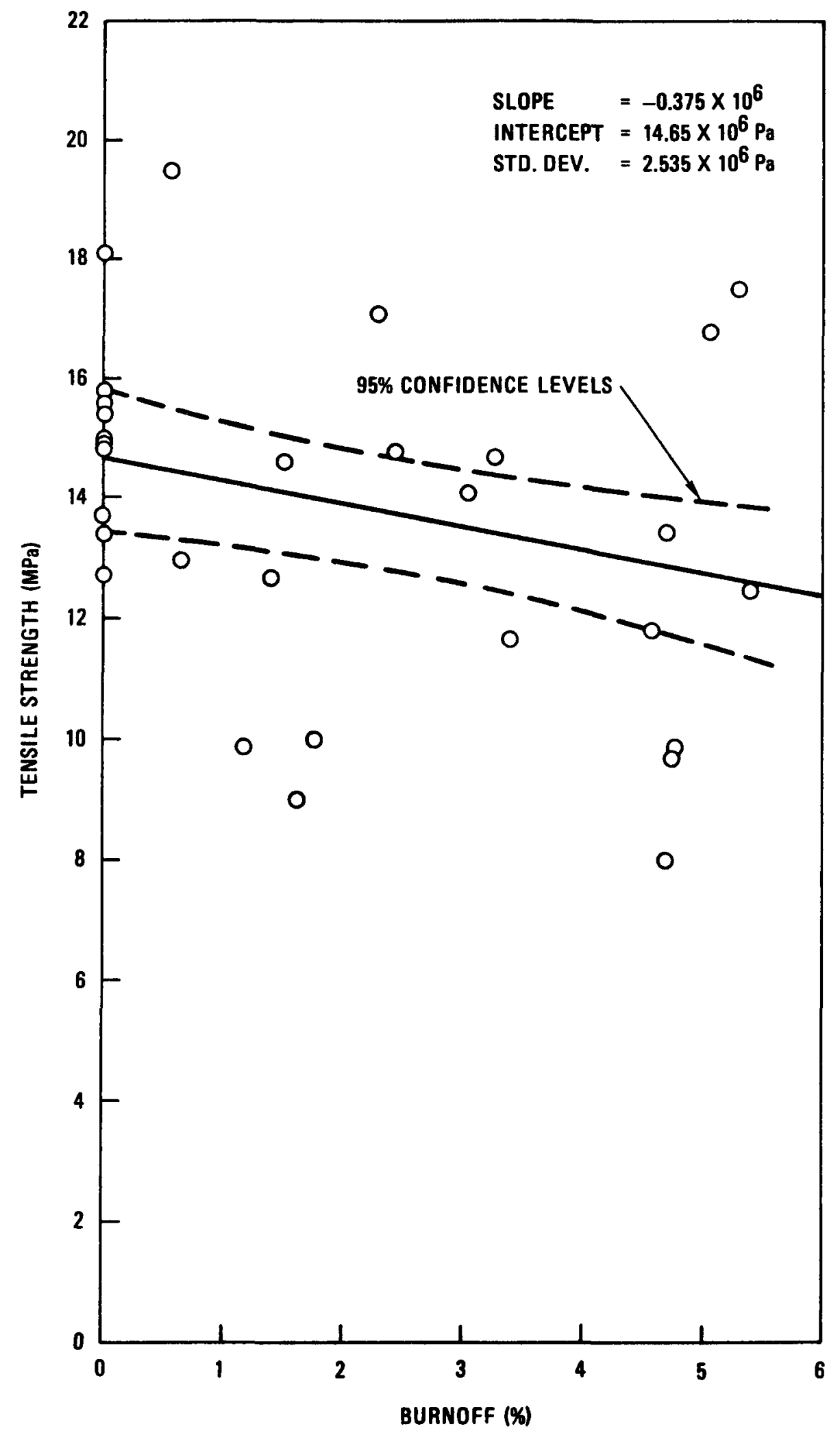

Fig. 8. UTS versus burnoff, axial, slab 5 


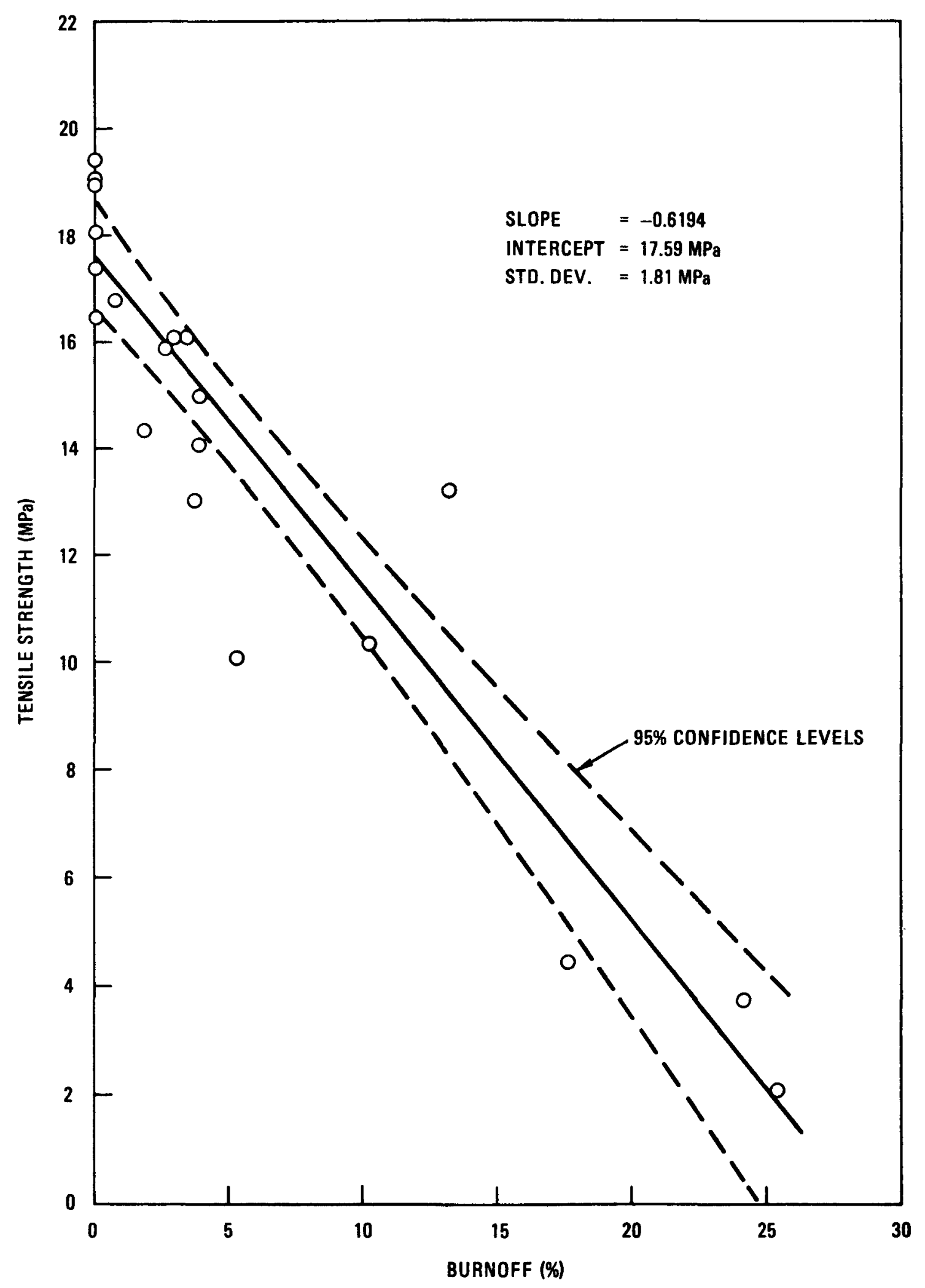

Fig. 9. UTS versus burnoff, axial, slab 1 (10t BKR) 


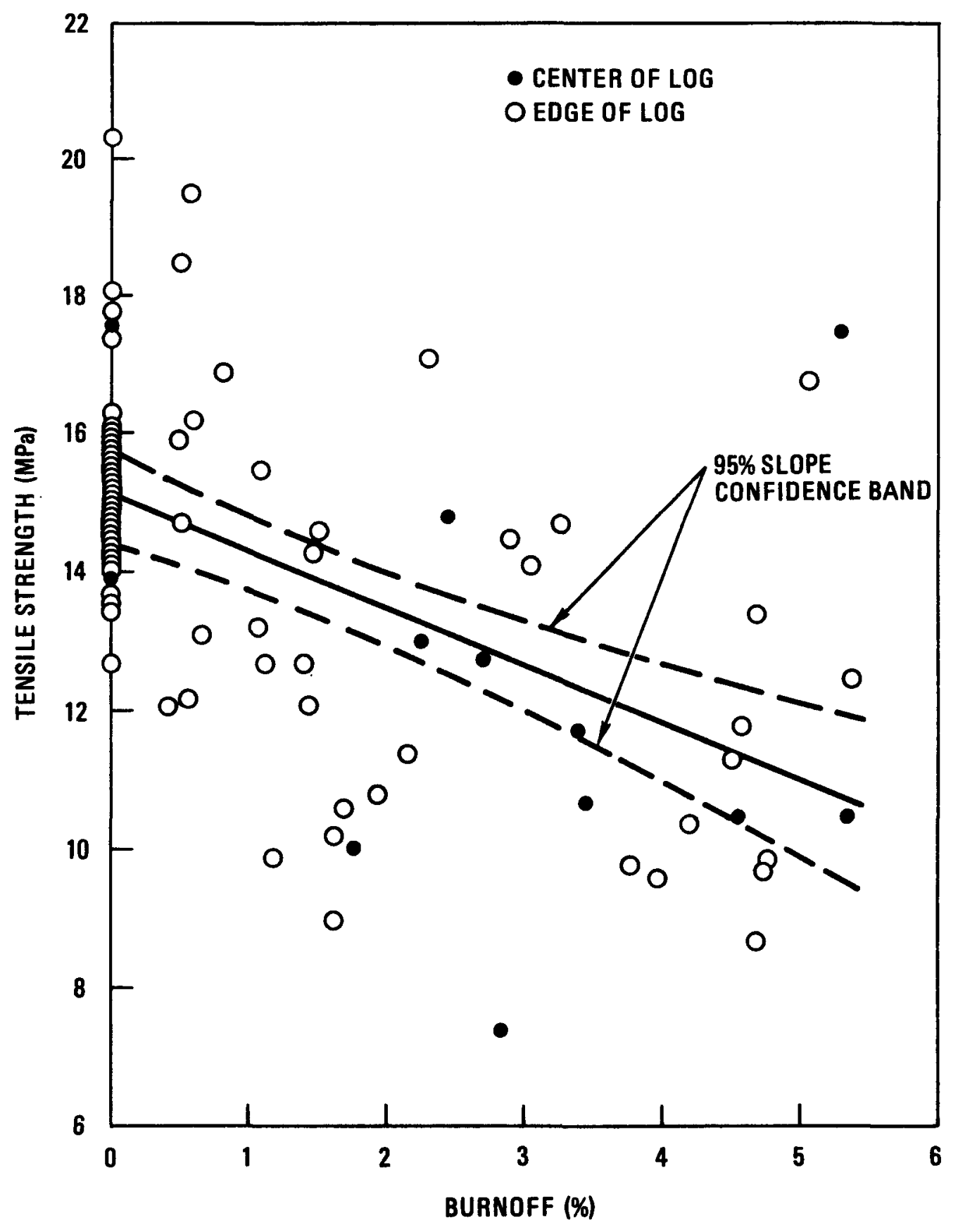

Fig. 10. UTS versus burnoff, axial, all slabs 


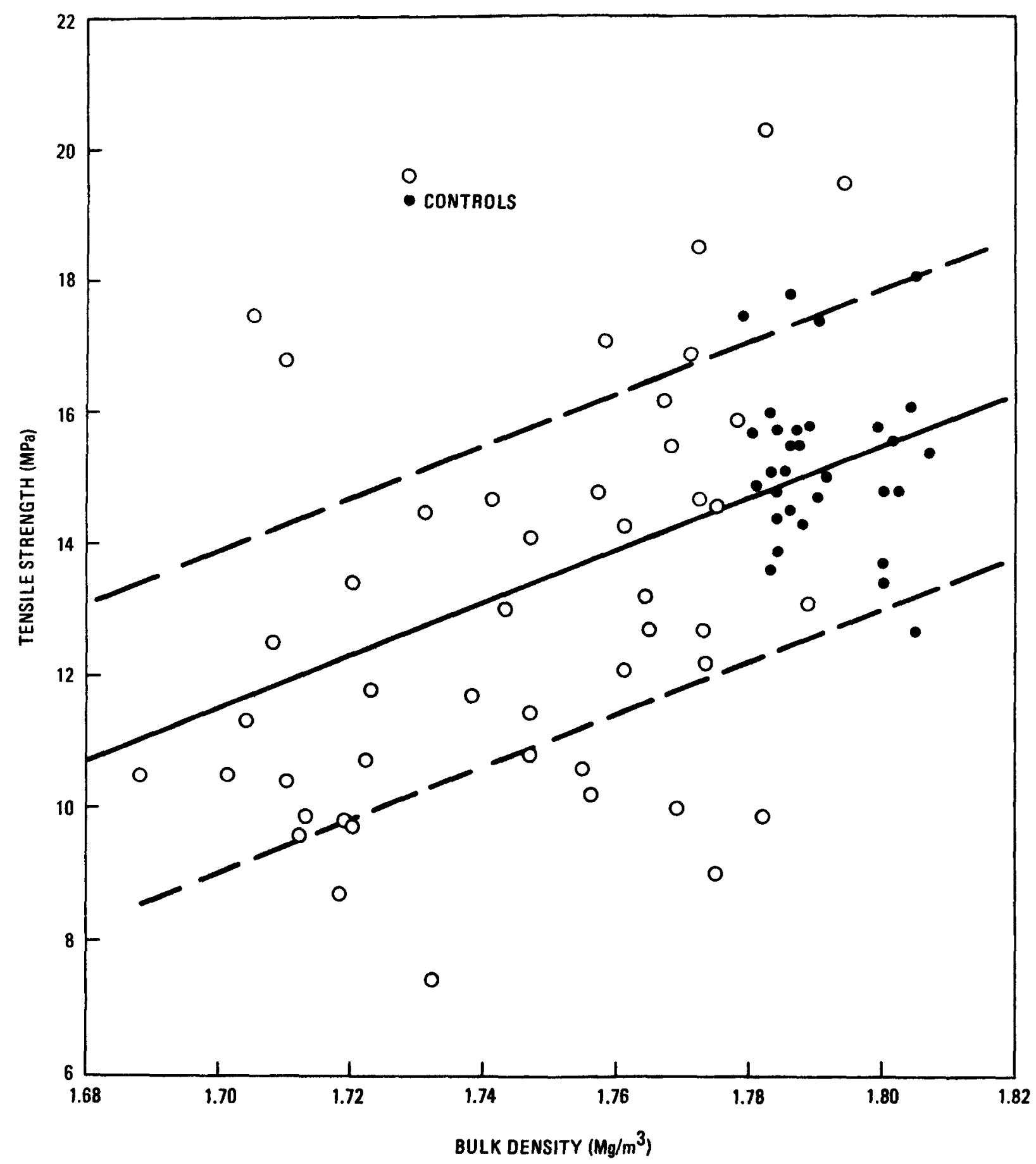

Fig. 11. UTS versus density for oxidized and nonoxidized axial specimens 


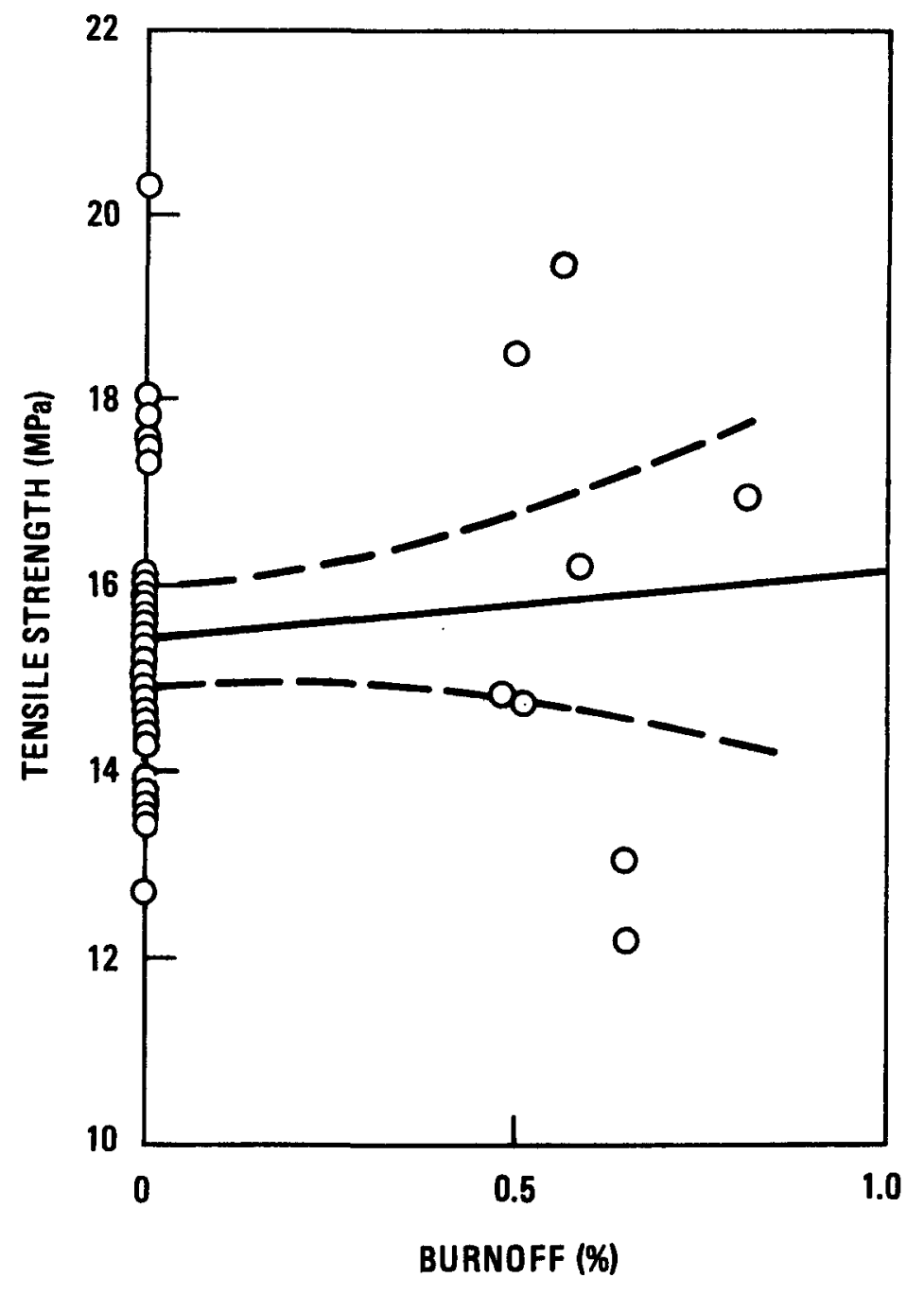

Fig. 12. UTS versus burnoff (to $1 \%$ ), axial samples 


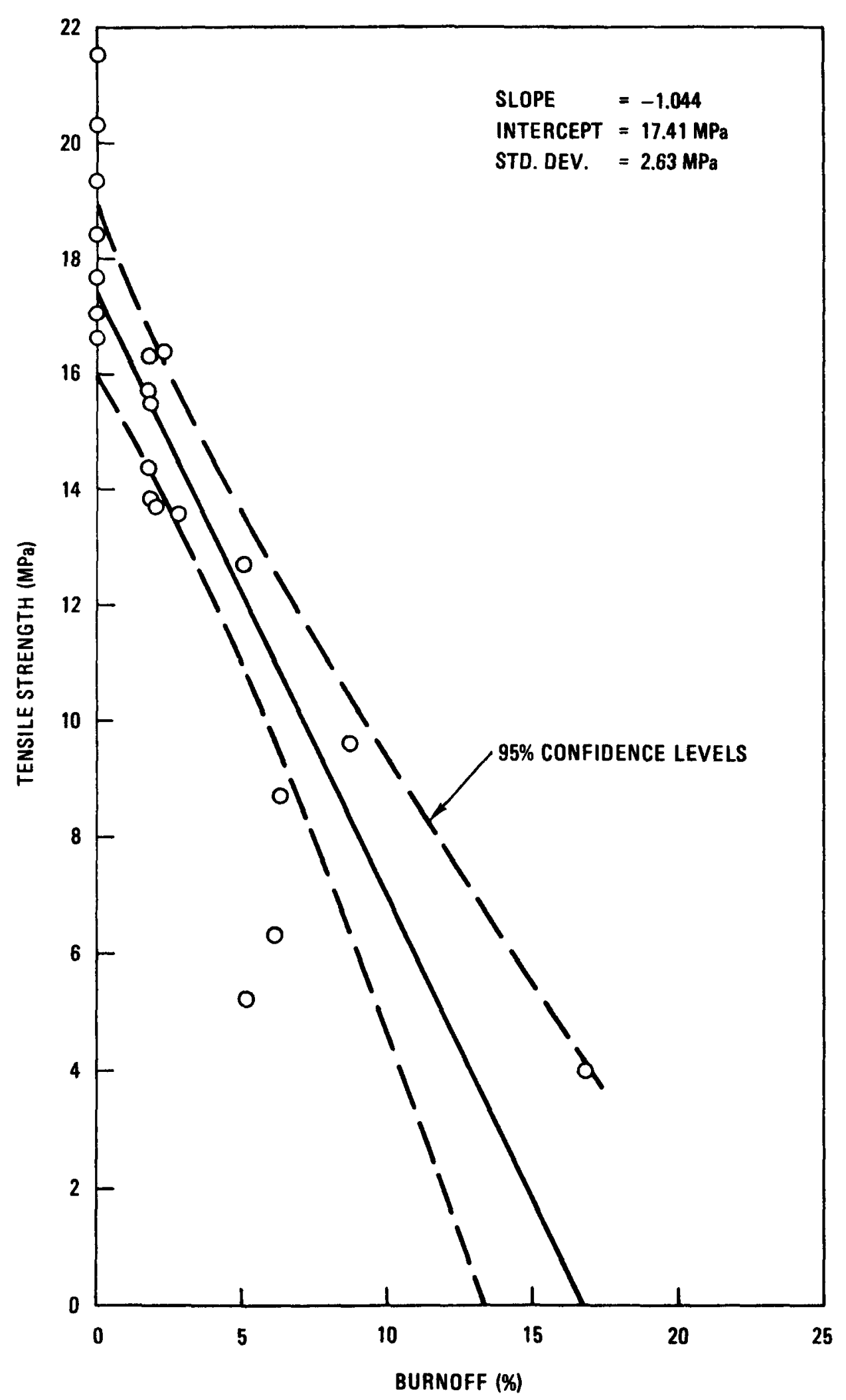

Fig. 13. UTS versus burnoff, radial, slab 1, lot BKR 


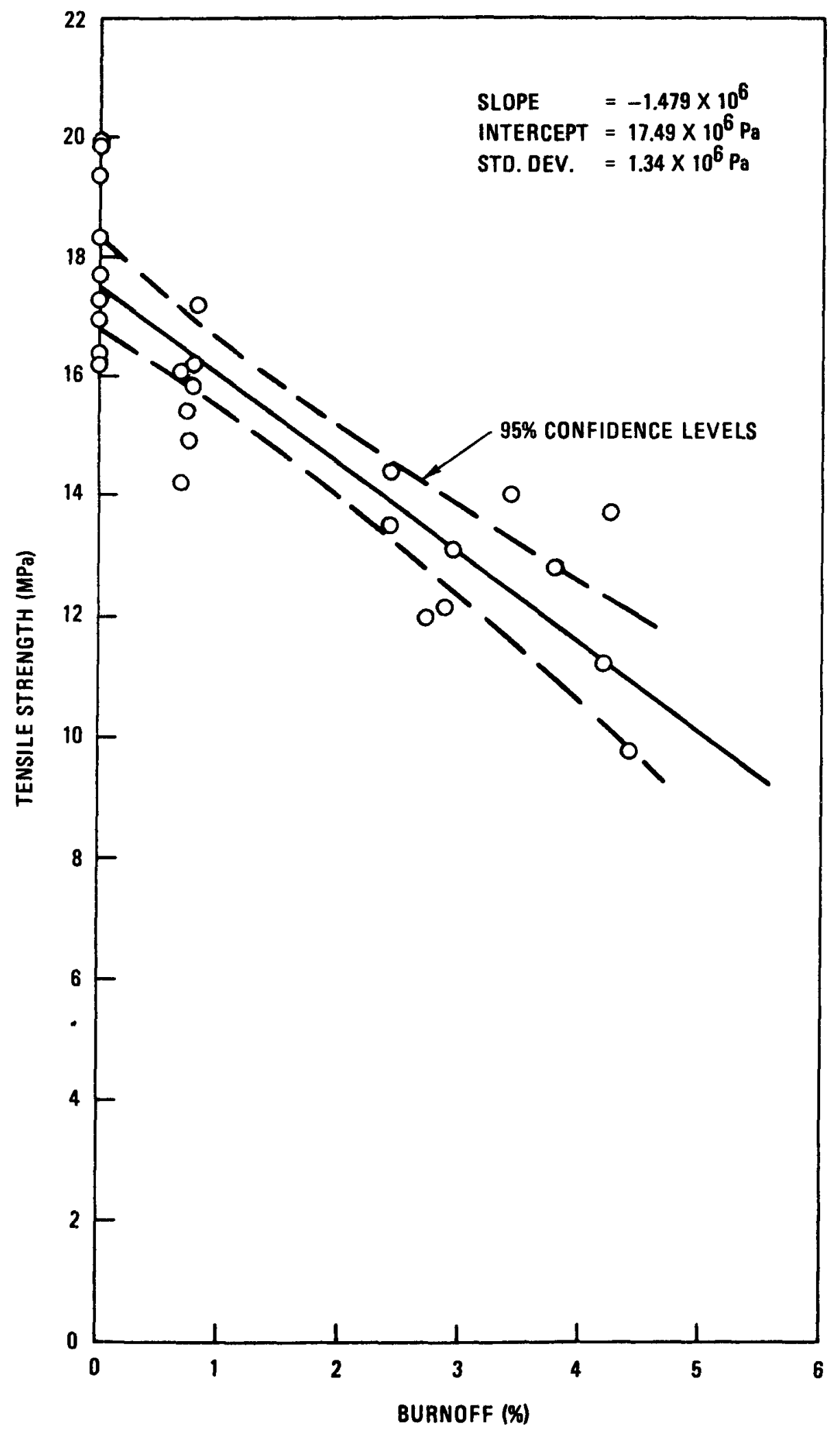

Fig. 14. UTS versus burnoff, radial, slab 3 


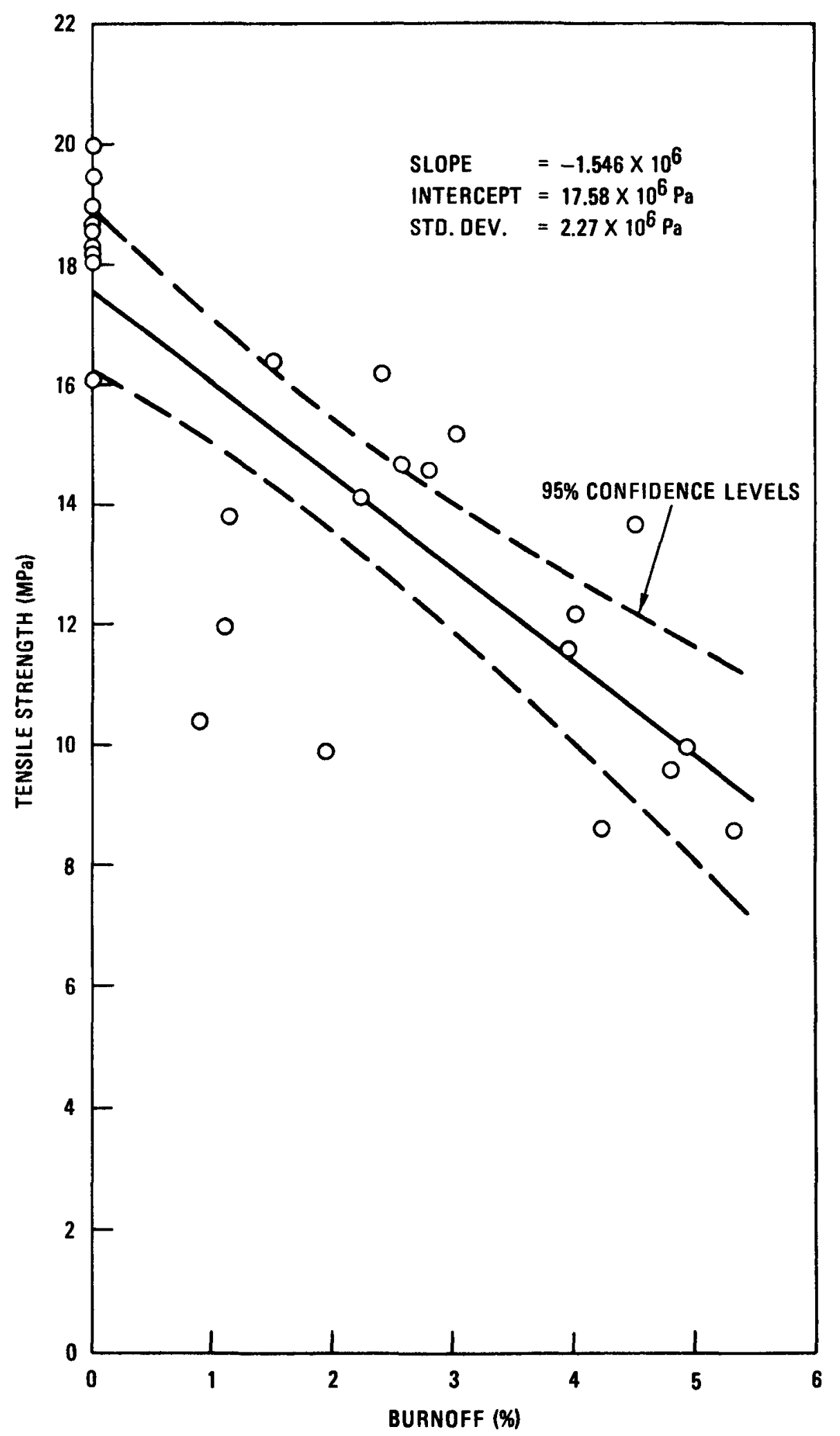

Fig. 15. UTS versus burnoff, radial, slab 5 


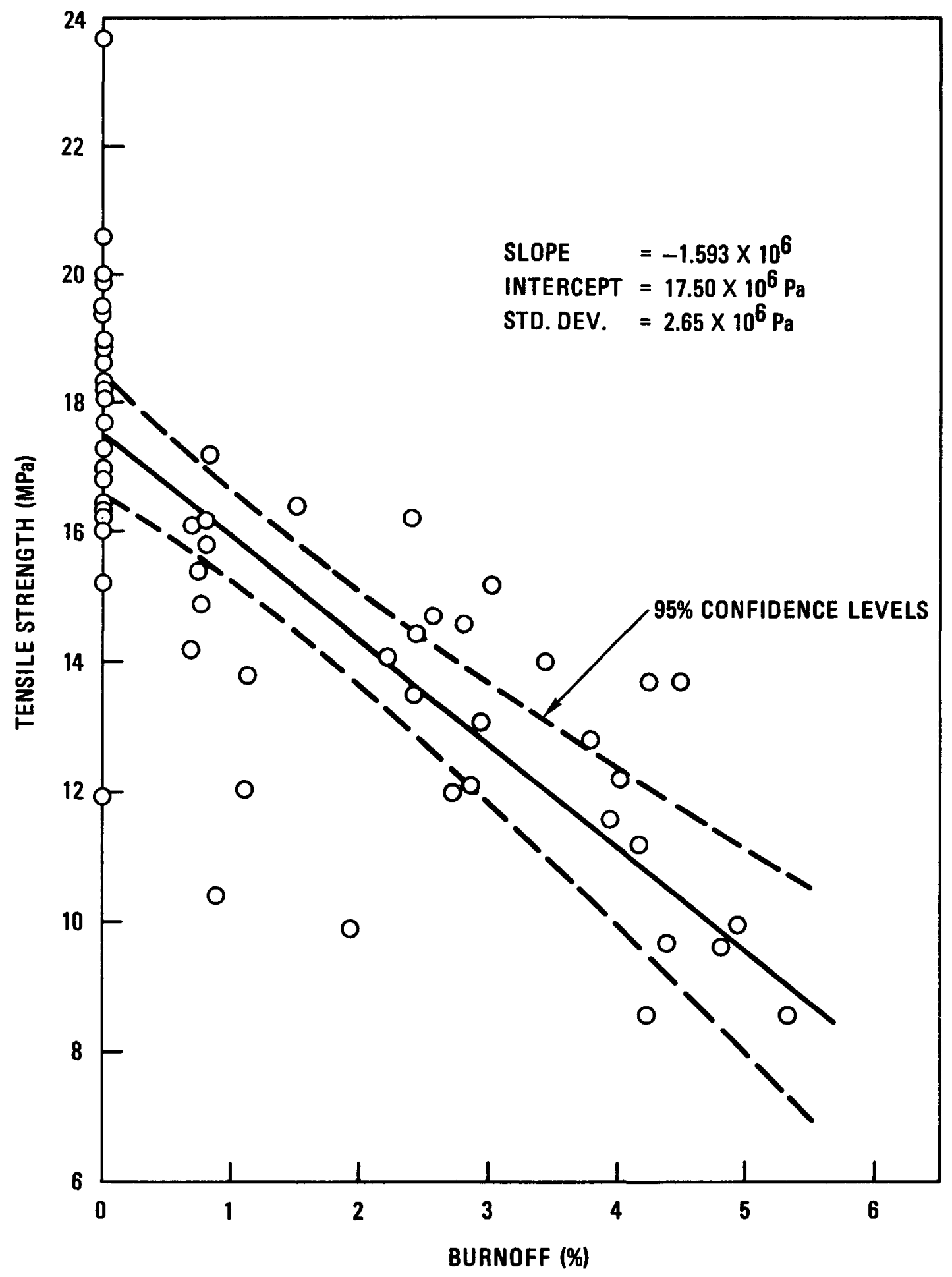

Fig. 16. UTS versus burnoff, radial, slabs 3 and 5 


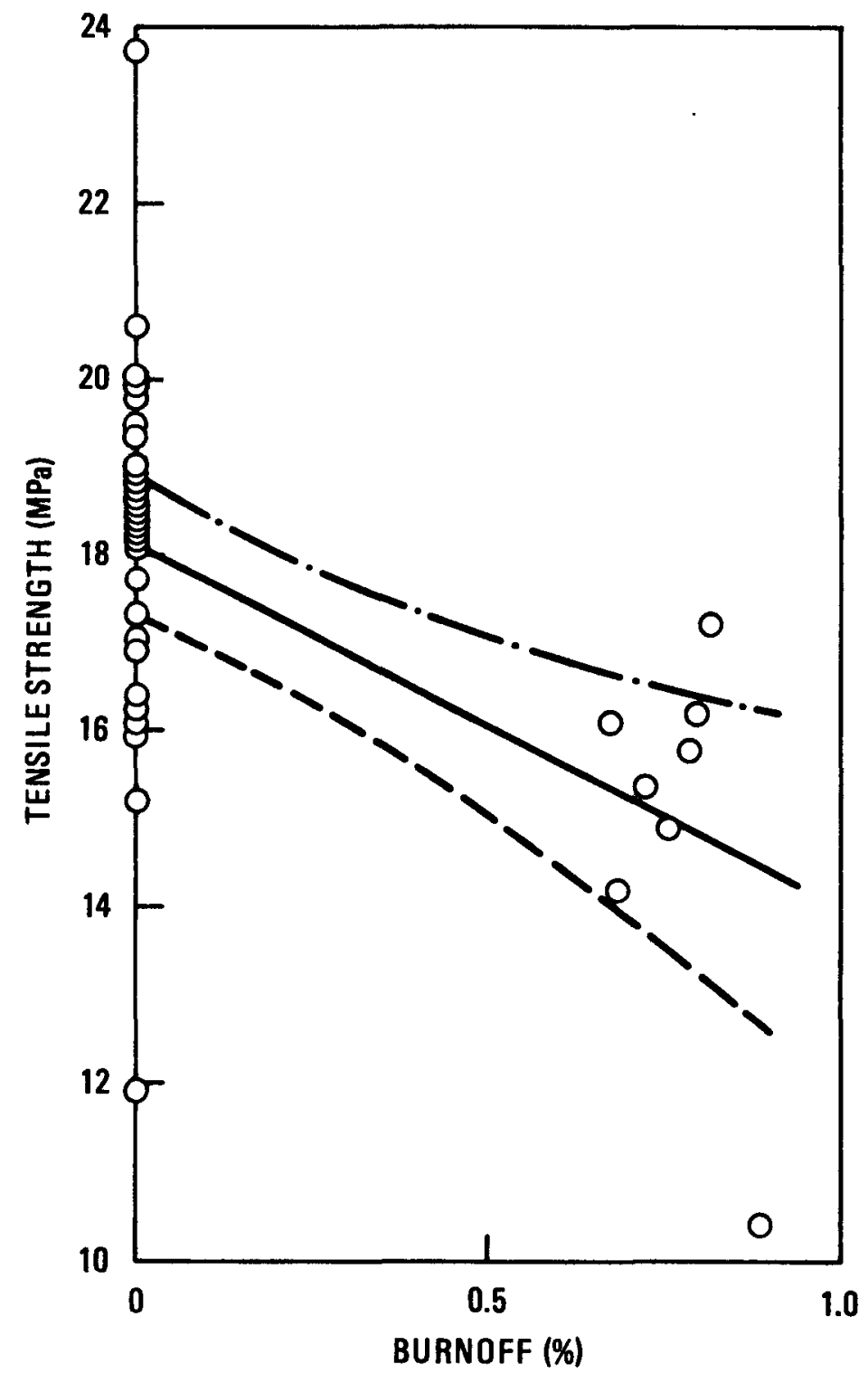

Fig. 17. UTS versus burnoff (to $1 \%$ ), radial specimens 


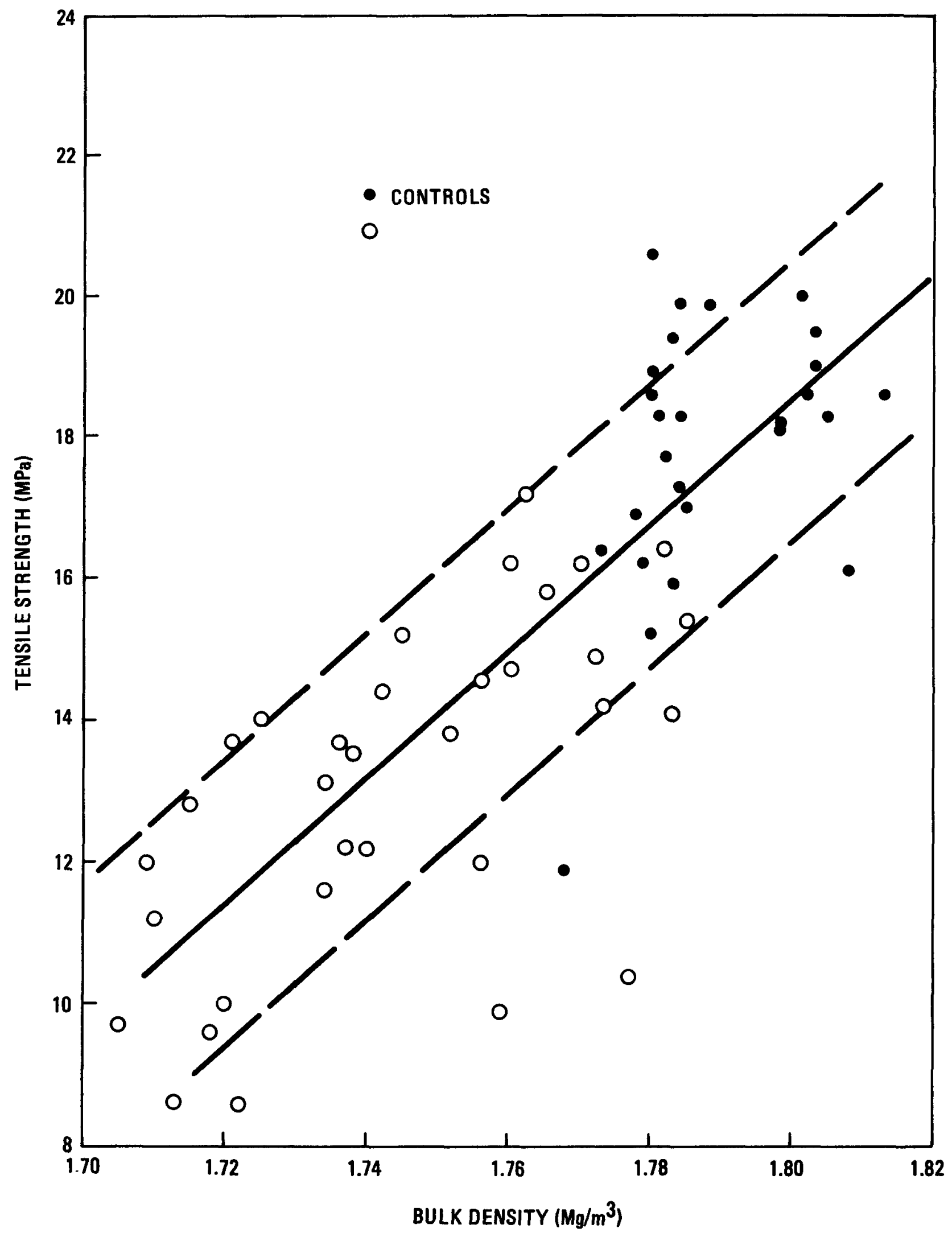

Fig. 18. UTS versus density of oxidized and nonoxidized radial specimens 


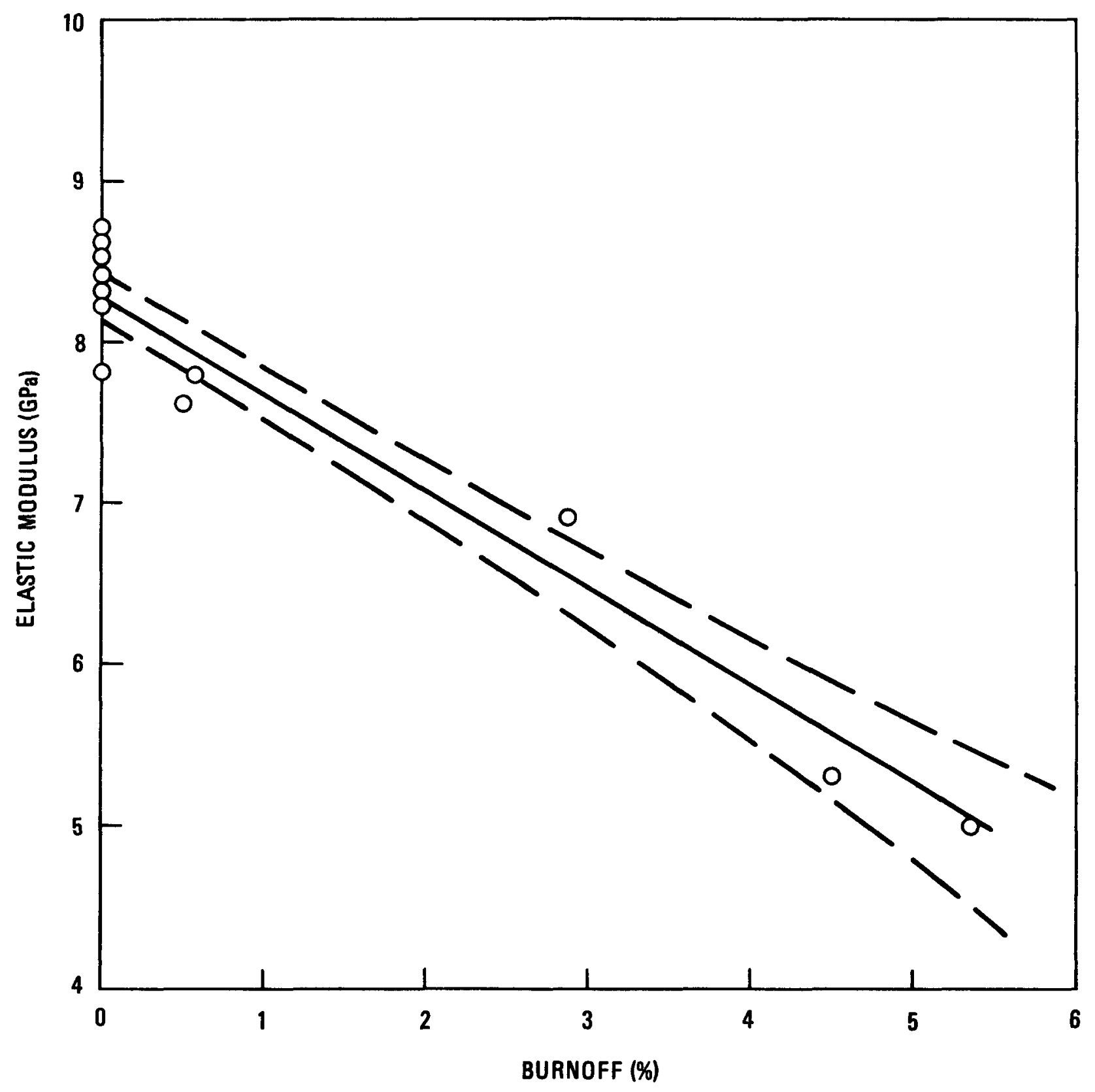

Fig. 19. Elastic modulus versus burnoff, axial, slab 1 


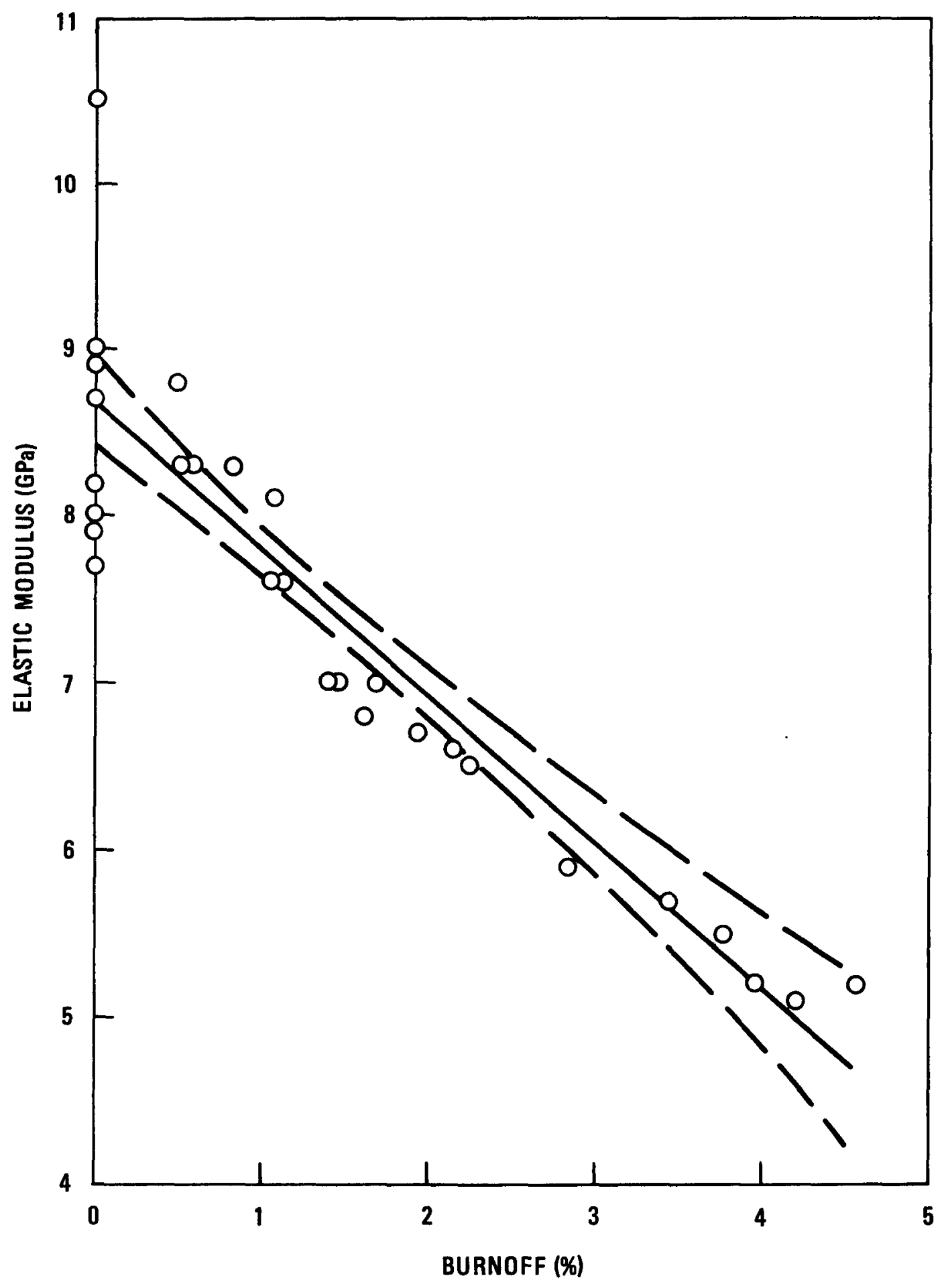

Fig. 20. Elastic modulus versus burnoff, axial, slab 3 


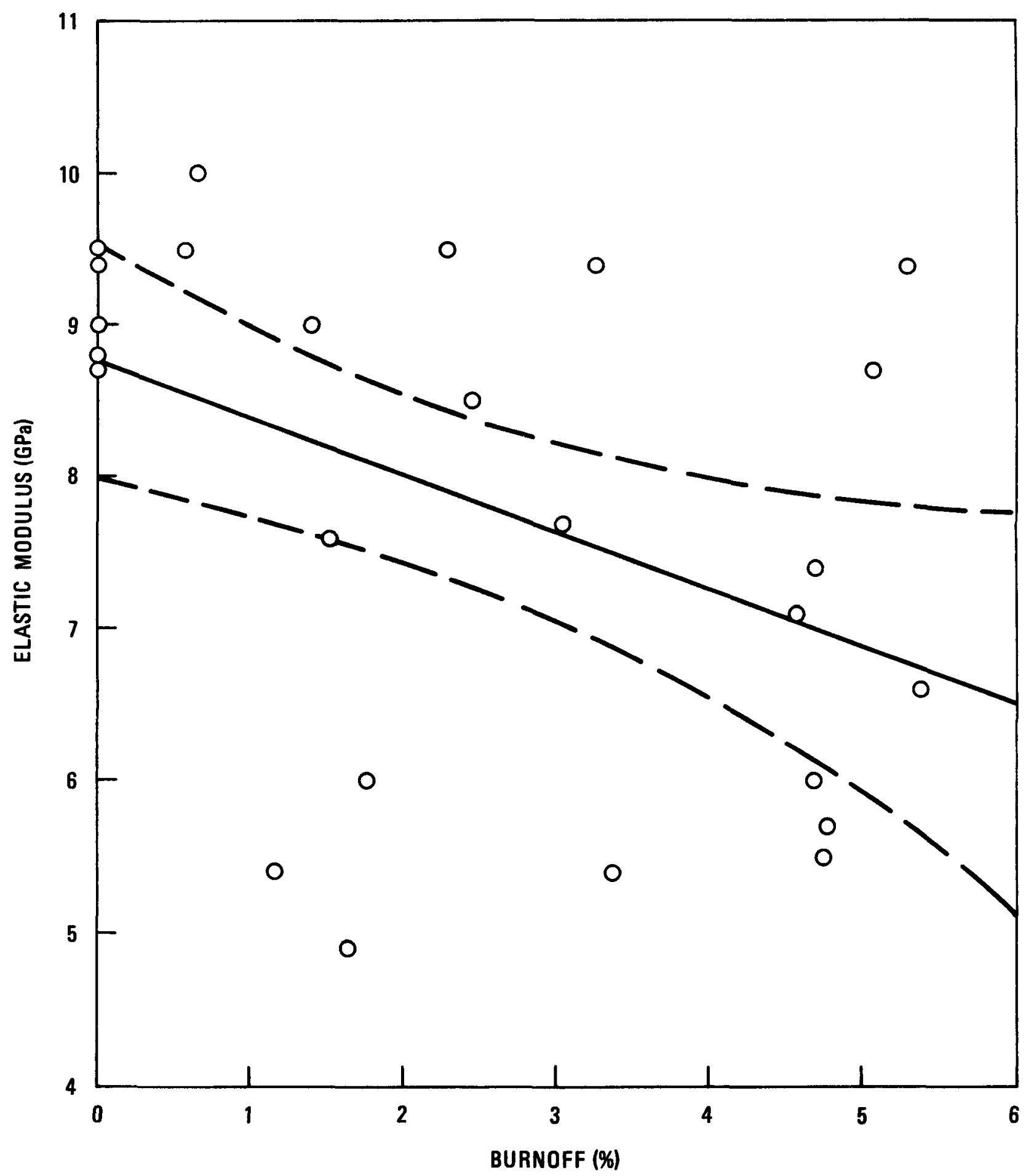

Fig. 21. Elastic modulus versus burnoff, axial, slab 5 


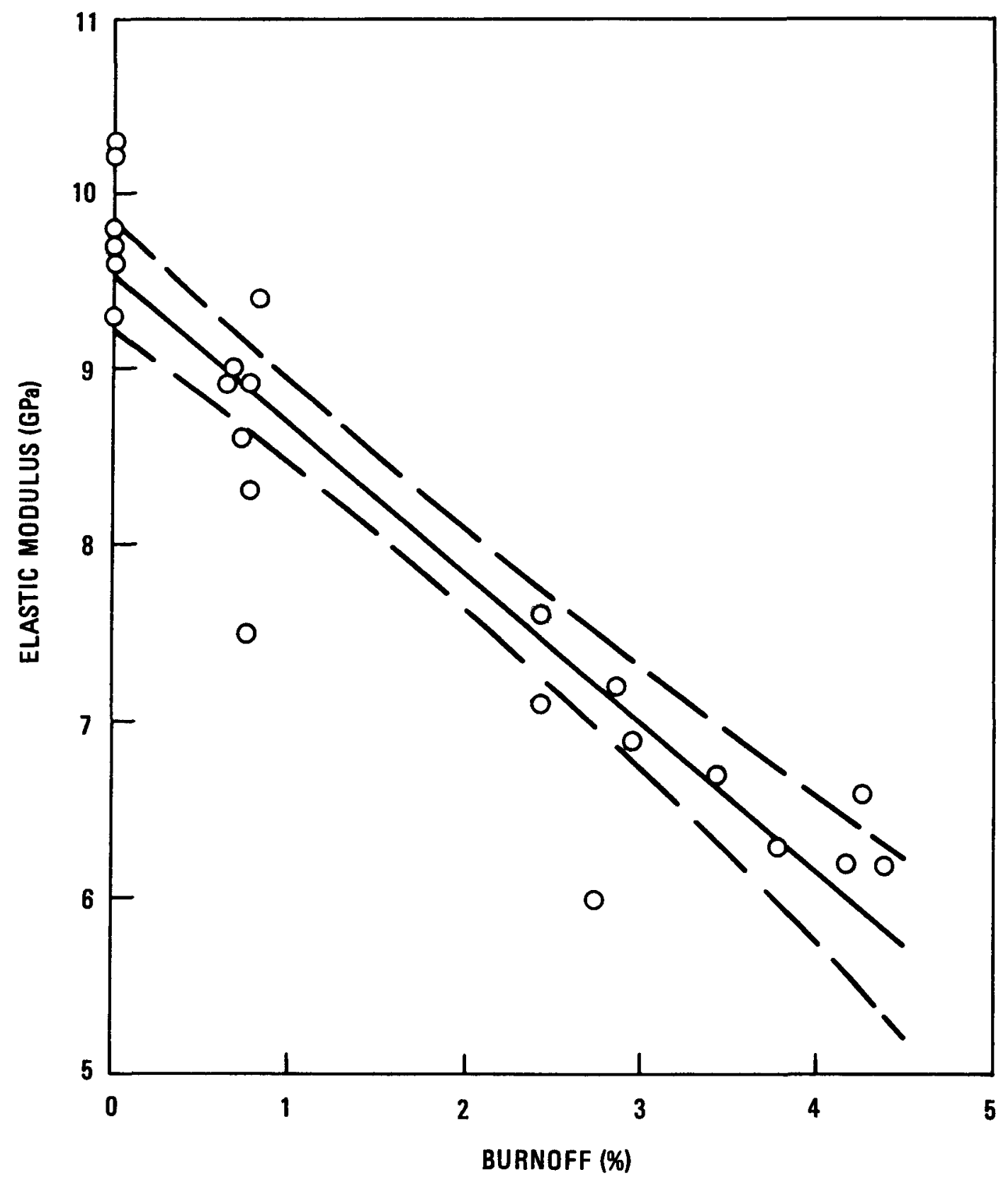

Fig. 22. Elastic modulus versus burnoff, radial, slab 3 


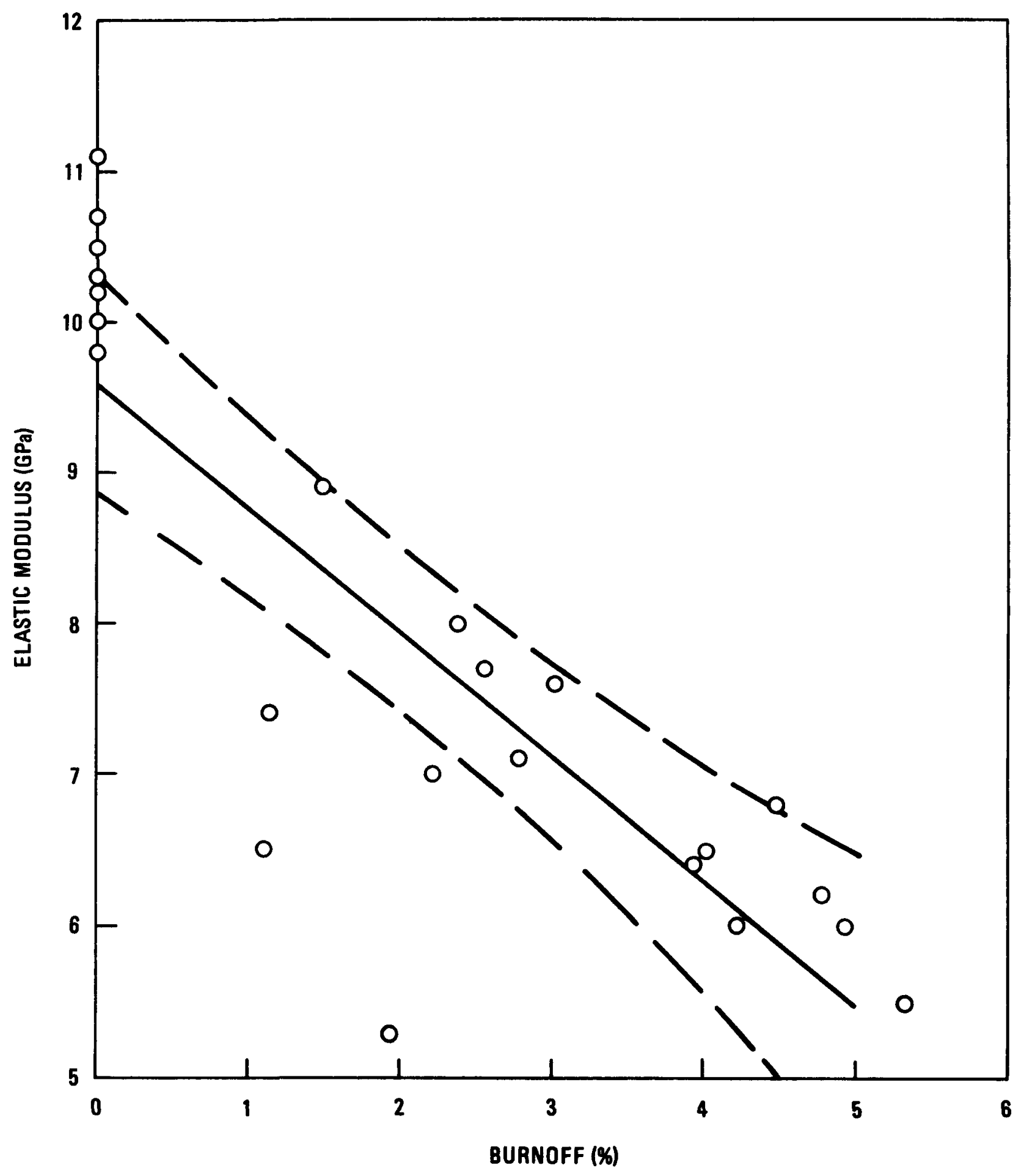

Fig. 23. Elastic modulus versus burnoff, radial, slab 5 


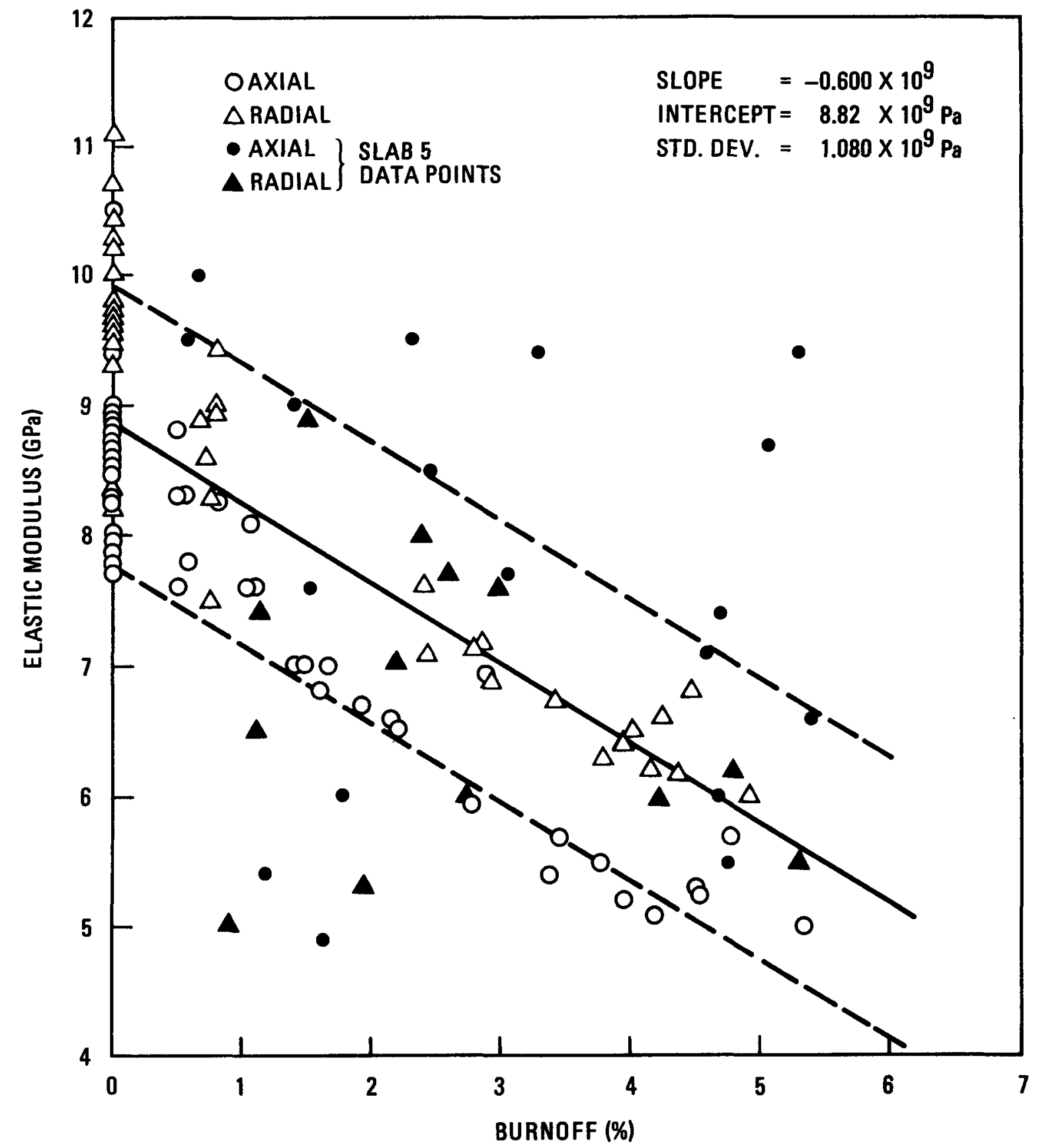

Fig. 24. Elastic modulus versus burnoff, all slabs 


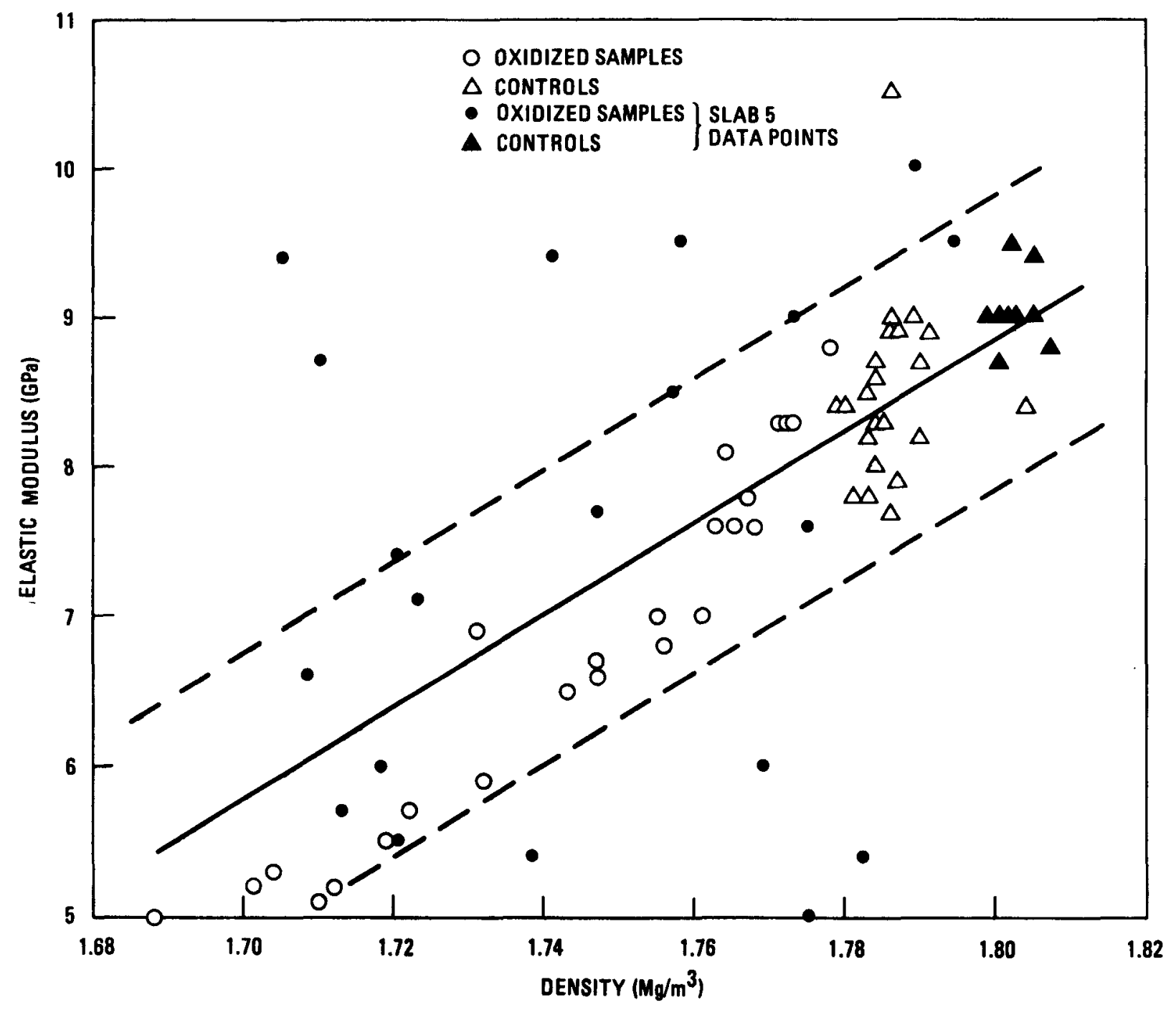

Fig. 25. Elastic modulus versus bulk density, axial specimens 


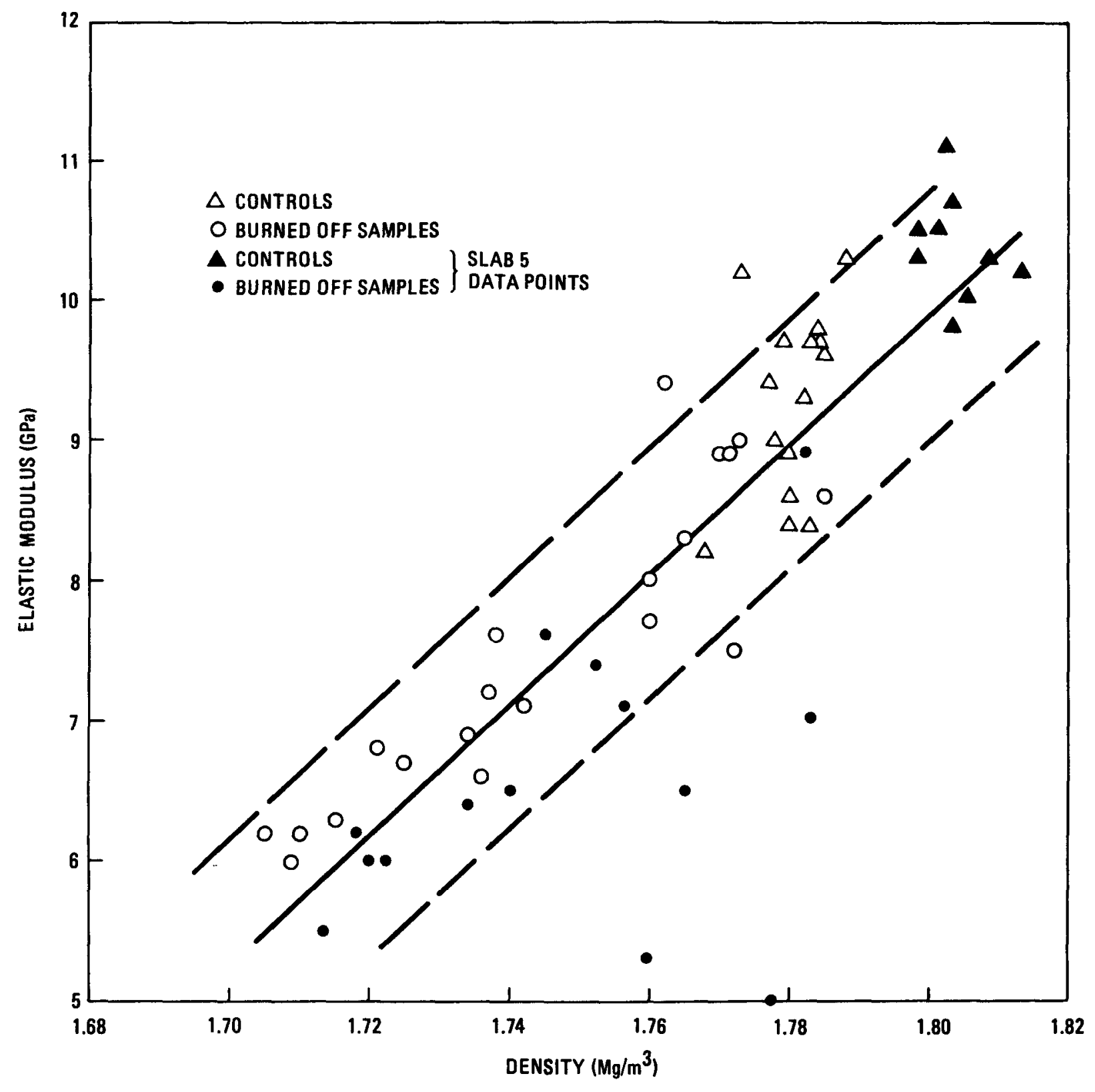

Fig. 26. Elastic modulus versus bulk density, radial specimens 


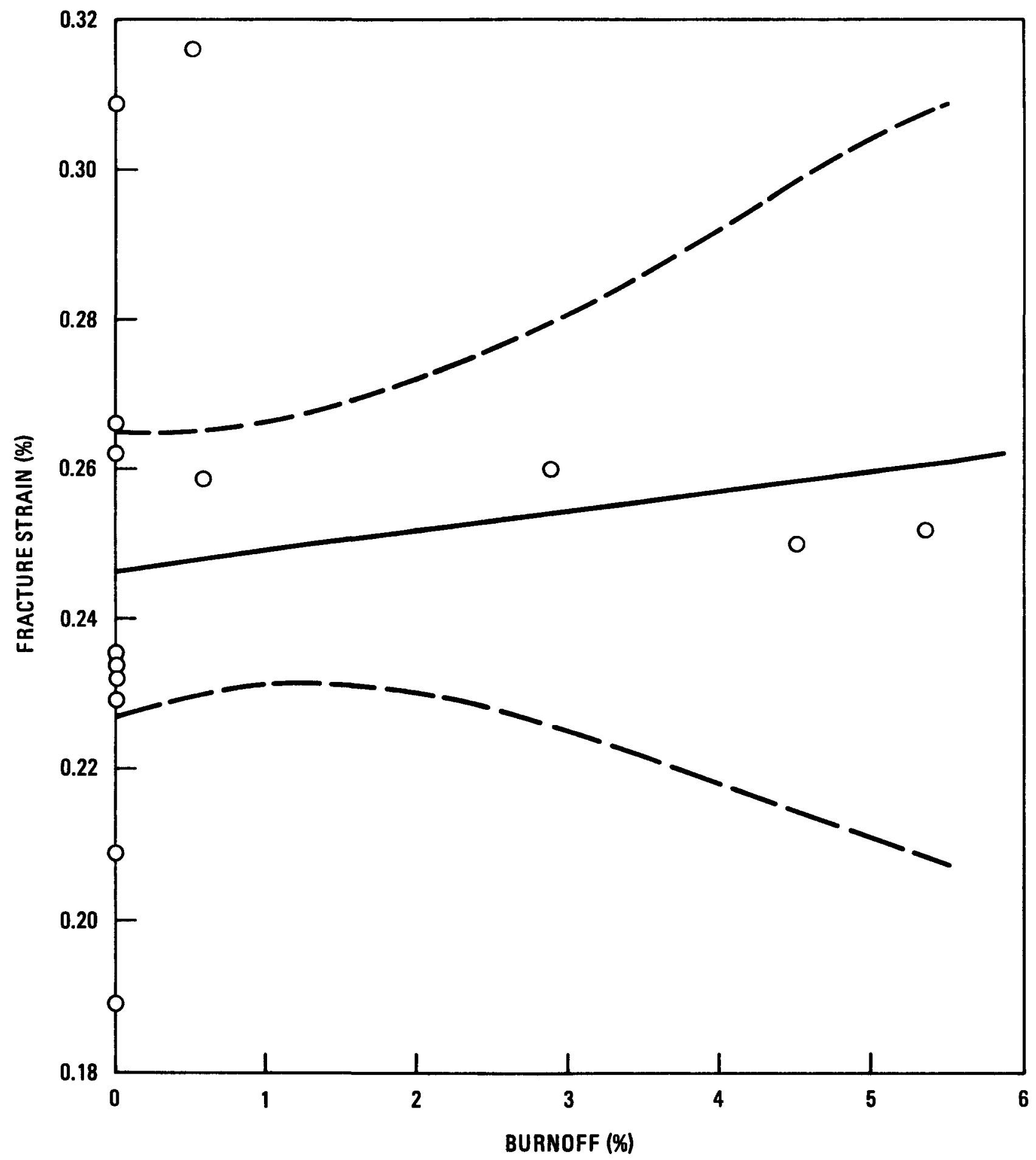

Fig. 27. Strain at fracture versus burnoff, axial, slab 1 


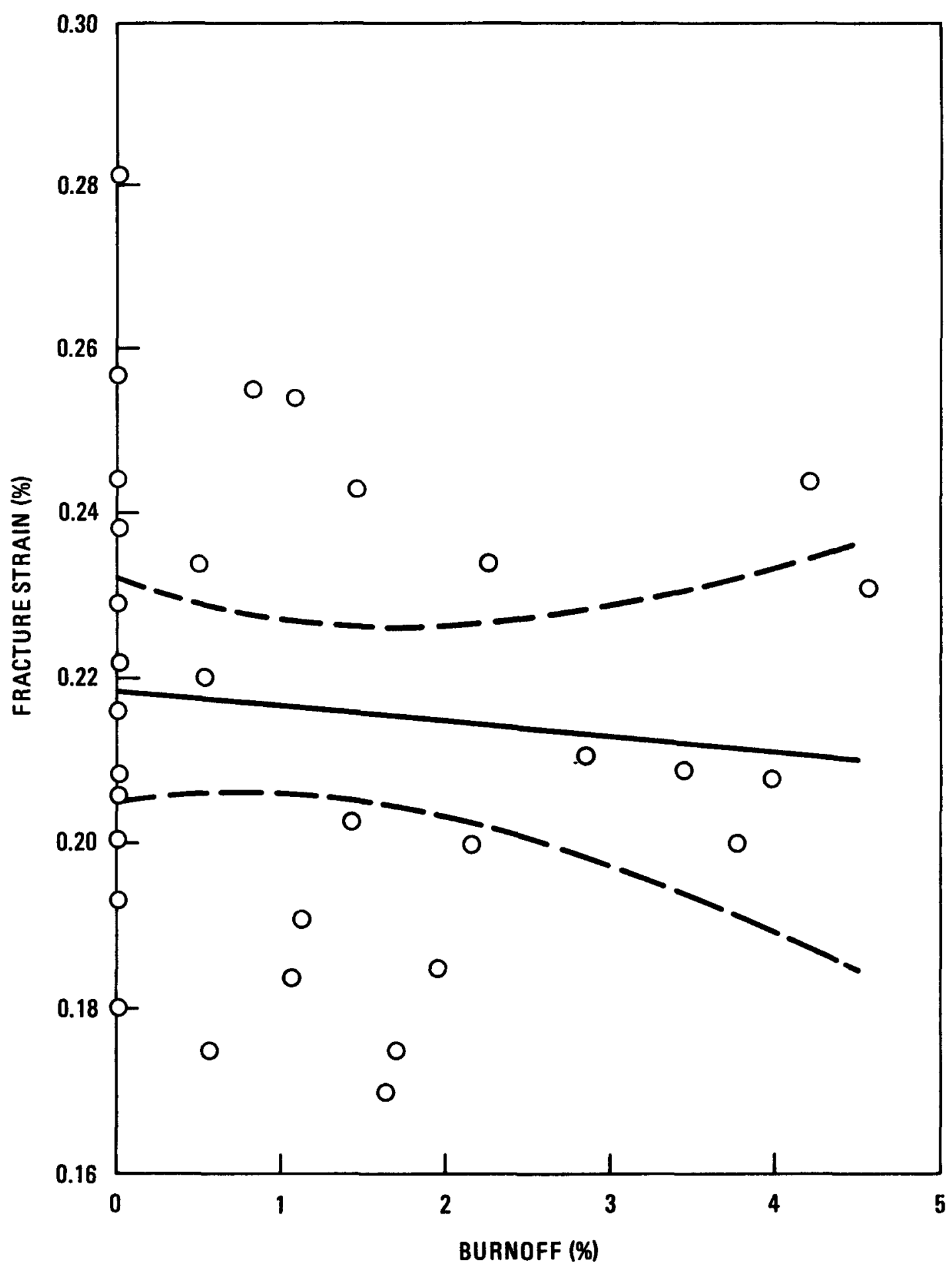

Fig. 28. Strain at fracture versus burnoff, axial, slab 3 


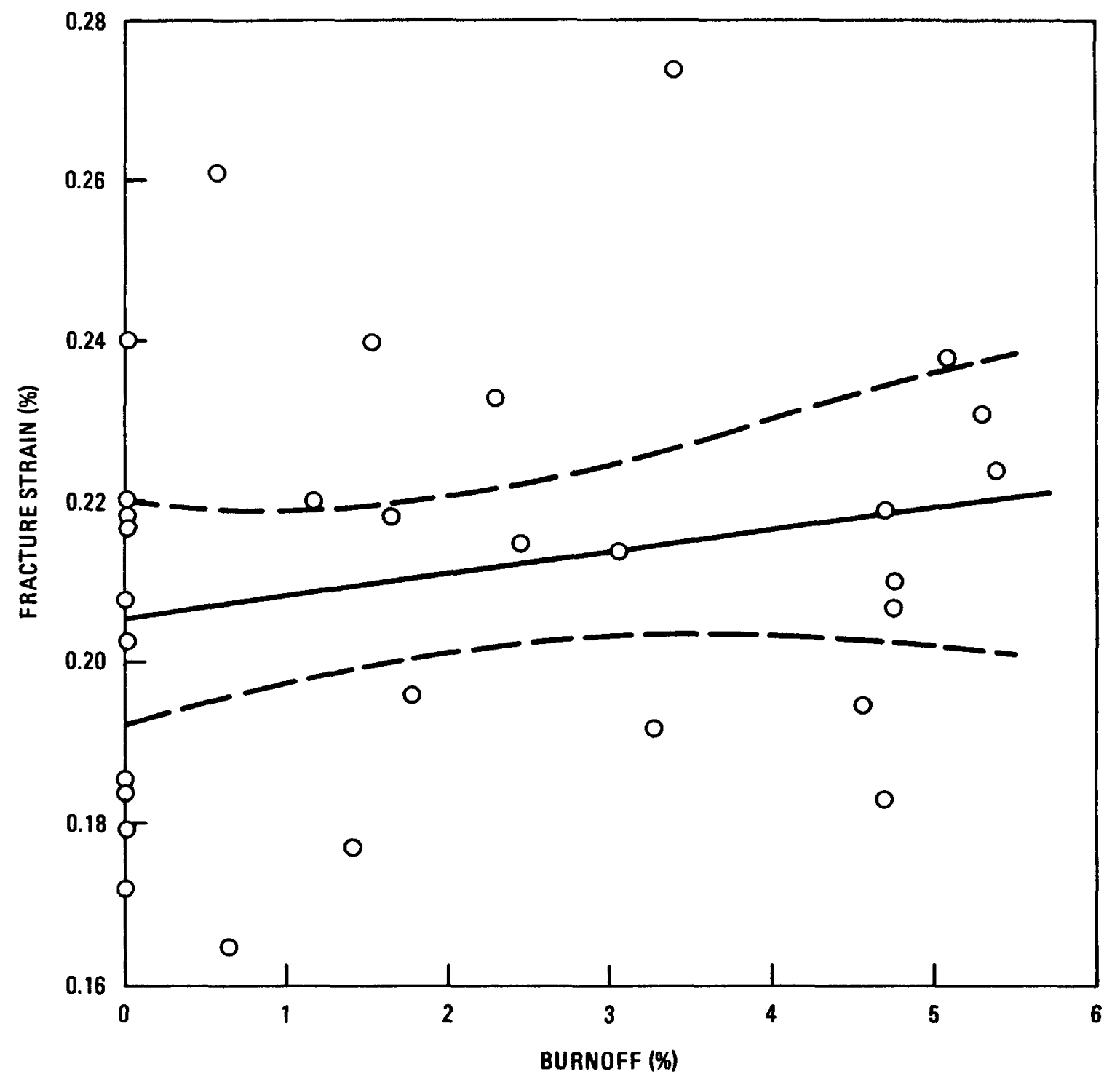

Fig. 29. Strain at fracture versus burnoff, axial, slab 5 


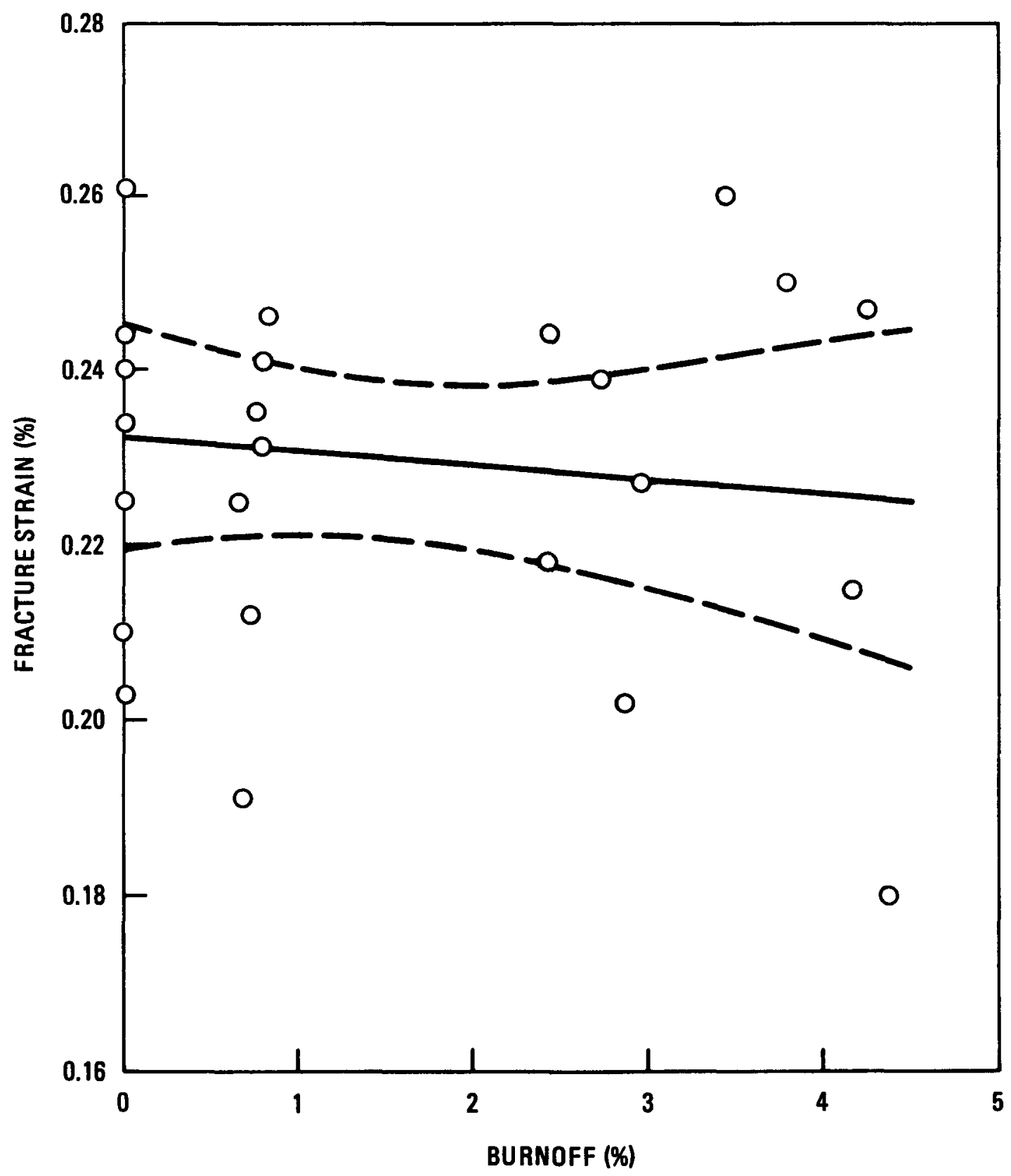

Fig. 30. Strain at fracture versus burnoff, radial, slab 3 


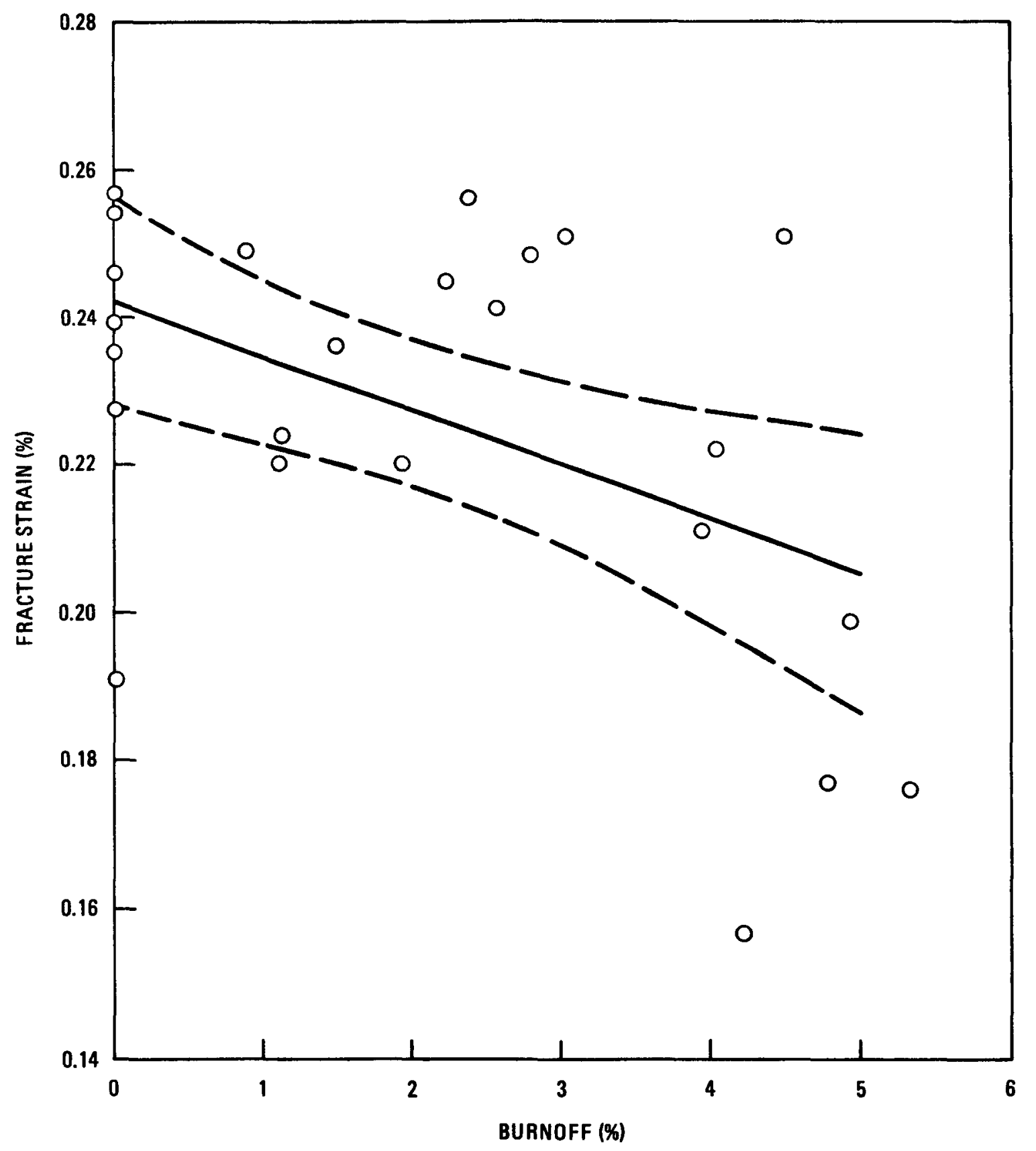

Fig. 31. Strain at fracture versus burnoff, radial, slab 5 


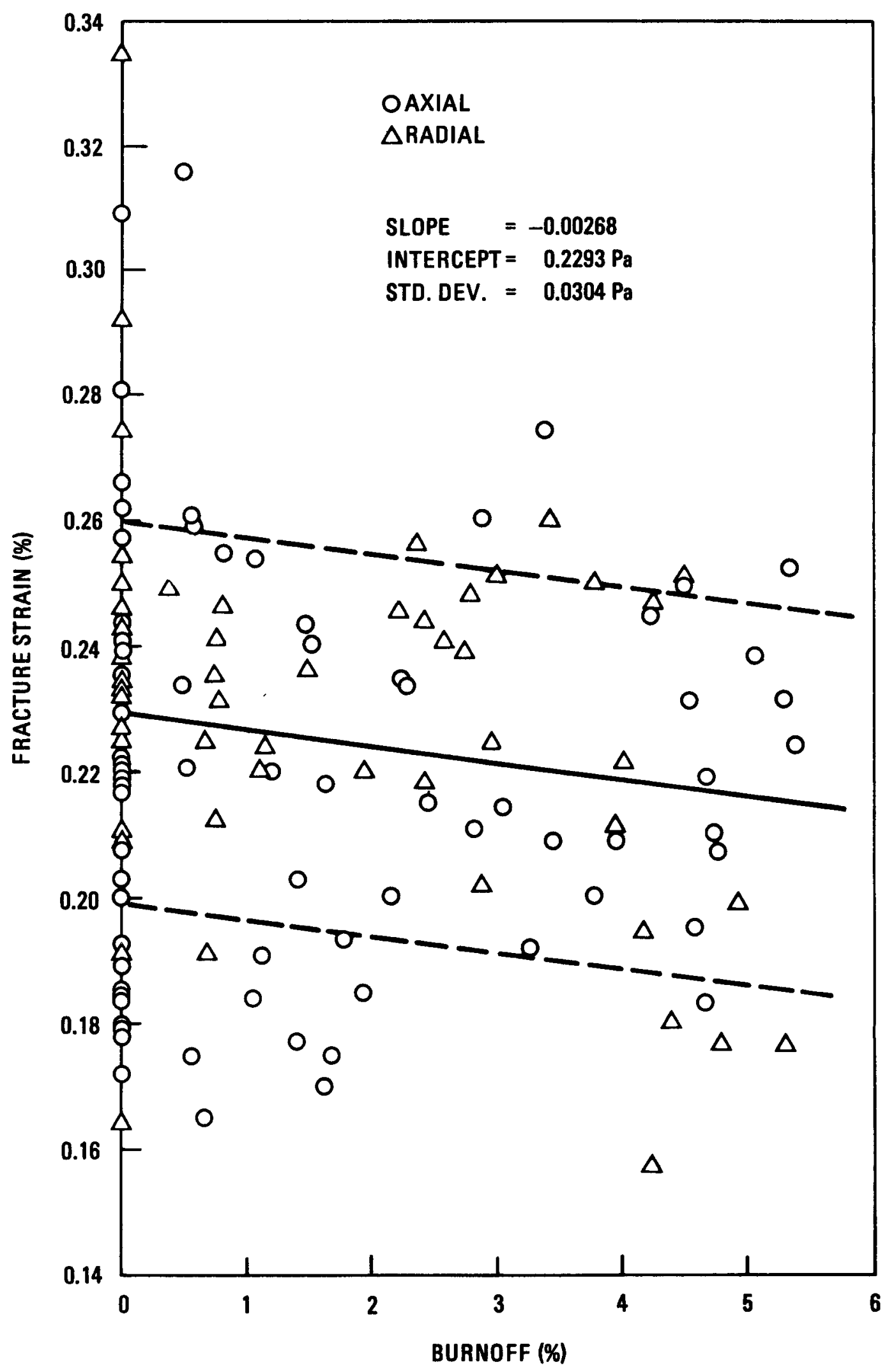

Fig. 32. Strain at fracture versus burnoff, all specimens 


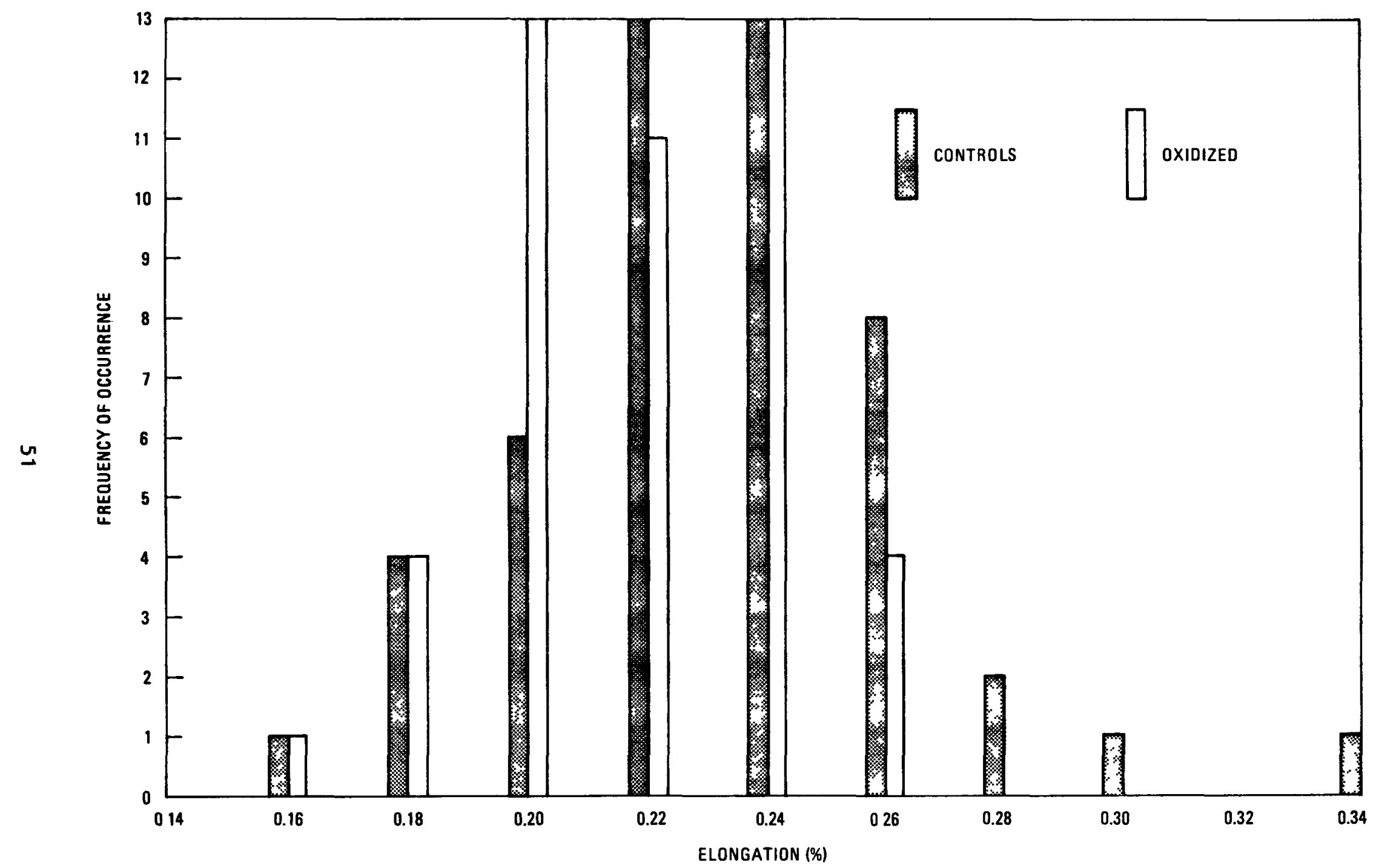

Fig. 33. Gaussian distribution of strain at fracture for oxidized and nonoxidized specimens 
APPENDIX A 


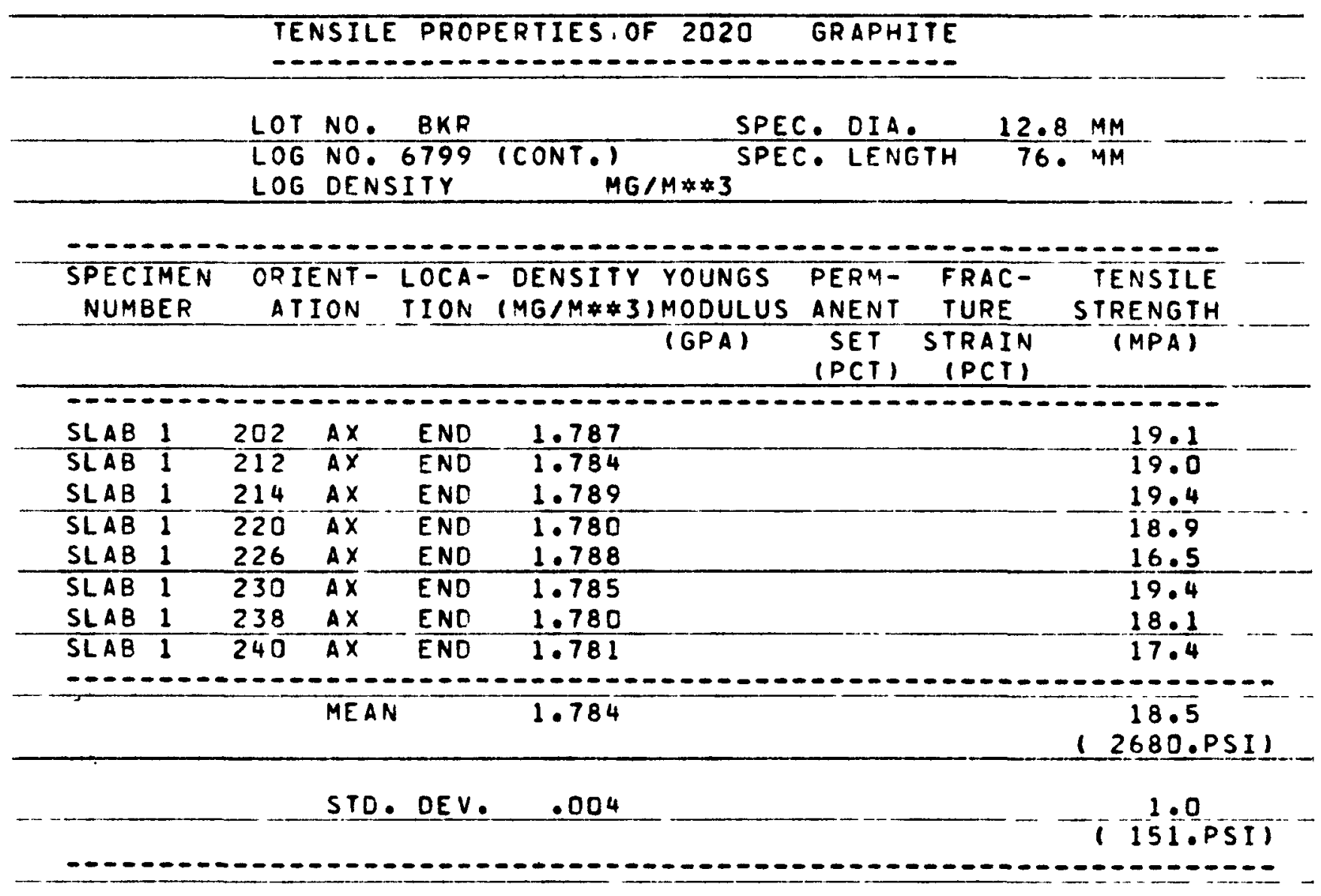




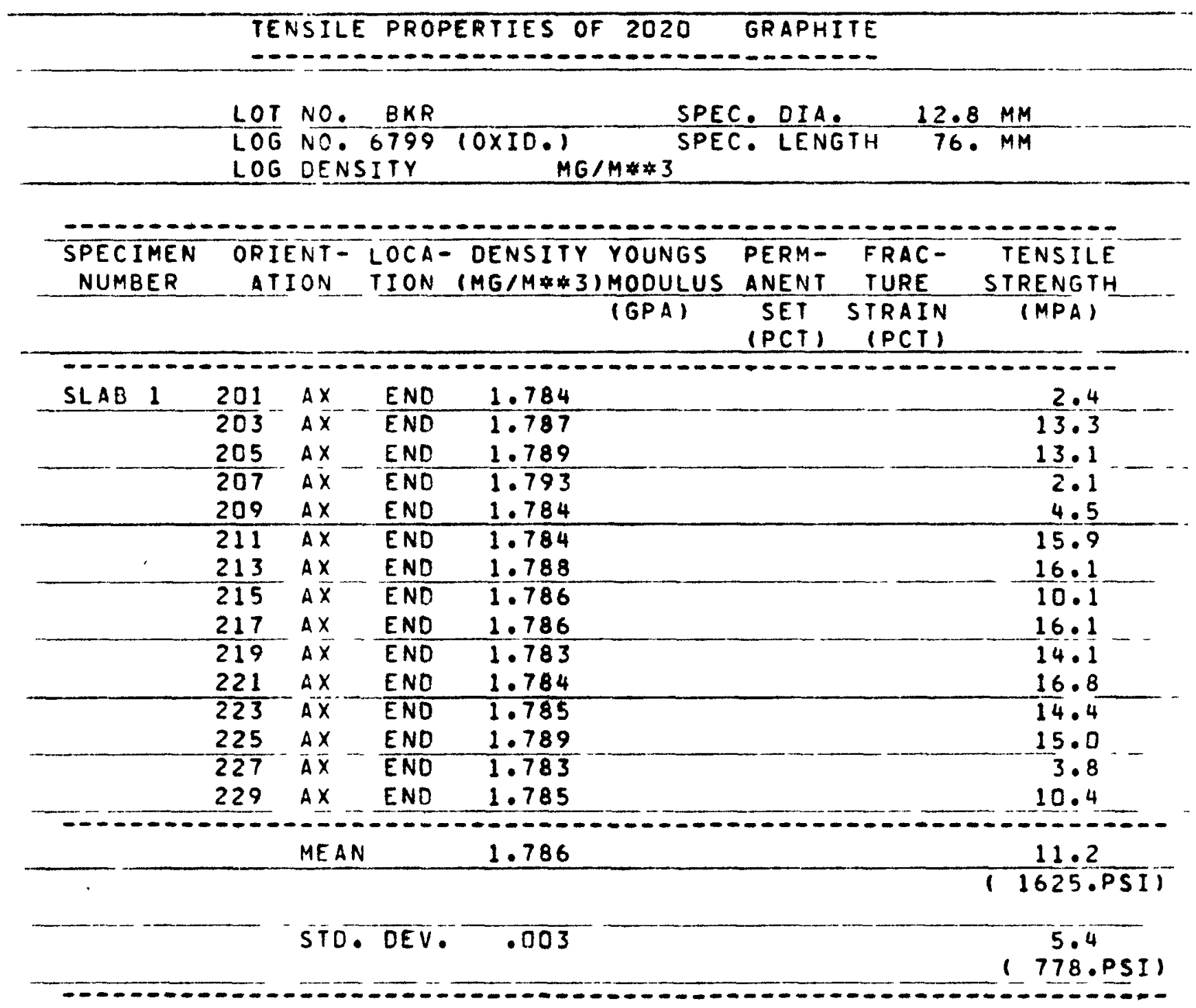




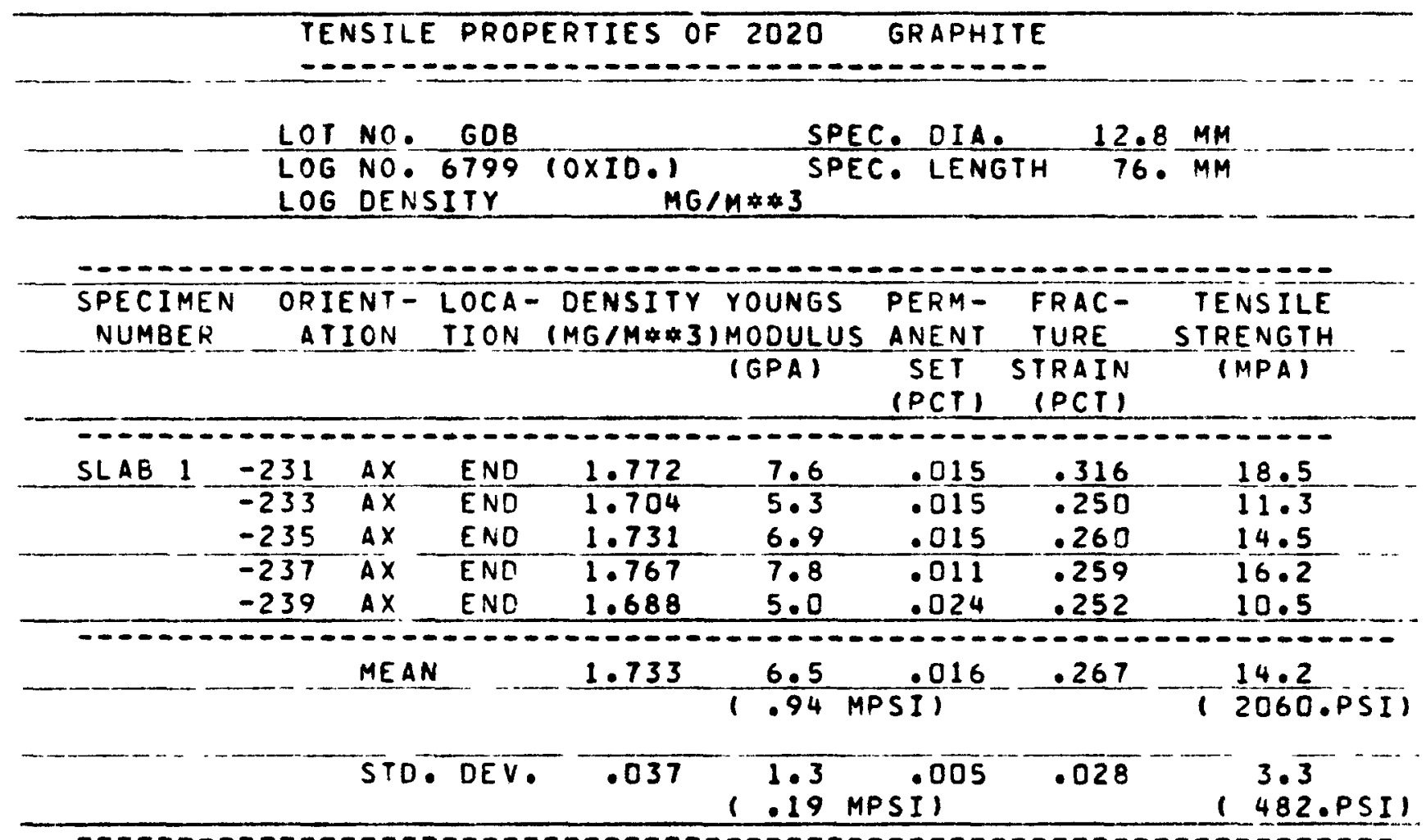


TABLE $4-4$

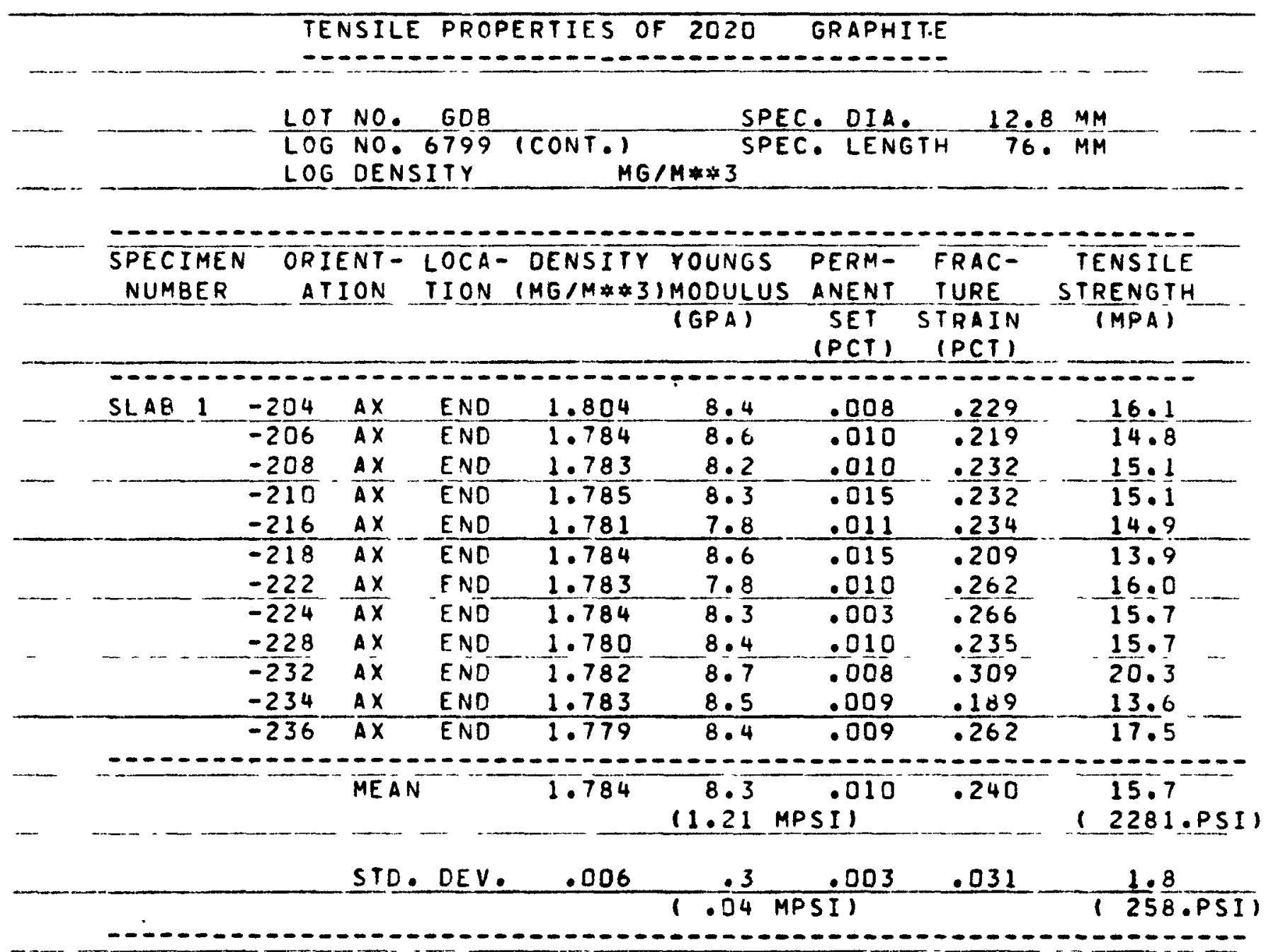




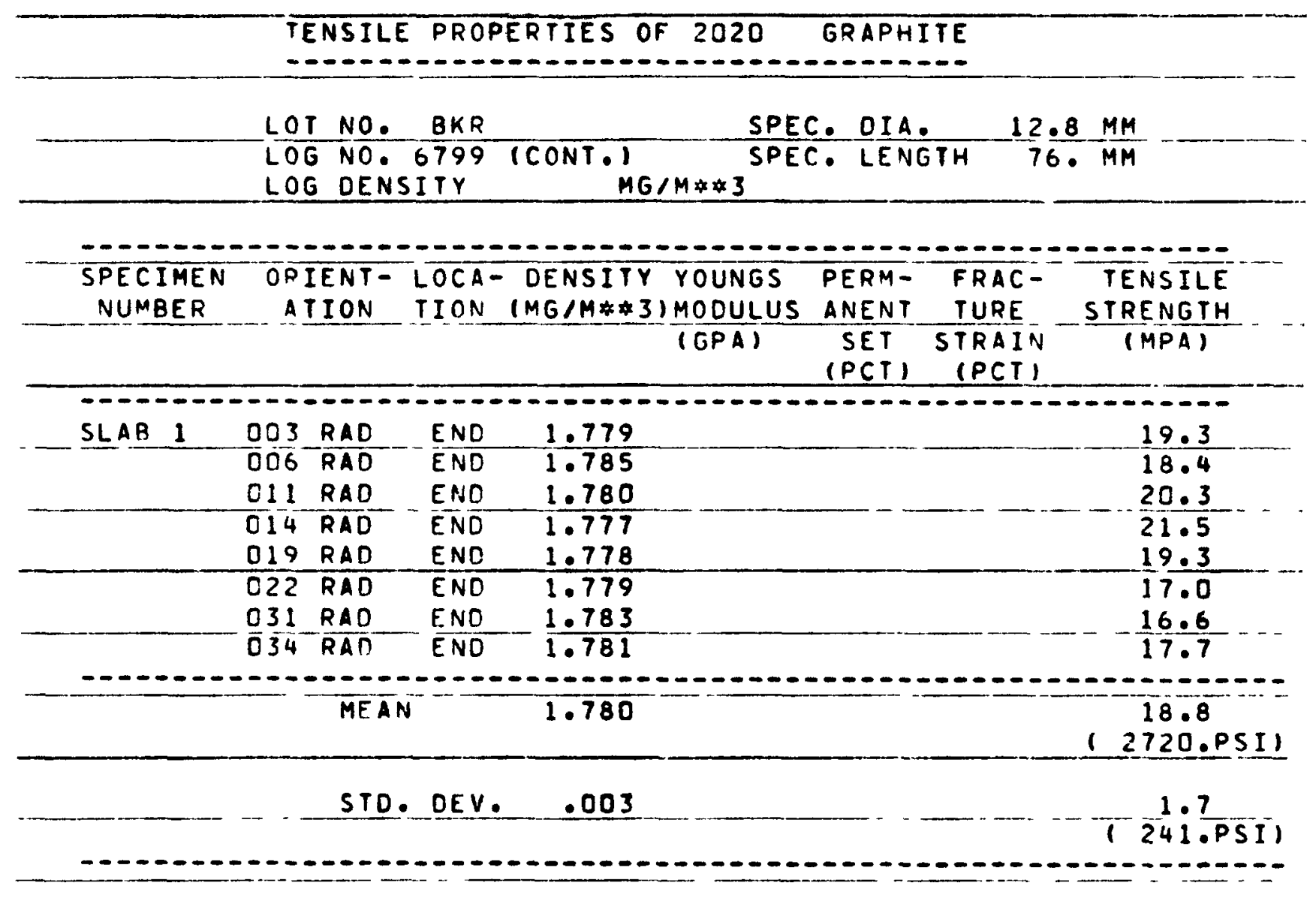


TABLE A-6

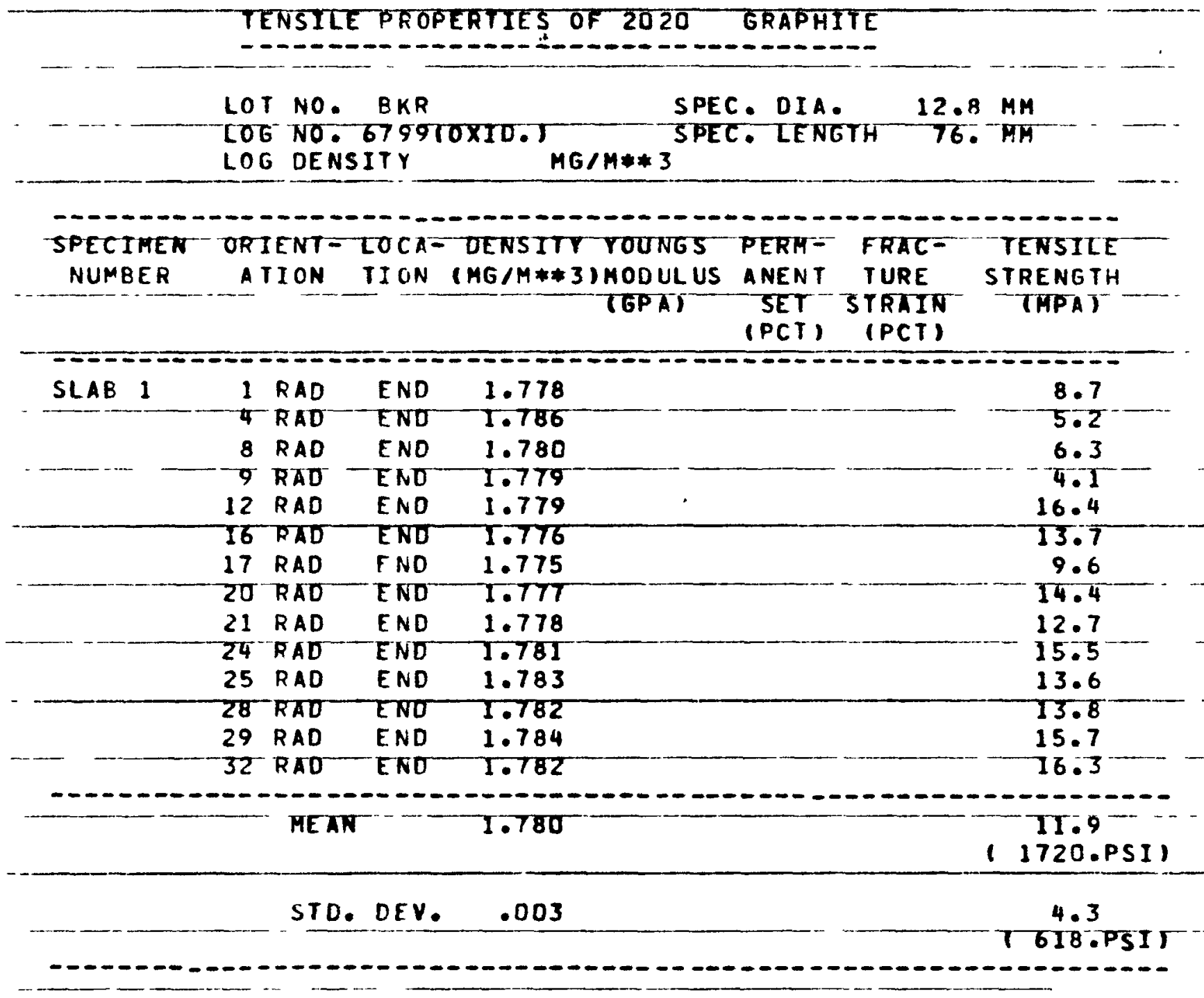




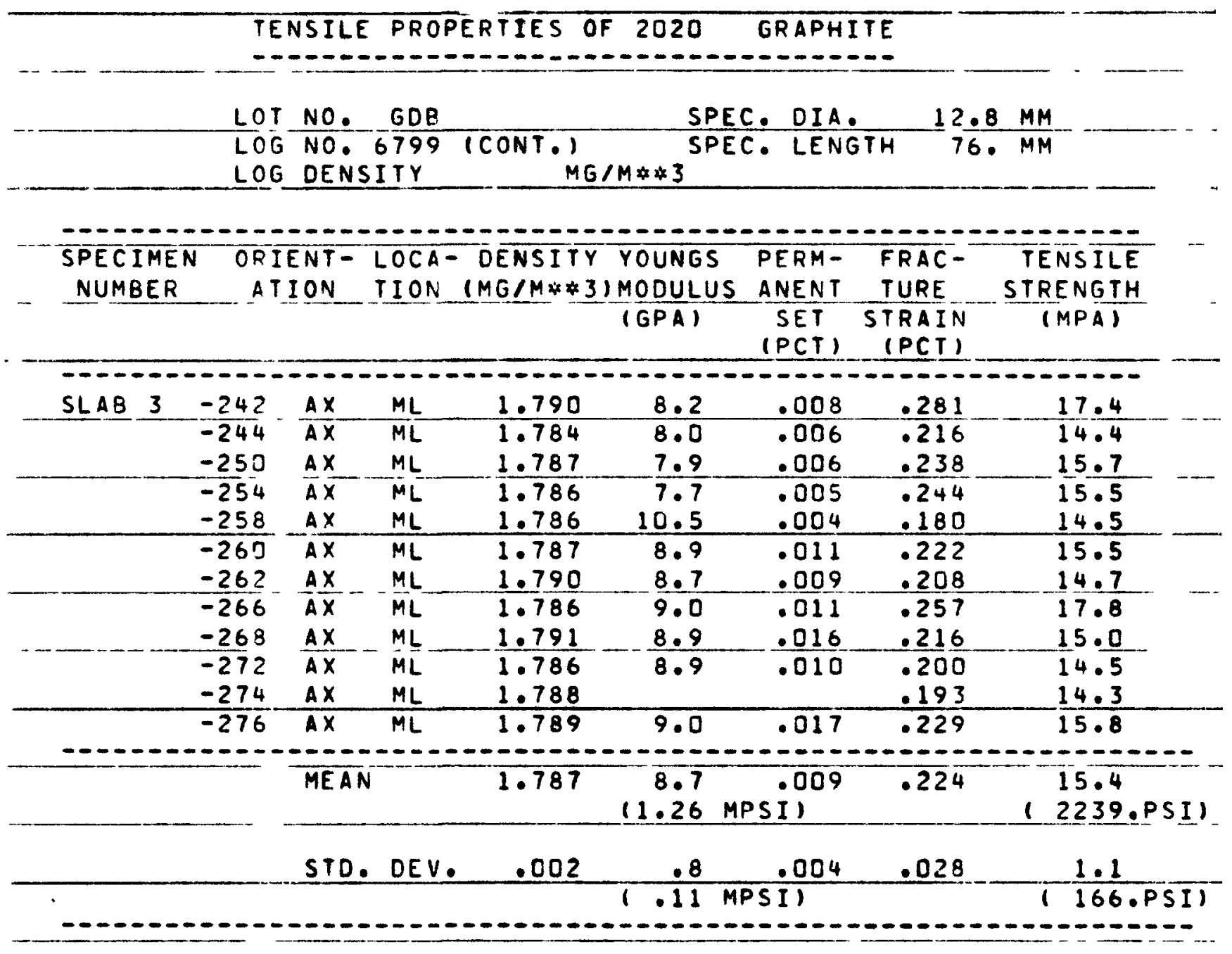




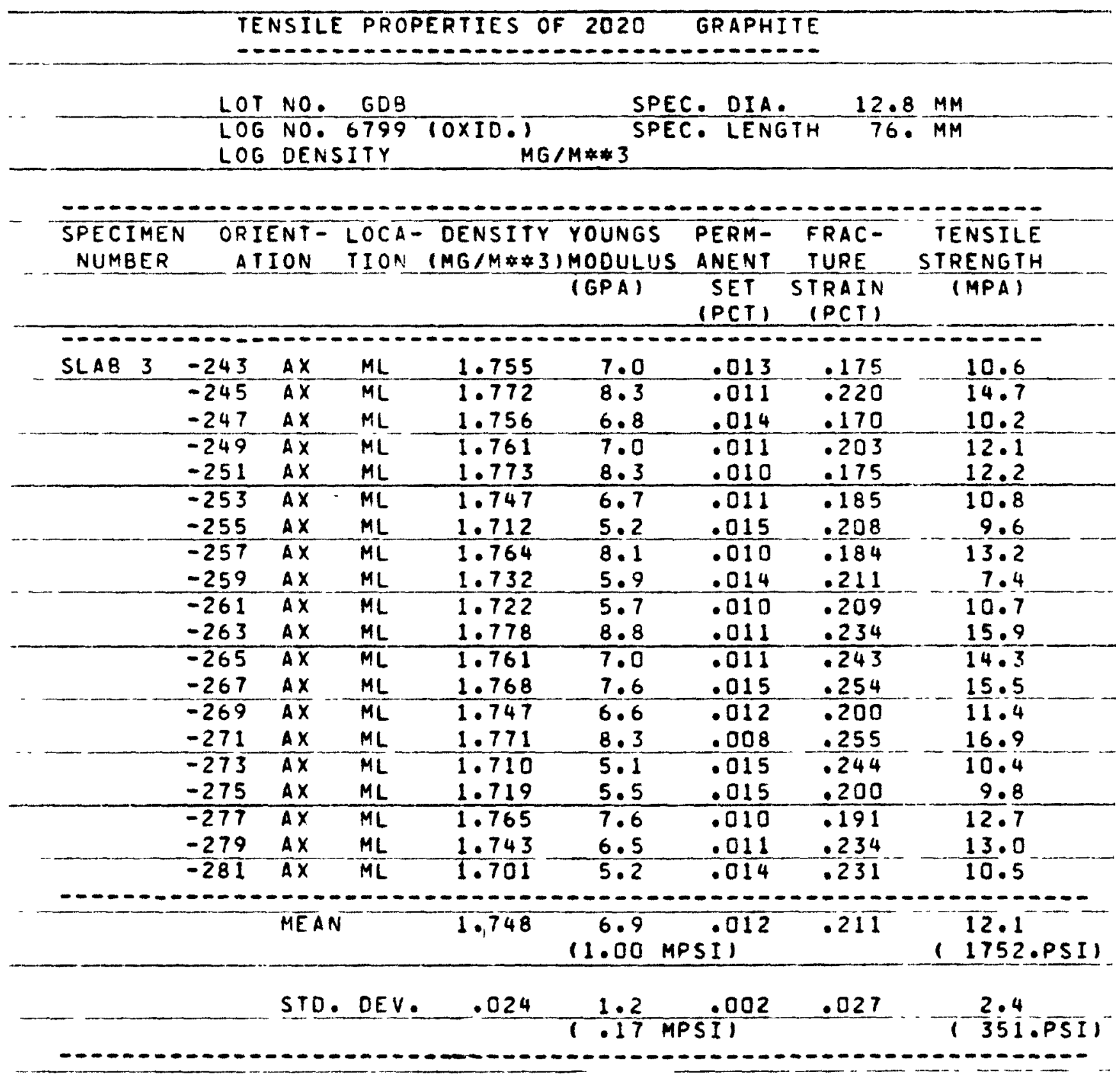


TABLE A-9

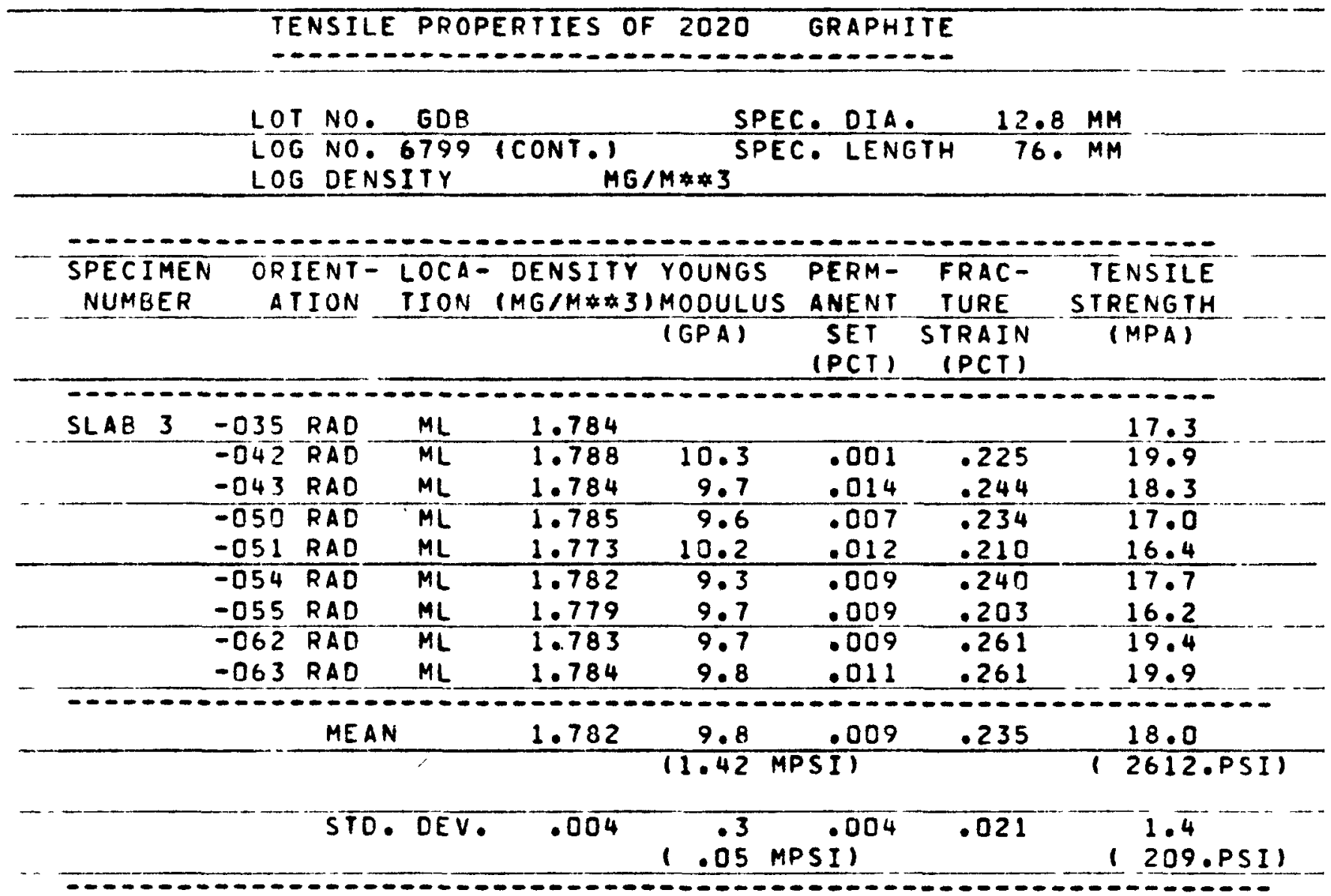


TABLE $A-10$

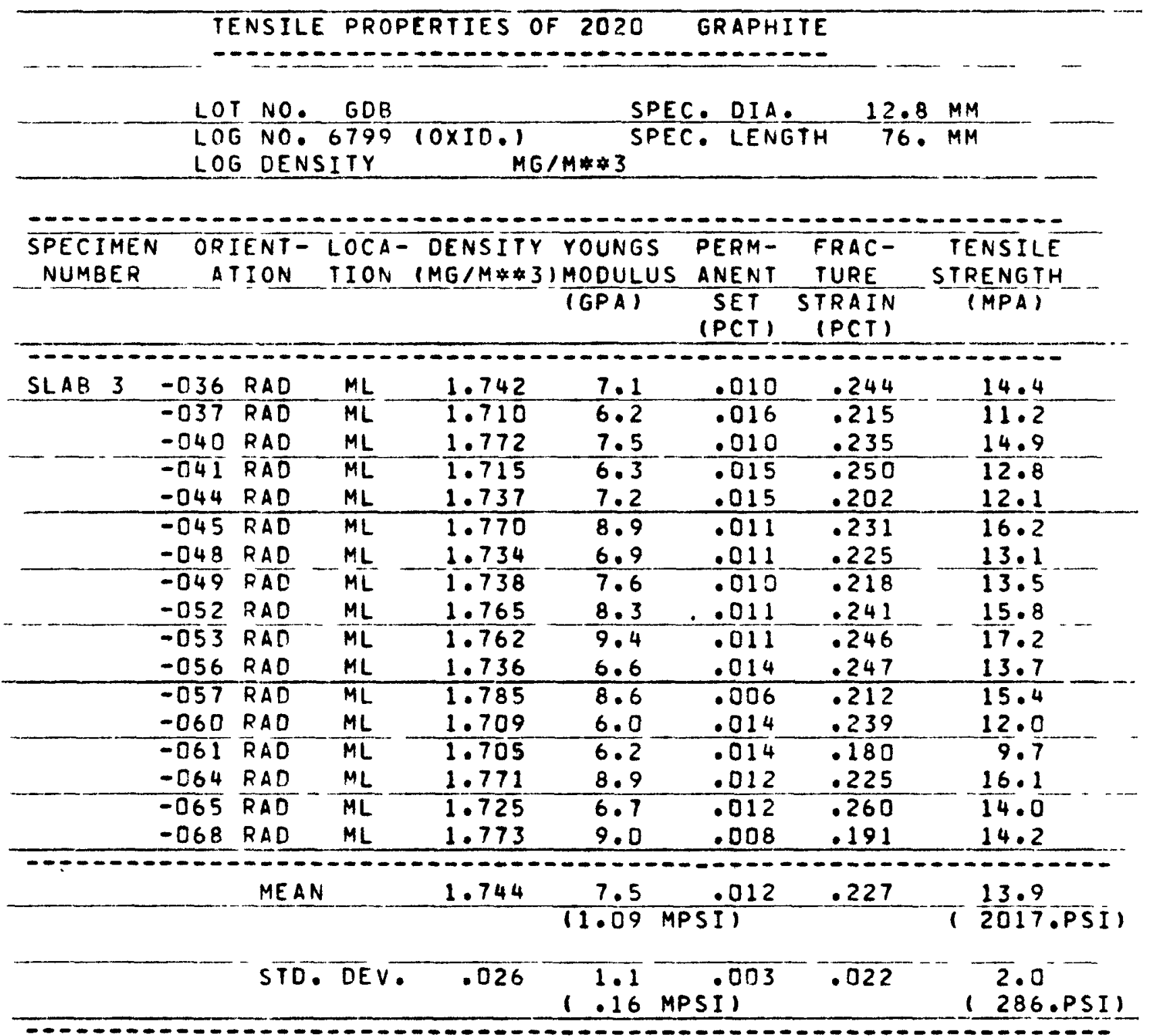


TABLE A-11

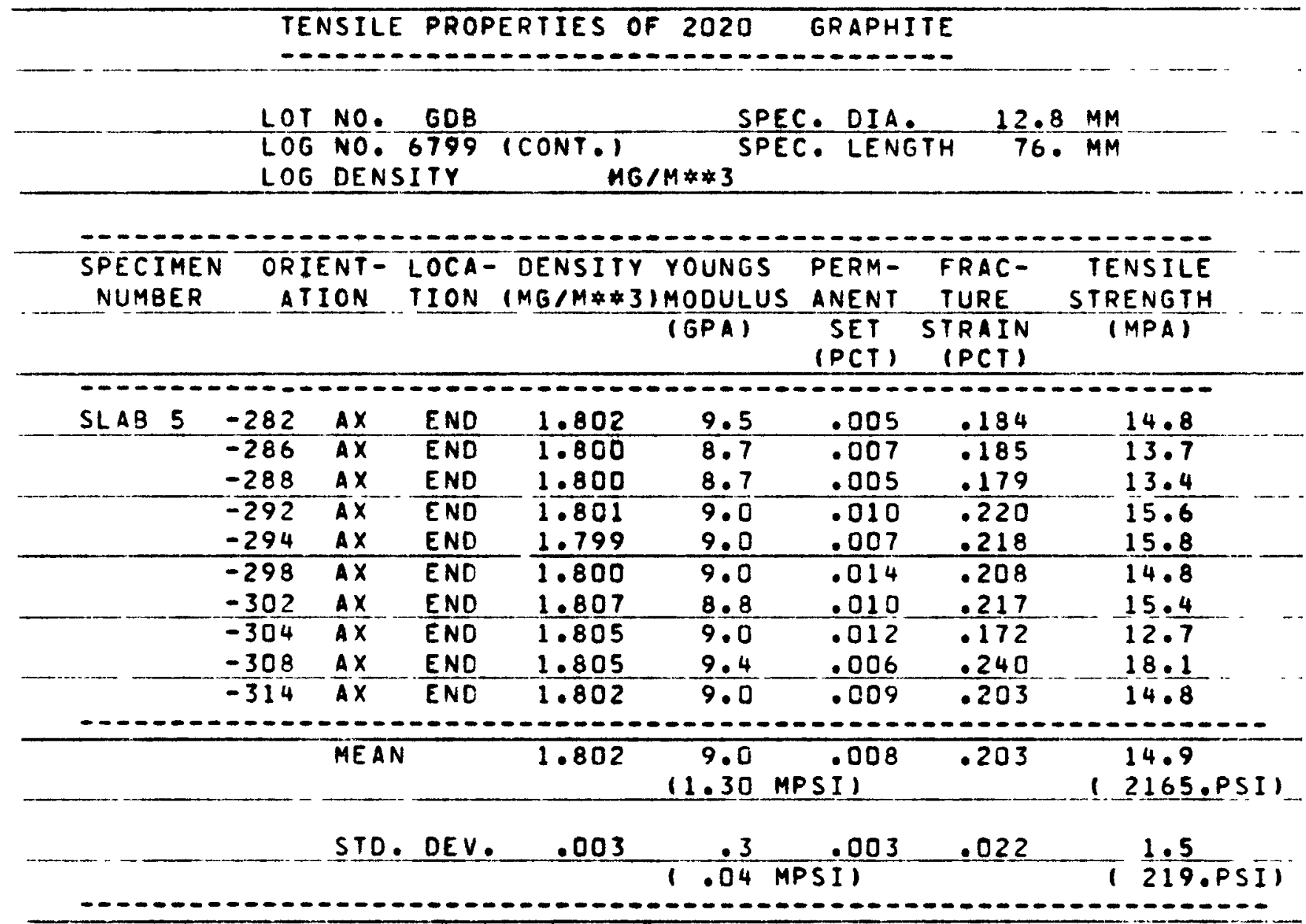


TABLE A-12

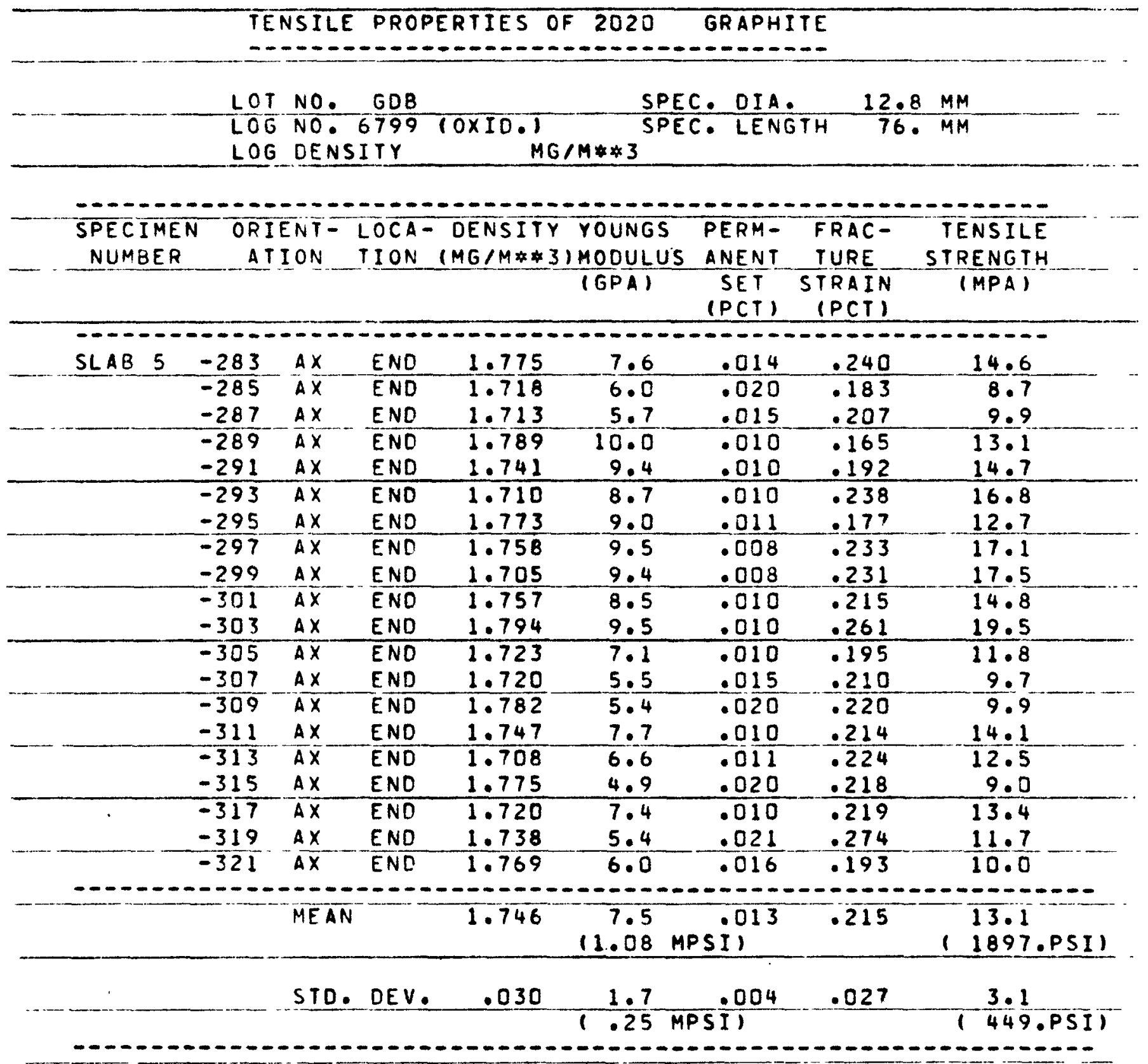




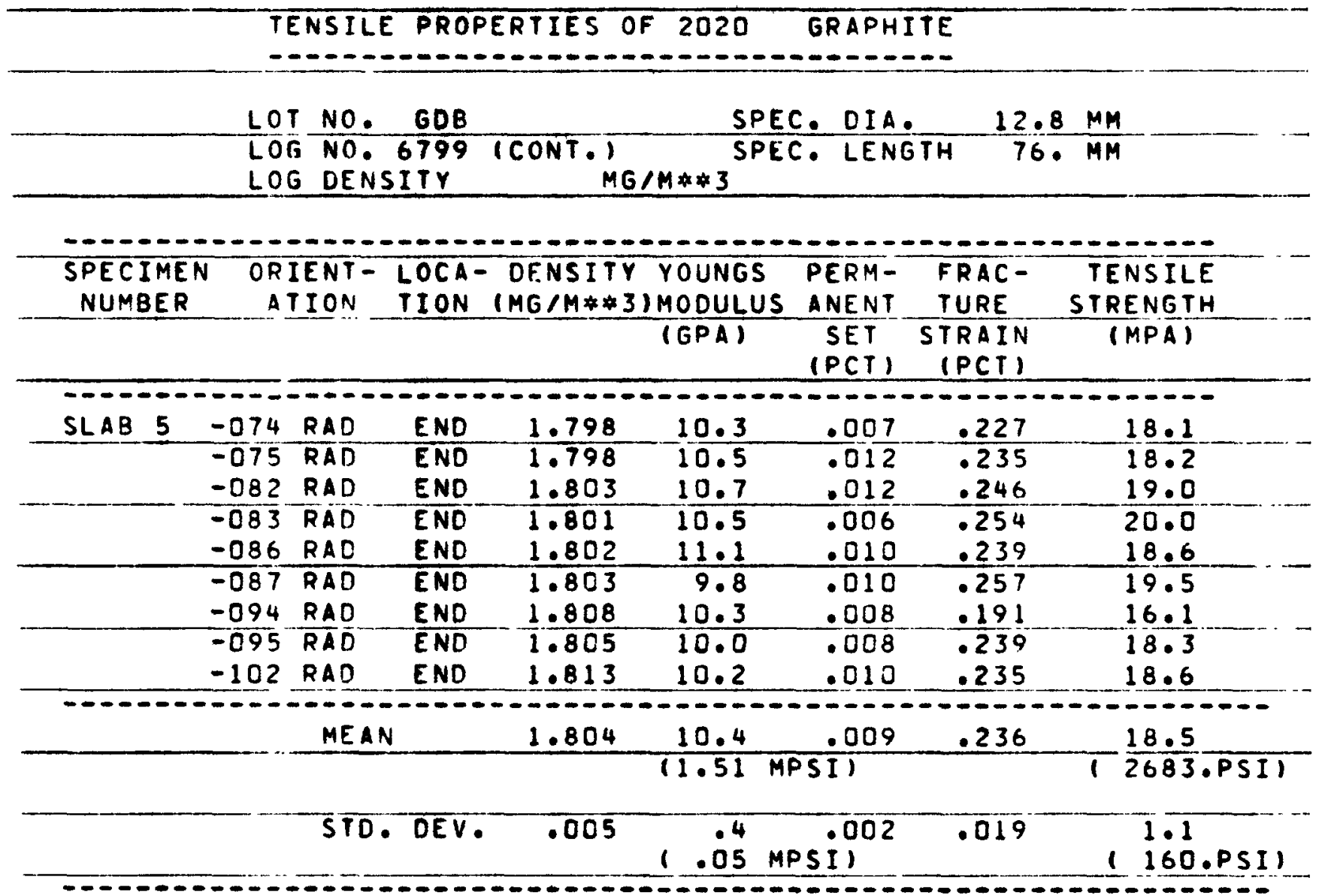




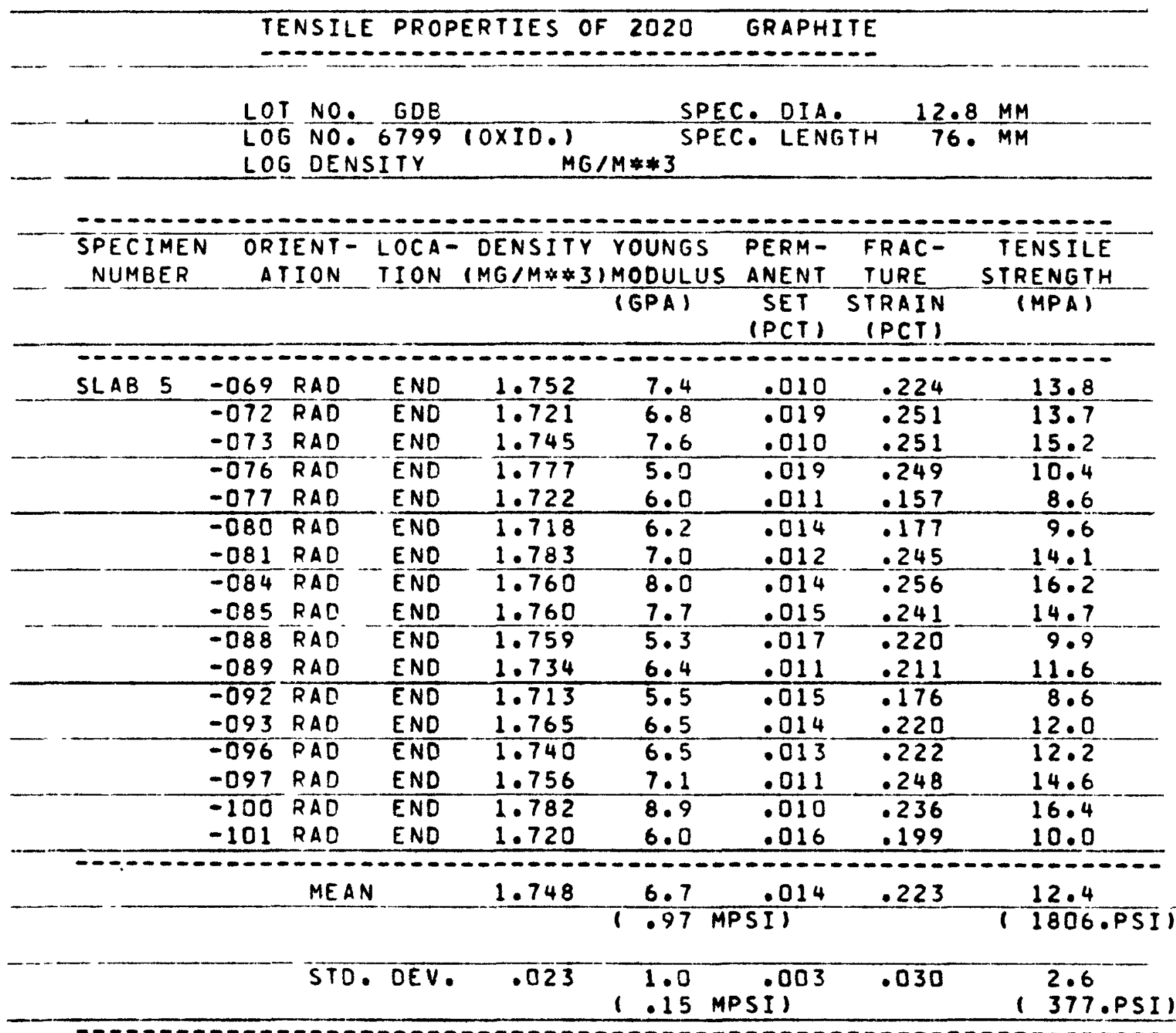




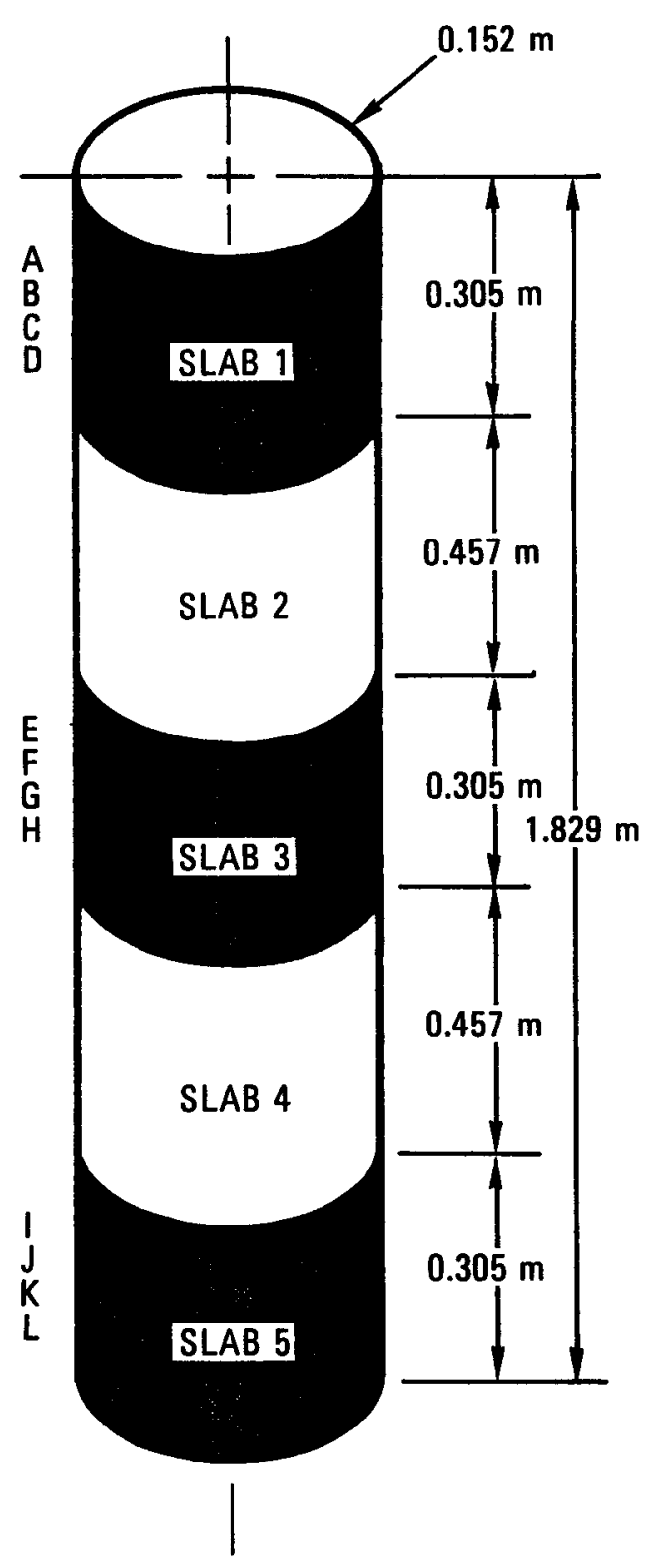

Fig. A-1. Stackpole 2020 graphite

$$
\text { A-15 }
$$




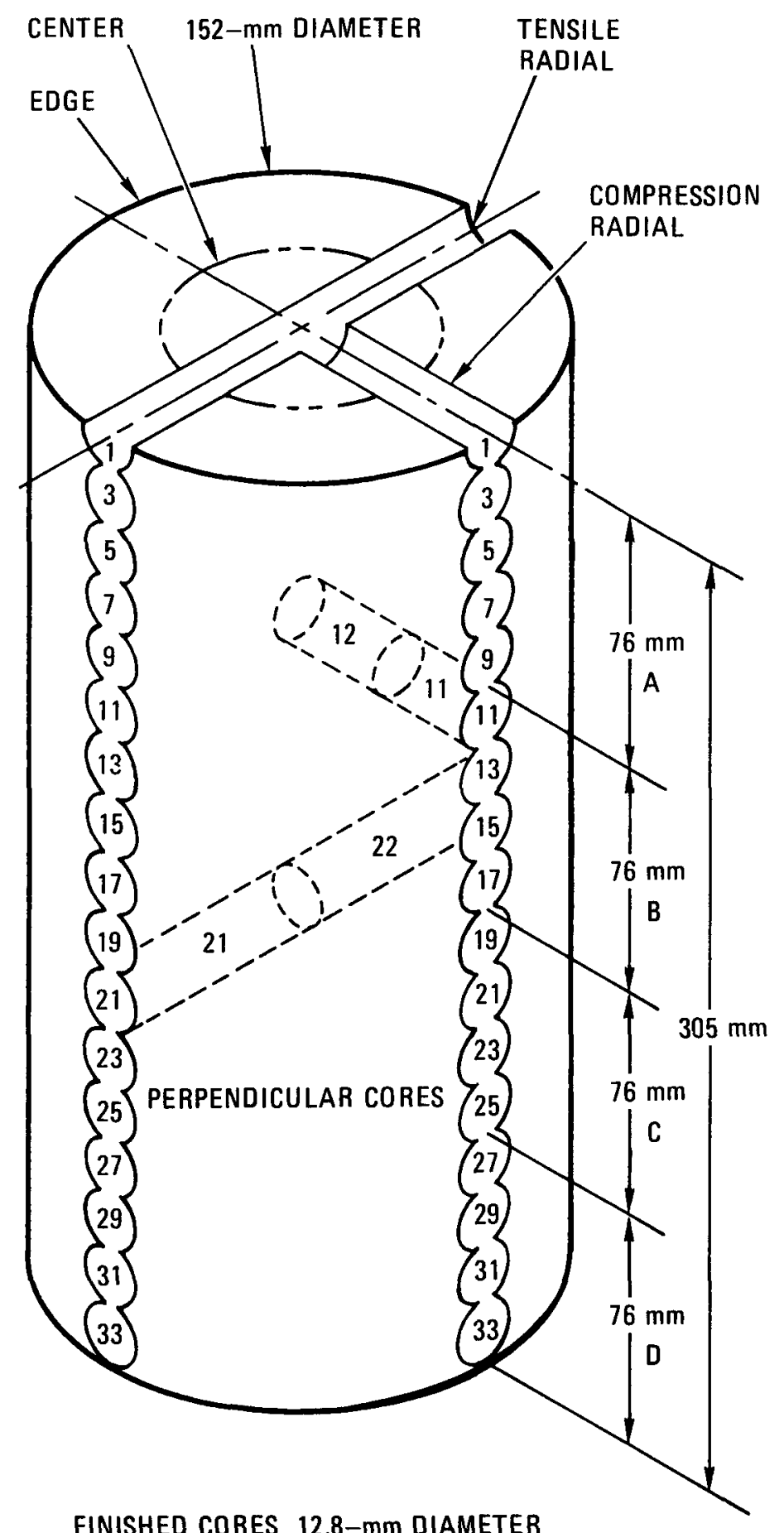

NO. 11-6799

$S=$ SPECTROGRAPHIC ANALYSIS

$C=$ CONTROL

\begin{tabular}{|c|c|c|c|}
\hline \multirow{2}{*}{ SECTION } & CORE & \multicolumn{2}{|c|}{ SAMPLES } \\
\hline & $25.4 \mathrm{~mm}$ & $\mathrm{COM}$ & SSION \\
\hline \multirow{5}{*}{ A } & 1 & 1 & $2 \mathrm{C}$ \\
\hline & 3 & $3 C$ & 4 \\
\hline & 5 & 5 & $6 \mathrm{C}$ \\
\hline & 7 & 7 & 8 \\
\hline & 9 & 9 & $10 \mathrm{C}$ \\
\hline \multirow{4}{*}{ B } & 11 & $11 \mathrm{~S}$ & 12 \\
\hline & 13 & 13 & $14 \mathrm{C}$ \\
\hline & 15 & $15 \mathrm{C}$ & 16 \\
\hline & 17 & 17 & $18 \mathrm{C}$ \\
\hline \multirow{4}{*}{ C } & 19 & $19 \mathrm{C}$ & 20 \\
\hline & 21 & 21 & $22 \mathrm{C}$ \\
\hline & 23 & $23 \mathrm{C}$ & 24 \\
\hline & 25 & 25 & $26 \mathrm{C}$ \\
\hline \multirow{4}{*}{ D } & 27 & $27 C$ & 28 \\
\hline & 29 & 29 & 30 \\
\hline & 31 & $31 \mathrm{C}$ & 32 \\
\hline & 33 & 33 & $34 \mathrm{~S}$ \\
\hline & $76.2 \mathrm{r}$ & $n \quad T E$ & \\
\hline \multirow{5}{*}{ A } & 1 & 1 & $2 \mathrm{C}$ \\
\hline & 3 & $3 \mathrm{C}$ & 4 \\
\hline & 5 & 5 & $6 C$ \\
\hline & 7 & $7 \mathrm{C}$ & 8 \\
\hline & 9 & 9 & $10 \mathrm{C}$ \\
\hline \multirow{4}{*}{ B } & 11 & $11 \mathrm{C}$ & 12 \\
\hline & 13 & 13 & $14 \mathrm{C}$ \\
\hline & 15 & $15 \mathrm{C}$ & 16 \\
\hline & 17 & 17 & $18 \mathrm{C}$ \\
\hline \multirow{4}{*}{ C } & 19 & $19 C$ & 20 \\
\hline & 21 & 21 & $22 \mathrm{C}$ \\
\hline & 23 & $23 \mathrm{C}$ & 24 \\
\hline & 25 & 25 & $26 \mathrm{C}$ \\
\hline \multirow{4}{*}{ D } & 27 & $27 C$ & 28 \\
\hline & 29 & 29 & $30 \mathrm{C}$ \\
\hline & 31 & $31 \mathrm{C}$ & 32 \\
\hline & 33 & 33 & $34 \mathrm{C}$ \\
\hline
\end{tabular}

Fig. A-2. Coring diagram, Stackpole 2020, slab 1, tensile and compression radial samples 


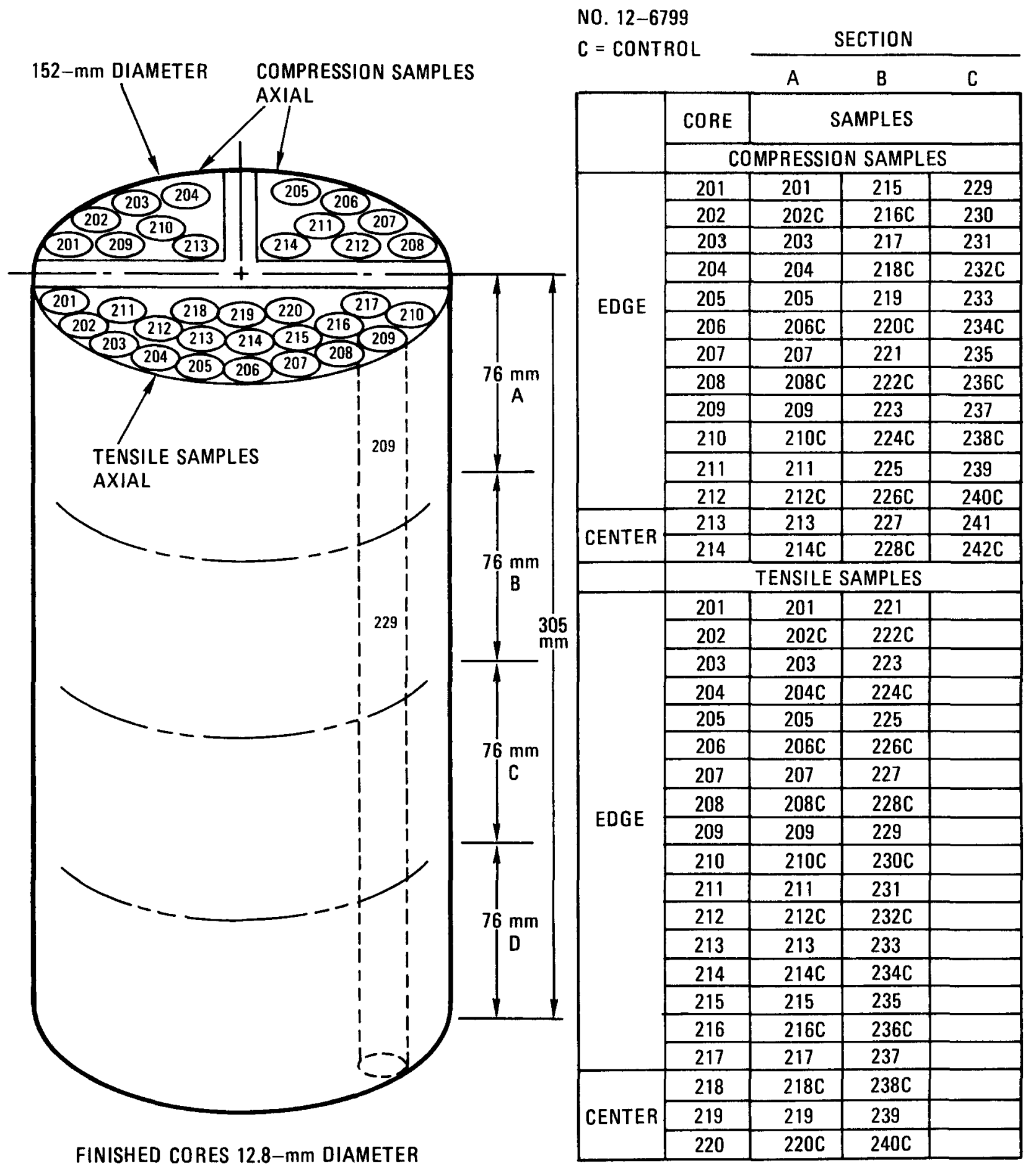

Fig. A-3. Coring diagram, Stackpole 2020, slab 1, tensile and compression axial samples 


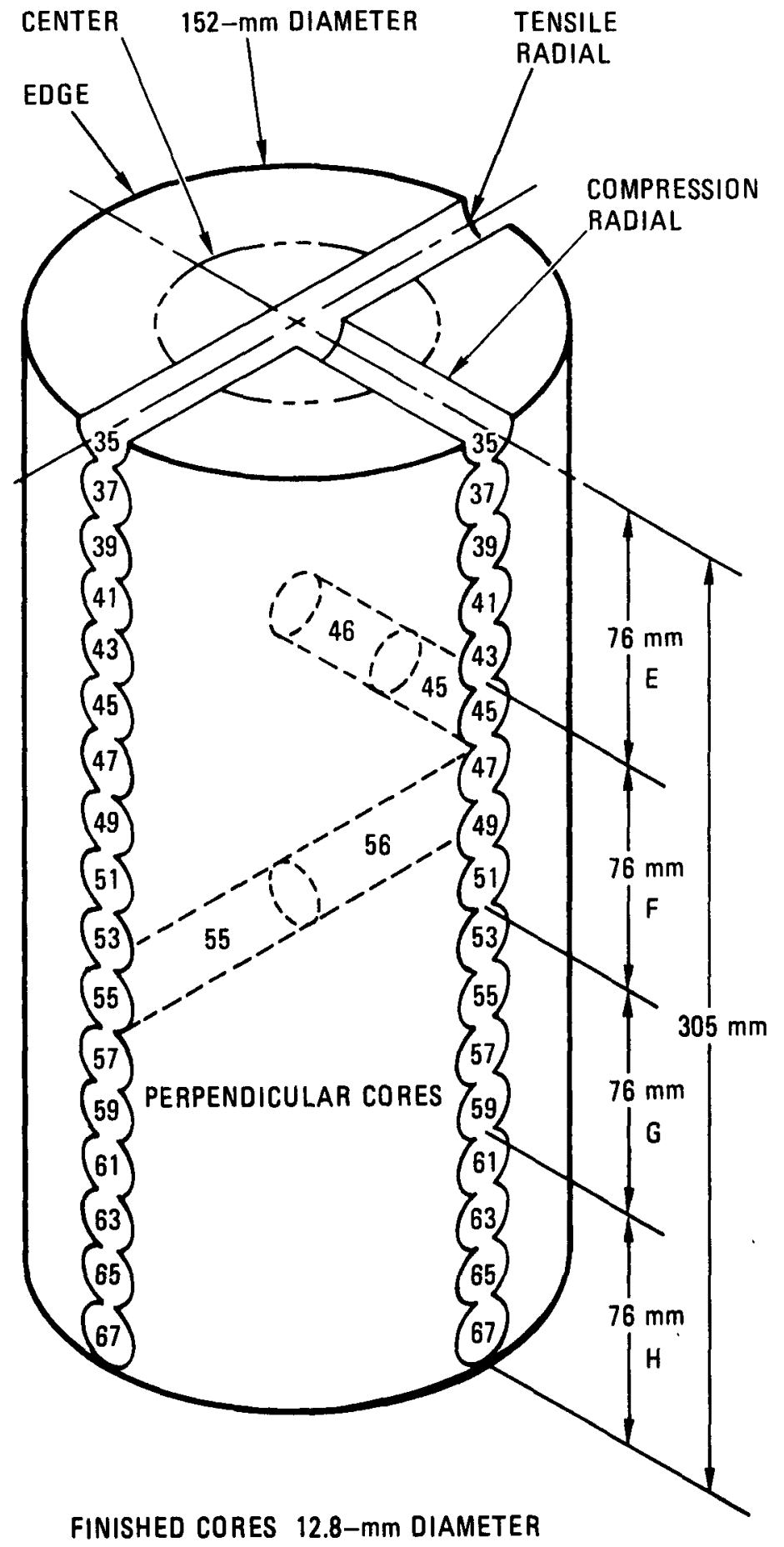

N0. 11-6799

$S=$ SPECTROGRAPHIC ANALYSIS

$C=$ CONTROL

\begin{tabular}{|c|c|c|c|}
\hline \multirow{2}{*}{ SECTION } & CORE & \multicolumn{2}{|c|}{ SAMPLES } \\
\hline & \multicolumn{3}{|c|}{ COMPRESSION } \\
\hline \multirow{5}{*}{$E$} & 35 & $35 \mathrm{C}$ & 36 \\
\hline & 37 & 37 & $38 \mathrm{C}$ \\
\hline & 39 & $39 \mathrm{C}$ & 40 \\
\hline & 41 & 41 & $42 \mathrm{C}$ \\
\hline & 43 & $43 \mathrm{~S}$ & 44 \\
\hline \multirow{4}{*}{$\mathrm{F}$} & 45 & 45 & $46 \mathrm{C}$ \\
\hline & 47 & 47 & 48 \\
\hline & 49 & 49 & $50 \mathrm{C}$ \\
\hline & 51 & $51 C$ & 52 \\
\hline \multirow{4}{*}{ G } & 53 & 53 & $54 \mathrm{C}$ \\
\hline & 55 & $55 \mathrm{C}$ & 56 \\
\hline & 57 & 57 & $58 \mathrm{~S}$ \\
\hline & 59 & $59 \mathrm{C}$ & 60 \\
\hline \multirow{4}{*}{$H$} & 61 & 61 & 62 \\
\hline & 63 & $63 \mathrm{C}$ & 64 \\
\hline & 65 & 65 & $66 \mathrm{C}$ \\
\hline & 67 & $67 C$ & 68 \\
\hline & \multicolumn{3}{|c|}{$76.2 \mathrm{~mm}$ TENSILE } \\
\hline \multirow{5}{*}{$E$} & 35 & $35 \mathrm{C}$ & 36 \\
\hline & 37 & 37 & $38 \mathrm{C}$ \\
\hline & 39 & $39 C$ & 40 \\
\hline & 41 & 41 & $42 C$ \\
\hline & 43 & $43 C$ & 44 \\
\hline \multirow{4}{*}{$\mathrm{F}$} & 45 & 45 & $46 C$ \\
\hline & 47 & $47 C$ & 48 \\
\hline & 49 & 49 & $50 \mathrm{C}$ \\
\hline & 51 & $51 \mathrm{C}$ & 52 \\
\hline \multirow{4}{*}{ G } & 53 & 53 & $54 \mathrm{C}$ \\
\hline & 55 & $55 \mathrm{C}$ & 56 \\
\hline & 57 & 57 & $58 \mathrm{C}$ \\
\hline & 59 & $59 \mathrm{C}$ & 60 \\
\hline \multirow{4}{*}{$\mathrm{H}$} & 61 & 61 & $62 \mathrm{C}$ \\
\hline & 63 & $63 \mathrm{C}$ & 64 \\
\hline & 65 & 65 & $66 \mathrm{C}$ \\
\hline & 67 & $67 \mathrm{C}$ & 68 \\
\hline
\end{tabular}

Fig. A-4. Coring diagram, Stackpole 2020, slab 3, tensile and compression radial samples 


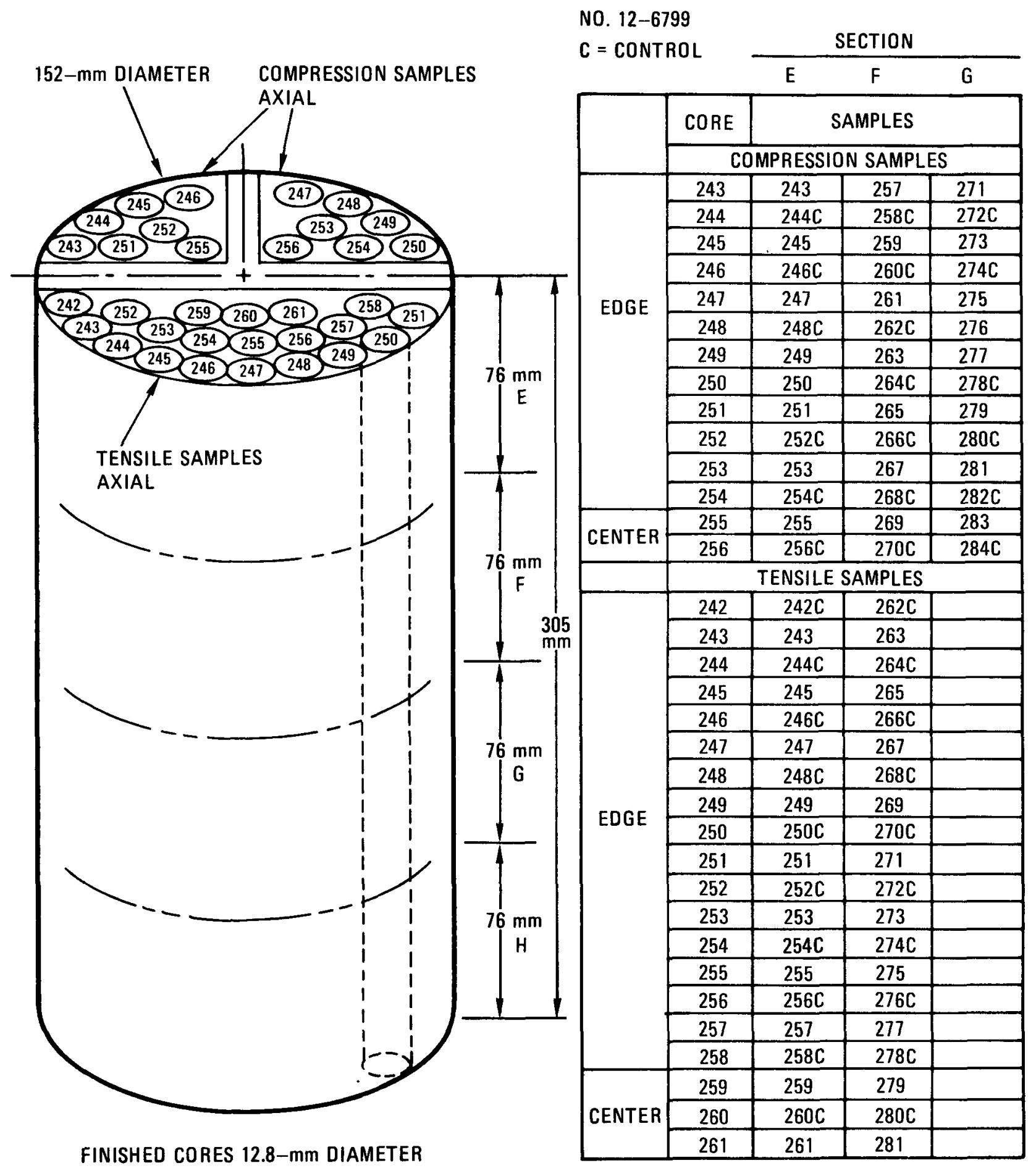

Fig. A-5. Coring diagram, Stackpole 2020, slab 3, tensile and compression axial samples 


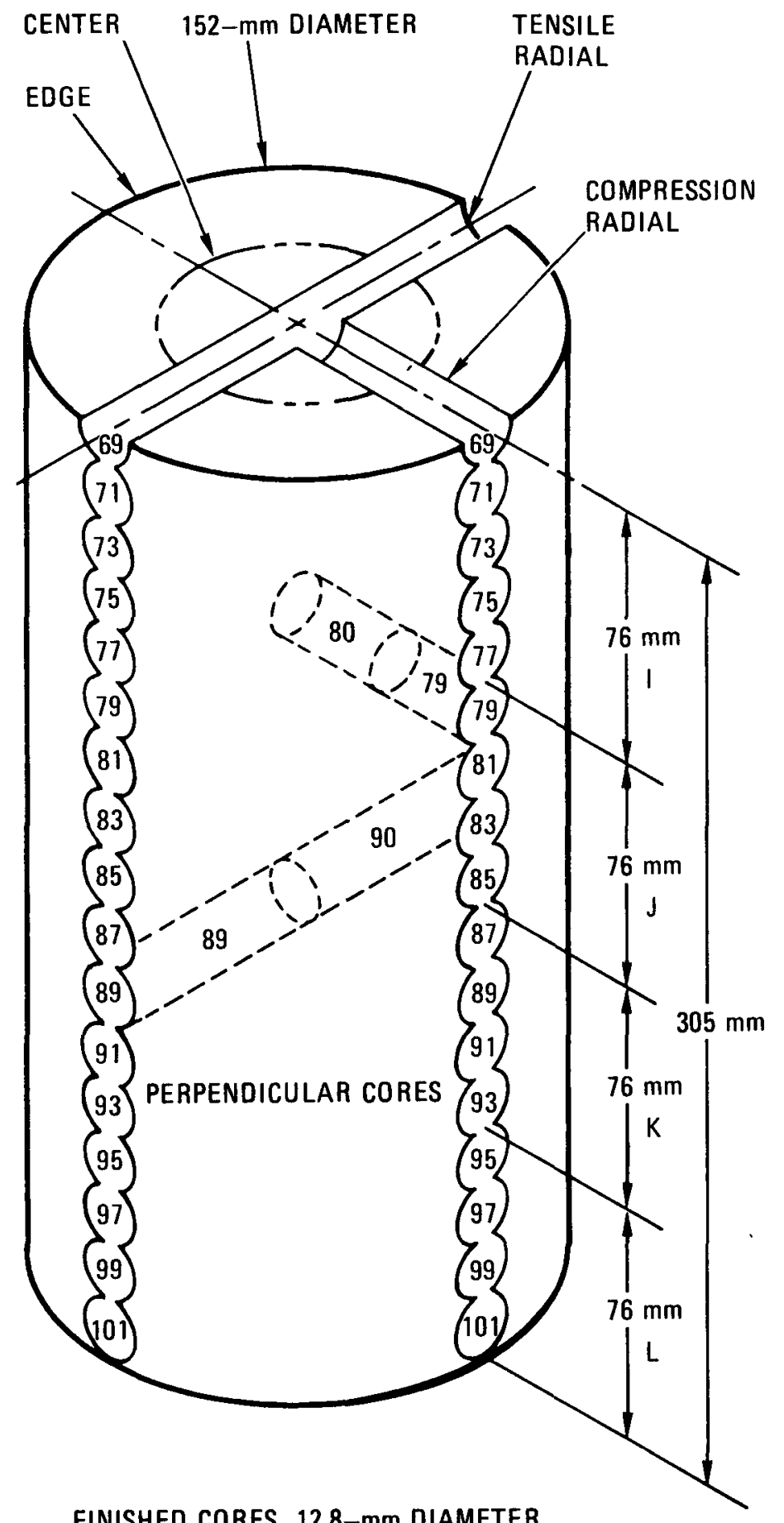

N0. 11-6799

$S=$ SPECTROGRAPHIC ANALYSIS

$C=$ CONTROL

\begin{tabular}{|c|c|c|c|}
\hline \multirow{2}{*}{ SECTION } & CORE & \multicolumn{2}{|c|}{ SAMPLES } \\
\hline & \multicolumn{3}{|c|}{$25.4 \mathrm{~mm}$ COMPRESSION } \\
\hline \multirow{5}{*}{1} & 69 & 69 & $70 \mathrm{C}$ \\
\hline & 71 & $71 \mathrm{~s}$ & 72 \\
\hline & 73 & 73 & $74 \mathrm{C}$ \\
\hline & 75 & $75 \mathrm{C}$ & 76 \\
\hline & 77 & 77 & 78 \\
\hline \multirow{4}{*}{$\mathrm{J}$} & 79 & $79 \mathrm{C}$ & 80 \\
\hline & 81 & 81 & $82 \mathrm{C}$ \\
\hline & 83 & $83 \mathrm{C}$ & 84 \\
\hline & 85 & 85 & $86 \mathrm{C}$ \\
\hline \multirow{4}{*}{$\mathrm{k}$} & 87 & $87 \mathrm{C}$ & 88 \\
\hline & 89 & 89 & $90 \mathrm{C}$ \\
\hline & 91 & $91 \mathrm{C}$ & 92 \\
\hline & 93 & 93 & $94 \mathrm{C}$ \\
\hline \multirow{4}{*}{ L } & 95 & $95 \mathrm{C}$ & 96 \\
\hline & 97 & 97 & $98 \mathrm{~S}$ \\
\hline & 99 & $99 \mathrm{C}$ & 100 \\
\hline & 101 & 101 & 102 \\
\hline & \multicolumn{3}{|c|}{$76.2 \mathrm{~mm}$ TENSILE } \\
\hline \multirow{5}{*}{1} & 69 & 69 & $70 \mathrm{C}$ \\
\hline & 71 & $71 \mathrm{C}$ & 72 \\
\hline & 73 & 73 & $74 C$ \\
\hline & 75 & $75 \mathrm{C}$ & 76 \\
\hline & 77 & 77 & $78 \mathrm{C}$ \\
\hline \multirow{4}{*}{$\mathrm{J}$} & 79 & $79 \mathrm{C}$ & 80 \\
\hline & 81 & 81 & $82 \mathrm{C}$ \\
\hline & 83 & $83 \mathrm{C}$ & 84 \\
\hline & 85 & 85 & $86 C$ \\
\hline \multirow{4}{*}{ K } & 87 & $87 C$ & 88 \\
\hline & 89 & 89 & $90 \mathrm{C}$ \\
\hline & 91 & $91 C$ & 92 \\
\hline & 93 & 93 & $94 \mathrm{C}$ \\
\hline \multirow{4}{*}{ L } & 95 & $95 \mathrm{C}$ & 96 \\
\hline & 97 & 97 & $98 \mathrm{C}$ \\
\hline & 99 & $99 \mathrm{C}$ & 100 \\
\hline & 101 & 101 & $102 \mathrm{C}$ \\
\hline
\end{tabular}

Fig. A-6. Coring diagram, Stackpole 2020, s1ab 5, tensile and compression radial samples 


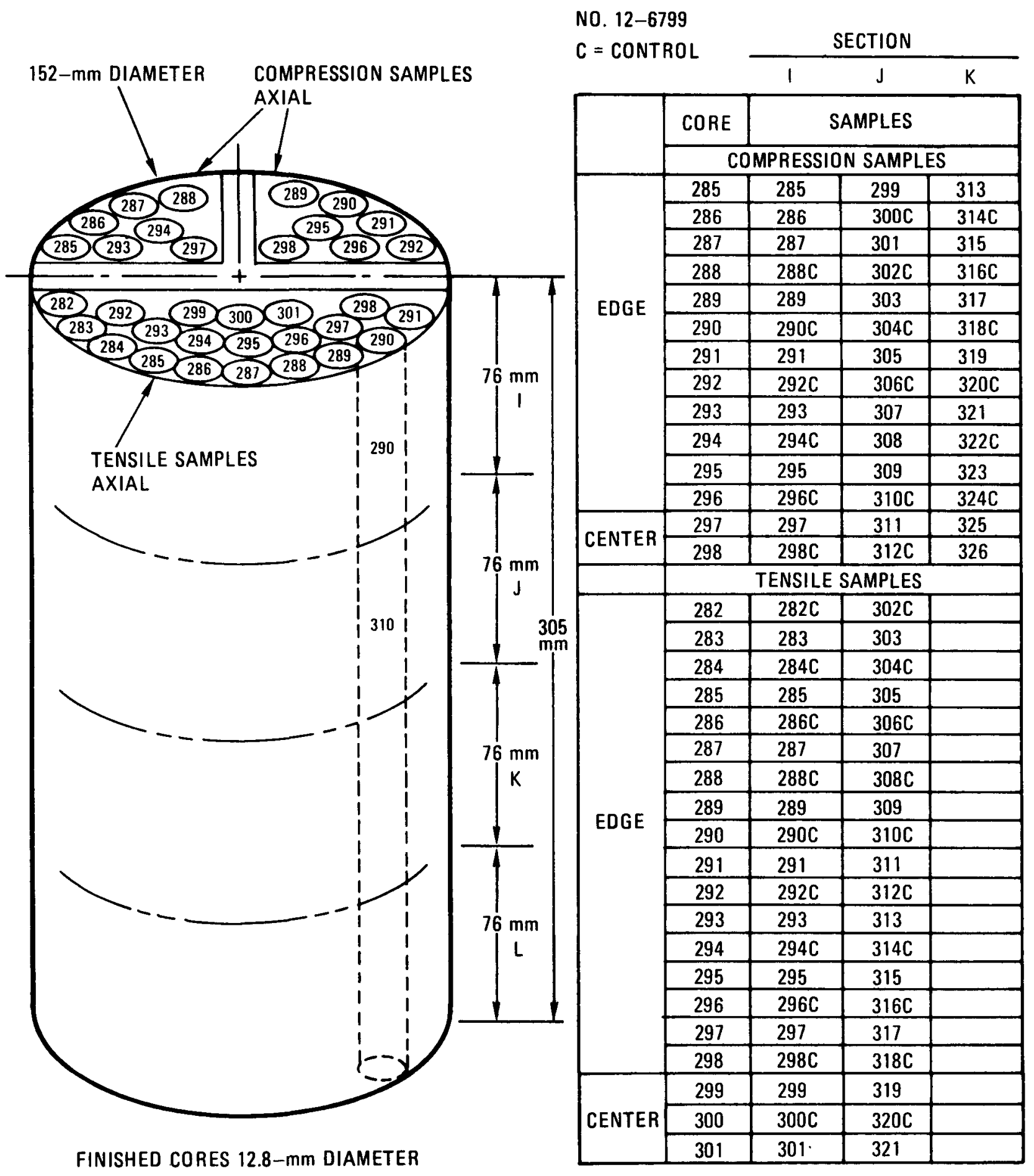

Fig. A-7. Coring diagram, Stackpole 2020, slab 5, tensile and compression axial samples 